\title{
Avaliação comportamental, eletroacústica e eletrofisiológica da audição em autismo
}

Dissertação apresentada à Faculdade de Medicina da Universidade de São Paulo para obtenção do título de Mestre em Ciências

Área de concentração: Fisiopatologia Experimental Orientadora: Profa Dra Carla Gentile Matas

\author{
São Paulo
}




\section{FICHA CATALOGRÁFICA}

Preparada pela Biblioteca da Faculdade de Medicina da Universidade de São Paulo

(reprodução autorizada pelo autor

Magliaro, Femanda Cristina Leite

Avaliação comportamental, eletroacústica e eletrofisiológica da audição em autismo / Fernanda Cristina Leite Magliaro. -- São Paulo, 2006.

Dissertação(mestrado)--Faculdade de Medicina da Universidade de São Paulo Para obtenção do titulo de Mestre em Ciências.

Árca de concentração: Fisiopatologia Experimental.

Orientadora: Carla Gentile Matas.

Descritores: I.POTENCIAIS EVOCADOS AUDITIVOS 2.POTENCIAIS EVOCADOS AUDITIVOS DE TRONCO ENCEFÁLICO 3.POTENCIAL EVOCADO P300 4.PSICO-ACÚSTICA 5.AUDIOMETRIA 6.TESTES DE IMPEDÂNCIA ACÚSTICA 7.TRANSTORNO AUTISTICO 8.TRANSTORNOS GLOBAIS DO DESENVOLVIMENTO INFANTIL

USP/FM/SBD-09/06 


\section{DEDICATÓRIA}

Dedico este trabalho...

À Deus, que está presente em todos os momentos da minha vida, protegendo-me e dando-me forças para seguir meu caminho.

Aos meus pais, Fernando e Laura, pois sem eles não teria chegado até aqui. Por ensinarem-me a não desistir dos meus objetivos e por apoiaremme sempre. A vocês que eu admiro tanto, cujo exemplo procuro seguir, muito obrigada.

À minha irmã, Flávia que sempre esteve ao meu lado, apoiando-me e ajudando-me. Saiba que admiro muito sua bondade, e capacidade para alcançar seus objetivos.

Ao meu marido Thiago, por todo incentivo nos momentos de desânimo, pelo carinho e compreensão nas muitas horas de ausência, e por estar sempre ao meu lado, obrigada.

Ao meu filho Lucas, por ser a razão pela qual eu procuro melhorar a cada dia, como pessoa e como profissional, por me ensinar a amar tanto e tão incondicionalmente. Pelos momentos em que um sorriso seu alegrou o meu dia, obrigada. 


\section{AGRADECIMENTO ESPECIAL}

À minha orientadora, Profa. Dra. Carla Gentile Matas, que desde a graduação vem ensinando-me muito sobre audiologia, cujo exemplo de humanismo e respeito ao paciente devem ser seguidos. Pela orientação cuidadosa deste trabalho, e por acreditar em meu potencial. Por tornar-se uma grande amiga com quem pude contar em diversas situações, obrigada. 


\section{AGRADECIMENTOS}

Aos indivíduos que participaram desta pesquisa e seu familiares, por participarem e por acreditarem na importância deste trabalho. Com a colaboração vocês, a audiologia cresce como ciência e expande sua atuação.

À toda minha família, em especial aos meus avós, pelo apoio e pela união. Essa união me dá forças e coragem, pois sei que mesmo longe posso contar com vocês.

Às amigas e fonoaudiólogas Renata Aparecida Leite e Isabela Crivellaro Gonçalves, por todos os momentos que compartilhamos durante esses anos de pesquisa, pelo apoio, pelo carinho, pelo ombro, pelo incentivo, e principalmente pela grande amizade. Vocês são como irmãs pra mim.

Às todas as amigas e amigos do Departamento de Fisioterapia, Fonoaudiologia e Terapia Ocupacional da FMUSP, em especial à Seisse Gabriela Gandolfi Sanches, Márcia Simões, Ivone Ferreira Neves, Rosângela Vieira Andrade, Luciene Stivanin, Christian César Cândido de Oliveira, Maria Cristina Godoy, e todos os outros, pelo auxílio e companheirismo em diversos momentos.

Aos meus sogros, Antonio e Ana, e meus cunhados, pelo incentivo e apoio desde a graduação.

Ao Prof. Dr. Francisco Baptista Assumpção Jre à Dra. Evelyn Kuczynski por encaminharem os sujeitos para esta pesquisa, e por auxiliarem os estudos referentes ao autismo. 
Às Profs Dras. Renata Mota Mamede Carvallo, leda Chaves Pacheco Russo e Ivone Ferreira Neves, que compuseram a banca de qualificação, por suas colocações pertinentes que auxiliaram e melhoraram este trabalho.

À Profa Dra Claudia Inês Scheuer, por encaminhar parte dos sujeitos desta pesquisa, e pela colaboração com o desenvolvimento deste trabalho.

À Profa Dra Maria Inês Vieira Couto, pelas contribuições como suplente da banca de qualificação e por estar sempre disposta a sanar minhas dúvidas .

Às docentes e supervisoras do Curso de Fonoaudiologia da FMUSP, pelo incentivo, e pelos ensinamentos que contribuiram com a minha formação.

Às fonoaudiólogas Cristina Ferraz Borges, Cíntia Vitória Ferreira e Fabiana Sanchez da Costa, amigas desde a graduação, pela grande amizade, pelo carinho, pelo auxílio em momentos de desânimo e por contribuirem com o meu crescimento profissional.

À Coordenação de Aperfeiçoamento de Pessoal de Nível Superior (CAPES), pelo apoio financeiro. 


\section{EPÍGRAFE}

“É melhor tentar e falhar,

que preocupar-se e ver a vida passar;

é melhor tentar, ainda que em vão,

que sentar-se fazendo nada até o final.

Eu prefiro na chuva caminhar,

que em dias tristes em casa me esconder.

Prefiro ser feliz, embora louco, que em conformidade viver ..." 


\section{NORMATIZAÇÃO ADOTADA}

Esta dissertação está de acordo com:

Referências: adaptado de International Committee of Medical Journals Editors (Vancouver)

Universidade de São Paulo. Faculdade de Medicina. Serviço de biblioteca e Documentação. Guia de apresentação de dissertações, teses e monografias. Elaborado por Anneliese Carneiro da Cunha, Maria Julia de ${ }^{a}$ L. Freddi, Maria F. Crestana, Marinalva de Souza Aragão, Suely Campos Cardoso, Valéria Vilhena. São Paulo: Serviço de Biblioteca e Documentação, 2004.

Abreviaturas dos títulos dos periódicos de acordo com List of Journals Indexed in Index. 


\section{SUMÁRIO}

Lista de Tabelas

Lista de Quadros

Lista de Abreviaturas e Símbolos

Lista de Siglas

Resumo

Summary

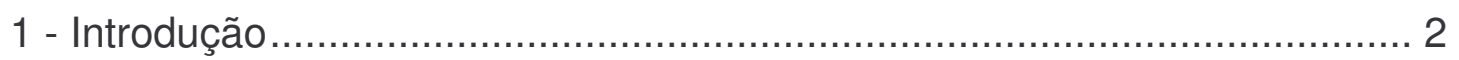

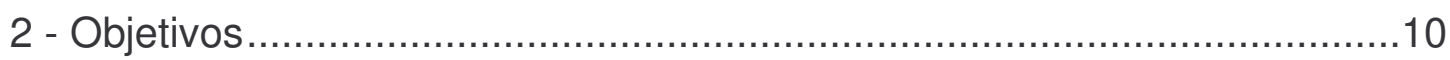

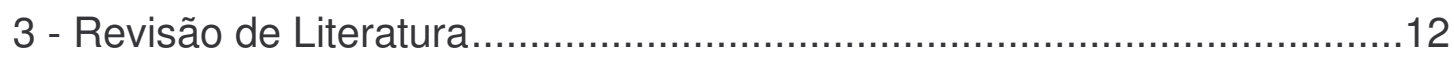

3.1 - Potenciais Evocados Auditivos...............................................12

3.2 - Achados comportamentais, eletroacústicos, e eletrofisiológicos da audição em autismo. ........................................................27

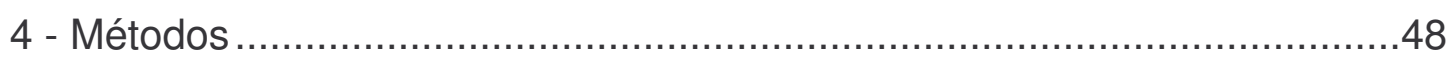

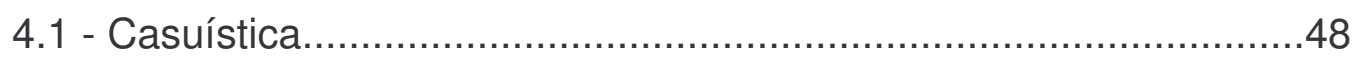

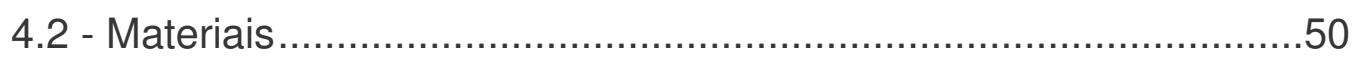

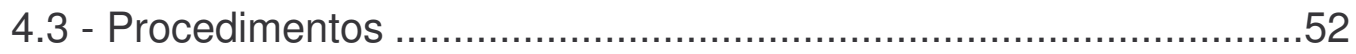

4.4 - Critérios de avaliação dos resultados....................................58

4.5 - Método estatístico .......................................................64

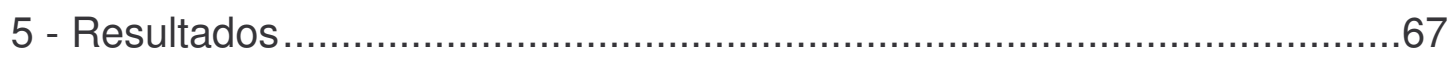

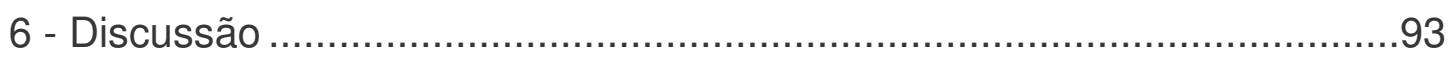

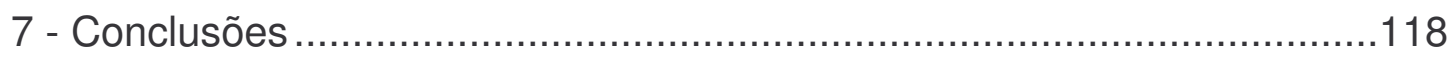

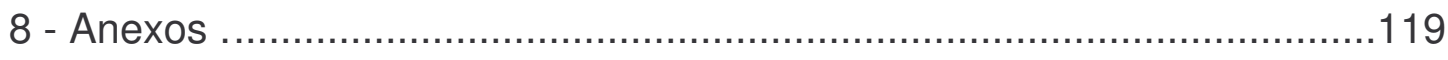

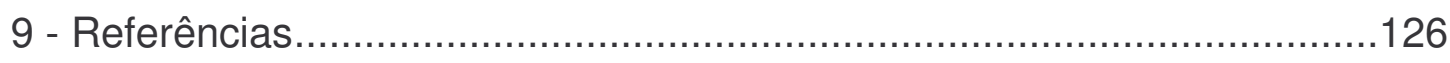

10 - Bibliografias Consultadas ................................................... 139 


\section{LISTA DE TABELAS}

TABELA 1 - Análise da distribuição dos gêneros nos grupos controle e pesquisa

TABELA 2 - Análise da distribuição das faixas etárias nos grupos controle e pesquisa

TABELA 3 - Distribuição da ocorrência de resultados normais e alterados na audiometria tonal, nos grupos controle e pesquisa

TABELA 4 - Distribuição da ocorrência de resultados normais e alterados na logoaudiometria, nos grupos controle e pesquisa

TABELA 5 - Distribuição da ocorrência de resultados normais e alterados na imitanciometria, nos grupos controle e pesquisa

TABELA 6 - Comparação das latências das ondas I, III, e V e dos interpicos I-III, III-V, e I-V entre as orelhas direita e esquerda no PEATE, para o grupo controle.

TABELA 7 - Comparação das latências das ondas I, III, e V e dos interpicos I-III, III-V, e I-V entre as orelhas direita e esquerda no PEATE, para o grupo pesquisa .76

TABELA 8 - Comparação das latências das ondas I, III, e V e dos interpicos I-III, III-V, e I-V do PEATE, entre os grupos controle e pesquisa

TABELA 9 - Distribuição da ocorrência de resultados normais e alterados no PEATE, nos grupos controle e pesquisa .78

TABELA 10 - Distribuição dos tipos de alterações encontrados no PEATE, nos grupos controle e pesquisa

TABELA 11 - Comparação das amplitudes $\mathrm{Na}-\mathrm{Pa}$ entre as modalidades $\mathrm{C} 3 / \mathrm{A} 1$ e $\mathrm{C} 3 / \mathrm{A} 2$, e entre $\mathrm{C} 4 / \mathrm{A} 1$ e $\mathrm{C} 4 / \mathrm{A} 2$ do PEAML, para o grupo controle 
TABELA 12 - Comparação das amplitudes $\mathrm{Na}-\mathrm{Pa}$ entre as modalidades $\mathrm{C} 3 / \mathrm{A} 1$ e $\mathrm{C} 3 / \mathrm{A} 2$, e entre $\mathrm{C} 4 / \mathrm{A} 1$ e $\mathrm{C} 4 / \mathrm{A} 2$ do PEAML, para o grupo pesquisa

TABELA 13 - Comparação das amplitudes $\mathrm{Na}-\mathrm{Pa}$ entre as modalidades $\mathrm{C} 3 / \mathrm{A} 1$ e C4/A1, e entre C3/A2 e C4/A2 do PEAML, para o grupo controle....

TABELA 14 - Comparação das amplitudes $\mathrm{Na}-\mathrm{Pa}$ entre as modalidades C3/A1 e C4/A1, e entre C3/A2 e C4/A2 do PEAML, para o grupo pesquisa

TABELA 15 - Comparação das amplitudes $\mathrm{Na}-\mathrm{Pa}$ nas modalidades C3/A1, C3/A2, C4/A1, C4/A2 do PEAML, entre os grupos controle e pesquisa .84

TABELA 16 - Distribuição da ocorrência de resultados normais e alterados no PEAML, nos grupos controle e pesquisa.

TABELA 17 - Distribuição dos tipos de alterações encontrados no PEAML, nos grupos controle e pesquisa .86

TABELA 18 - Comparação das latências do P300 entre as orelhas direita e esquerda, para o grupo controle.

TABELA 19 - Comparação das latências do P300 entre as orelhas direita e esquerda, para o grupo pesquisa

TABELA 20 - Comparação das latências do P300 entre os grupos controle e pesquisa......

TABELA 21 - Distribuição da ocorrência de resultados normais e alterados no P300, nos grupos controle e pesquisa .90

TABELA 22 - Distribuição dos tipos de alterações encontrados no P300, nos grupos controle e pesquisa 


\section{LISTA DE QUADROS}

Quadro 1: Padrão de normalidade dos valores de latência e interpicos do PEATE, para indivíduos acima de 24 meses, proposto pelo "Evoked Potential User Manual".

Quadro 2: Padrão de normalidade dos valores de latência da onda P300, para cada faixa etária, proposto por McPherson (1996) 


\section{LISTA DE ABREVIATURAS E SÍMBOLOS}

$\begin{array}{ll}\text { et al. } & \text { e outros } \\ \text { daPa } & \text { deca Pascal } \\ \mathrm{dB} & \text { decibel } \\ \mathrm{Hz} & \text { Hertz } \\ \text { kohms } & \text { kilo ohms } \\ \mathrm{ml} & \text { mililitro } \\ \mathrm{ms} & \text { milissegundo } \\ \text { p. } & \text { página } \\ \text { Qtde } & \text { quantidade } \\ \text { s } & \text { segundo }\end{array}$




\section{LISTA DE SIGLAS}

\begin{tabular}{|c|c|}
\hline A1 & Mastóide esquerda \\
\hline $\mathrm{A} 2$ & Mastóide direita \\
\hline ABR & Auditory Brainstem Response \\
\hline ANOVA & Analysis of variance \\
\hline ANSI & American National Standards Institute \\
\hline APA & Associação Psiquiátrica Americana \\
\hline BAER & Brainstem Auditory- Evoked Response \\
\hline BB & Broad Band \\
\hline BERA & Brainstem Evoked Response Audiometry \\
\hline BSER & Brainstem Evoked Response \\
\hline C3 & Junção têmporo-parietal esquerda \\
\hline $\mathrm{C} 4$ & Junção têmporo-parietal direita \\
\hline CAPPesq & $\begin{array}{l}\text { Comissão de Ética para Análise de Projetos de } \\
\text { Pesquisa }\end{array}$ \\
\hline $\mathrm{CZ}$ & Vértex \\
\hline DSM-IV & $\begin{array}{l}\text { Diagnostic and Statistical Manual of Mental } \\
\text { Disorders }\end{array}$ \\
\hline EEG & Eletroencefalograma \\
\hline EOA & Emissões Otoacústicas \\
\hline EOAPD & Emissões Otoacústicas Produto de Distorção \\
\hline ERP & Event-Related Brain Potentials \\
\hline $\mathrm{F}$ & Feminino \\
\hline
\end{tabular}


Faculdade de Medicina da Universidade de São Paulo

IEC

International Electrotechnical Commission

IRF

Índice de Reconhecimento de Fala

LLR

Long Latency Response

LRF

Limiar de Reconhecimento de Fala

M

Masculino

MLR

Middle Latency Response

MMF

Magnetoencephalographic

Measurements of

Mismatch Field

MMN

Mismatch Negativity

NA

Nível de audição

OD

Orelha direita

OE

Orelha esquerda

PA

Processamento Auditivo

PEALL

Potencial Evocado Auditivo de Longa Latência

PEAML

Potencial Evocado Auditivo de Média Latência

PEAs

Potenciais Evocados Auditivos

PEATE

Potencial Evocado Auditivo de Tronco Encefálico

P300

Potencial Cognitivo

SNR

Speech-to-Noise Ratio

SRT

Speech Reception Thresholds

USP

Universidade de São Paulo 
Resumo 


\section{RESUMO}

Magliaro FCL. Avaliação comportamental, eletroacústica e eletrofisiológica da audição em autismo. São Paulo: Faculdade de Medicina, Universidade de São Paulo; 2006.

INTRODUÇÃO: O Autismo é um distúrbio que tem início na infância, cujas principais características são a presença de um desenvolvimento anormal ou prejudicado na interação social e comunicação, e um repertório restrito de atividades e interesses. Algumas teorias consideram o autismo como um distúrbio do desenvolvimento causado por uma alteração do sistema nervoso central, e salientam a presença do déficit cognitivo nessa população. Estudos demonstram também a presença de anormalidades eletrofisiológicas nos potenciais evocados auditivos de curta, média e longa latências. Considerando a importância da integridade do sistema auditivo periférico e central na aquisição e desenvolvimento de fala, linguagem e aprendizado, mostra-se imprescindível que anormalidades auditivas tanto periféricas como centrais sejam identificadas e tratadas em indivíduos autistas. OBJETIVO: caracterizar os achados das avaliações comportamentais, eletroacústicas e eletrofisiológicas da audição em indivíduos com autismo, bem como compará-los aos obtidos em indivíduos normais da mesma faixa etária. MÉTODOS: foram realizadas anamnese, audiometria tonal, logoaudiometria, medidas de imitância acústica, potencial evocado auditivo de tronco encefálico, potencial evocado auditivo de média latência e potencial cognitivo em 16 indivíduos com autismo (grupo pesquisa) e 25 normais (grupo controle), com idades entre oito e 20 anos. RESULTADOS: Na comparação entre os resultados normais e alterados (análise qualitativa), não foram encontradas alterações na avaliação comportamental da audição para os dois grupos. Na comparação dos resultados das avaliações comportamentais e eletroacústicas entre os grupos, não ocorreram diferenças estatisticamente significantes. O grupo 
controle apresentou alterações apenas no resultado do potencial evocado auditivo de média latência, sendo que o tipo de alteração mais freqüentemente encontrada foi ambas (efeito eletrodo e efeito orelha ocorrendo concomitantemente). O grupo pesquisa apresentou resultados alterados em todos os potenciais evocados auditivos, havendo diferença estatisticamente significante quando comparado ao grupo controle. Com relação aos tipos de alterações encontradas no grupo pesquisa, foi observada uma maior ocorrência de alteração em tronco encefálico baixo no potencial evocado auditivo de tronco encefálico, alteração do tipo ambas (efeito eletrodo e efeito orelha ocorrendo concomitantemente) no potencial evocado auditivo de média latência e ausência de resposta no potencial cognitivo. $\mathrm{Na}$ análise quantitativa dos resultados dos potenciais evocados auditivos, verificou-se que apenas para o potencial evocado auditivo de tronco encefálico ocorreu diferença estatisticamente significante entre os grupos, com relação às latências das ondas III e V e interpicos I-III e I-V. CONCLUSÃO: Indivíduos com autismo não apresentam alterações nas avaliações comportamentais e eletroacústicas da audição, e apresentam alterações nos potenciais evocados auditivos de tronco encefálico e potencial cognitivo, sugerindo comprometimento da via auditiva em tronco encefálico e regiões corticais.

Descritores: potenciais evocados auditivos, potenciais evocados auditivos de tronco encefálico, potencial evocado P300, psico-acústica, audiometria, testes de impedância acústica, transtorno autístico, transtornos globais do desenvolvimento infantil. 
Summary 


\section{SUMMARY}

Magliaro FCL. Behavioral, electroacoustic and electrophysiological assessment of hearing in autism. São Paulo: Medicina School, University of São Paulo; 2006.

INTRODUCTION: Autism is a disorder, which begins in the infancy, and the main characteristics are the presence of an abnormal or impaired development of social interaction and communication, and restrict range of activities and interest. Some theories consider autism as a developmental disorder caused by a central nervous system alteration, and stress the presence of a cognitive deficit in this population. Studies also demonstrate the presence of electrophysiological abnormalities in the auditory evoked potentials of short middle and long latencies. Considering the importance of the peripheral and central auditory system integrity for the speech and language acquisition and development and for learning, it becomes important to identify and treat hearing abnormalities, either peripheral or central, in autistic individuals. AIM: to characterize the findings of behavioral, electroacoustic and electrophysiological assessments of autistic individuals, as well as to compare those findings with the ones of normal individuals of the same age. METHOD: 16 individuals with autism (study group) and 25 normal ones (control group), ranging in age from eight and 20 years underwent anamnesis, pure tone audiometry, speech audiometry, acoustic immitance measures, brainstem auditory evoked potential, middle latency response and cognitive potential. RESULTS: Comparing the normal and altered results (qualitative analysis), no alterations were found in the behavioral assessment of hearing in both groups. Comparing the results of the behavioral and electroacoustic evaluations between the two groups, there were no statistical differences. The control group presented altered results only in the middle latency auditory evoked potential and the most common type of alteration was both electrode effect and ear effect occurring 
simultaneously. The study group presented altered results in all auditory evoked potentials with a significant statistical difference when compared to the control group. Concerning the types of alterations found in the study group it was verified higher occurrence of lower brainstem alteration in the brainstem auditory evoked potential, both electrode and ear effect occurring simultaneously in the middle latency auditory evoked potential, and absence of response in the cognitive potential. The quantitative analysis of the auditory evoked potentials results showed a significant statistical difference between the groups only in the brainstem auditory evoked potential, concerning the latencies of waves $\mathrm{III}$ and $\mathrm{V}$ and interpeaks I-III and I-V. CONCLUSION: autistic individuals do not present altered behavioral and electroacoustic evaluations, and present altered brainstem auditory evoked potential and cognitive potential, suggesting prejudice in the brainstem auditory pathway and cortical regions.

Descriptors: auditory evoked potentials, auditory brain stem evoked potentials, P300 event-related potentials, psychoacoustics, audiometry, acoustic impedance tests, autistic disorder, pervasive child development disorders. 


\section{Introdução}




\section{1 - INTRODUÇÃO}

Em 1943, Kanner descreveu 11 casos de crianças que apresentavam tendência ao isolamento antes de completar um ano de idade, e propôs que o quadro fosse denominado de "Autismo infantil precoce". Desde então, outras crianças foram analisadas e vários trabalhos semelhantes foram publicados. Kanner relatou que a maioria dos casos chegava até a clínica com o diagnóstico de deficiência auditiva ou de deficiência mental grave, porém, um exame minucioso demonstrou que o transtorno básico mascarava a capacidade cognitiva das crianças, e que elas não apresentavam deficiência auditiva. Continuando a estudar este distúrbio, o autor observou que essas crianças mostravam uma dificuldade profunda no contato com as pessoas, um desejo obsessivo de preservar as coisas e as situações, um afeto especial aos objetos, e alterações de linguagem (do mutismo a uma linguagem sem função comunicativa) (Kanner,1962).

Ritvo (1976) foi um dos primeiros pesquisadores a considerar a síndrome autística como um distúrbio do desenvolvimento causado por uma alteração do sistema nervoso central, e a salientar a presença dos déficits cognitivos no autismo. Para o autor, a caracterização do quadro é feita a partir da idade de surgimento e por suas características comportamentais, como distúrbios de percepção, do desenvolvimento, de relacionamento social, da fala e da linguagem, e da motilidade. 
Alguns autores, como Wing (1988), consideram o autismo como um transtorno específico sintomatológico dependente do comprometimento cognitivo. Essa abordagem reforça a tendência de considerar o autismo não mais como uma entidade única, mas sim como um grupo de doenças. Assim, para Wing, existe um "continuum" autista que pode abranger, desde os quadros que caracterizam um autismo mais severo, até aqueles com potencial mais preservado, como o encontrado na síndrome de Asperger.

Para Assumpção (1997), o diagnóstico diferencial do Autismo Infantil é extremamente complexo, apresenta uma série de dificuldades, e é passível de controvérsias, uma vez que este transtorno engloba um grande número de distúrbios diferentes e de quadros clínicos que têm como fator comum o isolamento.

Várias são as teorias que tentam compreender e explicar as origens dos déficits encontrados no autismo. Dentre elas, encontram-se a psicanálise, a teoria afetiva, a teoria da mente, as teorias neuropsicológicas e de processamento de informação. Bosa e Callias (2000) fizeram críticas a cada uma dessas abordagens e propuseram maior integração dos achados entre as diferentes áreas, a fim de melhor compreenderem os mecanismos formadores do perfil que caracteriza o autismo.

Evidências comportamentais e neuropsicológicas sugerem que a 
síndrome de Asperger é uma variação do autismo típico, o qual ocorre em indivíduos com alto-funcionamento, ou seja, aqueles que apresentam menor compromentimento das habilidades prejudicadas no autismo. Portanto, não é um transtorno distinto do autismo. A natureza e a abrangência do distúrbio social nesta síndrome ainda precisam ser mais investigadas. No entanto, este comprometimento parece ser menos severo do que no autismo (Frith, 2004)

Na população de crianças com quadros psiquiátricos graves (autismo, por exemplo), a ausência de linguagem pode ser considerada, também, decorrente de problemas cognitivos que impedem o processo de aquisição de linguagem ou o acesso ao mundo simbólico. Crianças com distúrbios psiquiátricos apresentam algum desenvolvimento cognitivo, porém sua construção parece ser entrecortada, e se manifesta desconexa com o estágio anterior demonstrado pela criança (Scheuer, 1996).

O DSM-IV (Diagnostic and Statistical Manual of Mental Disorders), que é um sistema classificatório elaborado pela Associação Psiquiátrica Americana (APA, 1995), insere o Autismo dentro do grupo dos Transtornos Invasivos do Desenvolvimento, sendo este último caracterizado por prejuízo severo e invasivo em diferentes áreas do desenvolvimento, como habilidades de interação social recíproca, habilidades de comunicação, ou presença de comportamento, interesses, e atividades estereotipadas. Os prejuízos qualitativos que definem essas condições representam um desvio 
acentuado em relação ao nível de desenvolvimento ou à idade mental do indivíduo. Para essa classificação, as características marcantes do transtorno autista consistem na presença de um desenvolvimento anormal, ou prejudicado na interação social e na comunicação, e um repertório marcantemente restrito de atividades e de interesses. As manifestações variam imensamente, dependendo do nível de desenvolvimento e da idade cronológica do indivíduo. O autismo é relatado como um quadro iniciado antes dos três anos de idade, com prevalência de dois a cinco casos por 10.000 indivíduos, com predomínio maior no sexo masculino (5:1 ou 4:1), e decorrente de uma vasta gama de condições pré, peri, e pós-natais.

Indivíduos com autismo apresentam distúrbios perceptuais, de atenção e de memória, e, por vezes, podem ser confundidos com deficientes auditivos, visto que não respondem consistentemente a ordens verbais e a estímulos ambientais. Devido a esta inconsistência de respostas, os resultados obtidos nos procedimentos básicos de rotina para avaliação audiológica podem mostrar-se inconclusivos, fazendo com que seja necessário empregar testes objetivos, os quais não dependam da resposta do paciente para a obtenção dos resultados.

Um dos métodos objetivos mais utilizados é a pesquisa dos Potenciais Evocados Auditivos (PEAs), os quais avaliam a atividade neuroelétrica na via auditiva, desde o nervo auditivo até o córtex cerebral, em resposta a um estímulo ou evento acústico (Junqueira e Frizzo, 2002). 
Os PEAs podem ser classificados em potenciais evocados auditivos de curta, média, e longa latências, ou respectivamente, precoces, médios e tardios (Ruth e Lambert, 1991).

Dentre os PEAs de curta latência ou precoces, o mais conhecido e utilizado clinicamente é o Potencial Evocado Auditivo de Tronco Encefálico (PEATE), também denominado Audiometria de Tronco Encefálico ("Auditory Brainstem Response "- $A B R$ ), constituído por sete ondas que surgem entre zero e oito milissegundos (ms) após a apresentação do estímulo acústico, originando-se do nervo auditivo até o tronco encefálico (Durrant e Ferraro, 2001).

Para Matas et al. (1998), dentre as aplicações clínicas do PEATE, destacam-se a verificação da função auditiva em crianças difíceis de serem avaliadas por procedimentos de rotina, a avaliação da maturação do sistema auditivo central, a detecção de tumores do nervo acústico, o diagnóstico topográfico de distúrbios que afetam a fossa posterior, entre outras.

Os Potenciais Evocados Auditivos de Média Latência (PEAML), também denominados Respostas de Média Latência (Middle Latency Response - MLR), são compostos por um conjunto de ondas presentes entre 10 e 80 ms após o início da estimulação acústica (Ruth e Lambert, 1991). 
A primeira onda do PEAML é a $\mathrm{Na}$, seguida pela $\mathrm{Pa}, \mathrm{Nb}, \mathrm{Pb}$, e, às vezes, Nc e Pc, sendo a onda Pa a mais robusta e consistente (Musiek e Lee, 2001), e sua amplitude o parâmetro de medida mais freqüentemente utilizado para fins diagnósticos.

Este potencial pode ser utilizado, clinicamente, na determinação do limiar eletrofisiológico de audição para a faixa de freqüências baixas, na avaliação do funcionamento do implante coclear, na avaliação do funcionamento da via auditiva e possível localização de lesões neste trajeto, e no monitoramento intra-operatório, podendo também contribuir para o diagnóstico de síndromes que comprometem o sistema de geração das ondas.

O Potencial Evocado Auditivo de Longa Latência (PEALL) mais utilizado é o Potencial Cognitivo ou P300, inicialmente descrito por Sutton et al. (1965), surgindo, aproximadamente, a 300 ms após a estimulação acústica.

O P300 é um potencial endógeno, ou seja, seu resultado depende de uma tomada de decisão por parte do indivíduo avaliado. Assim, este potencial é gerado, satisfatoriamente, desde que o indivíduo seja capaz de focalizar sua atenção em alguns estímulos raros que aparecem, aleatoriamente, dentro de uma série de estímulos freqüentes (Schochat, 2004). 
De acordo com Picton (1992), quando a amplitude do P300 encontra-se menor ou a latência atrasada, é possível que exista algum déficit no processamento cognitivo.

O P300 mostra-se útil no estudo das funções cognitivas e dos níveis de atenção, estando os processos de atenção, discriminação auditiva, memória e perspectiva semântica, envolvidos na geração desse potencial (Kraus e McGee, 1999).

O fonoaudiólogo tem um importante papel junto a crianças autistas, não só no que tange as avaliações comportamentais e eletrofisiológicas da audição destes sujeitos, mas também em seu processo de reabilitação. Desta forma, torna-se de suma importância a avaliação da via auditiva tanto em sua porção periférica quanto central, a fim de verificar eventuais correlações entre déficits cognitivos, de linguagem e auditivos em indivíduos autistas. 
Objetivos 


\section{2 - OBJETIVOS}

\section{1 - Objetivo Geral}

O objetivo deste trabalho é caracterizar os achados das avaliações comportamentais, eletroacústicas e eletrofisiológicas da audição em indivíduos com autismo.

\section{2 - Objetivos Específicos}

- Comparar os resultados das avaliações comportamentais e eletroacústicas da audição entre indivíduos com autismo e indivíduos normais, da mesma faixa etária.

- Comparar os resultados das avaliações eletrofisiológicas da audição entre indivíduos com autismo e indivíduos normais, da mesma faixa etária. 
Revisão de Literatura 


\section{3 - REVISÃO DE LITERATURA}

Nesta revisão de literatura, apresentamos os trabalhos considerados pertinentes ao assunto estudado, sendo respeitados os termos originalmente utilizados pelos autores.

Para melhor clareza de apresentação, este capítulo foi dividido em duas partes distintas, organizadas em ordem cronológica:

3.1 - Potenciais Evocados Auditivos:

3.1.1 - Potencial Evocado Auditivo de Tronco Encefálico;

3.1.2 - Potenciais Evocados Auditivos de Média Latência;

3.1.3 - Potenciais Evocados Auditivos de Longa Latência;

3.2 - Achados comportamentais, eletroacústicos, e eletrofisiológicos da audição em autismo.

\section{1 - Potenciais Evocados Auditivos}

Os Potenciais Evocados têm sido muito utilizados em Neurociência como uma ferramenta útil para diagnósticos funcionais, sendo que os aumentos na latência ou a diminuição nas amplitudes das respostas são evidências objetivas de problemas clínicos e sub-clínicos. 
Davis (1939) foi o primeiro a descrever os potenciais evocados eliciados por estímulos acústicos, ressaltando que as respostas encontradas eram modificações do traçado do eletroencefalograma (EEG), e que tinham, como provável origem, o córtex cerebral.

Um dos sistemas de classificação e nomenclatura dos Potenciais Evocados Auditivos (PEAs) baseia-se no tempo em que as respostas ocorrem, após o início da estimulação, conhecido, também, como "latência". Assim, estes potenciais podem ser classificados em potenciais evocados auditivos de curta, média, e longa latências, ou respectivamente, em precoces, médios, e tardios (Ruth e Lambert, 1991).

Alguns fatores podem influenciar os PEAs, como o nível de consciência do indivíduo durante o exame. De modo geral, o indivíduo deve cooperar, permanecendo quieto e relativamente imóvel durante a avaliação, uma vez que movimentos do corpo, especialmente da cabeça e da mandíbula, produzem potenciais miogênicos e/ou artefatos elétricos (Ferraro e Durrant, 1999).

As duas principais razões para a utilização dos PEAs, segundo Kraus et al. (1999), são: determinar o limiar de detecção do sinal acústico, e inferir sobre a integridade funcional e estrutural dos componentes neurais da via auditiva. 
Atualmente, no campo da audiologia clínica, a associação de métodos objetivos e subjetivos que avaliam a audição vem ganhando espaço e tornando-se cada vez mais freqüente. Esta associação de métodos contribui para complementar e tornar mais preciso o diagnóstico dos distúrbios auditivos centrais. Um dos métodos objetivos utilizados pelos profissionais é a pesquisa dos PEAs, os quais avaliam a atividade neuroelétrica na via auditiva, desde o nervo auditivo até o córtex cerebral, em resposta a um estímulo ou evento acústico. Os PEAs podem ser captados, em humanos, por meio de eletrodos fixados na superfície do couro cabeludo, fronte, lóbulos das orelhas ou mastóides. As respostas captadas passam por um processo de filtragem e amplificação, e posteriormente, são promediadas (separadas dos artefatos e somadas), permitindo assim, sua observação em forma de ondas no computador (Junqueira e Frizzo, 2002).

Uma série de mudanças elétricas, que ocorrem no sistema nervoso periférico e central, podem ser denominadas como potencial evocado, e quando ocorrem no sistema auditivo, são chamadas de potenciais evocados auditivos. O seu registro requer uma amplificação sofisticada da atividade elétrica, cálculos computadorizados do sinal elétrico, e estimulação acústica adequada, para evocar as respostas auditivas. Este registro reflete uma atividade elétrica sincrônica de várias estruturas do sistema nervoso auditivo periférico e central, visualizado em forma de ondas (Schochat, 2004). 


\subsection{1 - Potencial Evocado Auditivo de Tronco Encefálico}

Dentre os PEAs de curta latência ou precoces, o mais conhecido e utilizado clinicamente, devido à sua reprodutibilidade e propriedade de localização, é o Potencial Evocado Auditivo de Tronco Encefálico (PEATE), também denominado Audiometria de Tronco Encefálico (ABR- Auditory Brainstem Response) ou, ainda, Brainstem Evoked Response Audiometry (BERA).

Davis (1979) foi um dos primeiros a relatar a importância da ABR como instrumento de avaliação da audição em recém-nascidos, crianças pequenas, indivíduos hiperativos, indivíduos com distúrbios emocionais, pacientes com alterações neurológicas, e indivíduos difíceis de serem avaliados pelos métodos comportamentais. Neste estudo, o autor concluiu que era necessária a realização de mais pesquisas que utilizassem a $A B R$, a fim de encontrar uma padronização das nomenclaturas e dos procedimentos. Além disso, destacou a necessidade de se confirmar os sítios geradores das primeiras cinco ondas deste potencial.

Podemos encontrar sete ondas no registro do PEATE, sendo as ondas I, III, e V as maiores em amplitude e, conseqüentemente, as mais visíveis, geradas por uma ou mais estruturas ao longo da via auditiva no tronco encefálico. A classificação mais aceita, atualmente, é a de Möller et al. (1981), a qual descreve os seguintes sítios geradores: onda I - porção distal 
ao tronco encefálico do nervo auditivo; onda II - porção proximal ao tronco encefálico do nervo auditivo; onda III - núcleo coclear; onda IV - complexo olivar superior; onda V - lemnisco lateral; onda VI - colículo inferior; onda VII - corpo geniculado medial.

Os Potenciais Evocados Auditivos precoces são obtidos entre zero e 10 milissegundos (ms) após a apresentação do estímulo acústico, e são captados desde os primeiros neurônios do sistema auditivo até o tronco encefálico (Ruth e Lambert, 1991).

A ABR e os outros potenciais evocados avaliam a sincronia neural, que é a habilidade do sistema nervoso central em responder à estimulação externa de maneira sincrônica (o disparo de um grande grupo de neurônios ao mesmo tempo). Sendo assim, quando o sistema nervoso central está funcionando normalmente, podemos usar estes potenciais para registrar respostas neurais a estímulos apresentados em vários níveis de intensidade. Desta forma, podemos encontrar o menor nível de intensidade da resposta neural e relacioná-lo ao limiar da audição. Devido ao fato dos PEAs testarem o sistema neural, eles podem também fornecer informações a respeito da integridade da via neural (Hood, 1995).

O estímulo acústico mais empregado para captar as ondas do PEATE é o clique, já que esse apresenta um espectro amplo de freqüências e, portanto, estimula maior quantidade de fibras nervosas. Esse estímulo 
enfatiza as freqüências mais altas $(3000 \mathrm{a} 6000 \mathrm{~Hz})$. Para Matas et al. (1998), algumas aplicações clínicas da ABR são: testagem da função auditiva em neonatos e em crianças difíceis de serem avaliadas por procedimentos de rotina, avaliação da maturação do sistema auditivo central, detecção de tumores do nervo acústico, diagnóstico topográfico de distúrbios que afetam a fossa posterior, entre outras.

Para Musiek et al. (1999), várias medidas da ABR podem ser utilizadas com propósito de neurodiagnóstico, cada uma delas fornecendo informações únicas. Entretanto, algumas medidas são mais sensíveis e confiáveis do que outras. As medidas de latência dos picos das ondas da ABR são bons parâmetros para fins diagnósticos, sendo que as mais utilizadas são: a latência absoluta da onda $V$, a diferença interaural da latência da onda $V$, e os interpicos I-III, I-V, e III-V. Ressaltaram que a presença ou ausência destas respostas, dentro de um determinado tempo de latência, permite verificar a existência de anormalidades estruturais e funcionais que possam interferir na transmissão do estímulo acústico ao longo da via auditiva, desde o nervo auditivo até o tronco encefálico.

Para a realização adequada do BERA, é necessário que o indivíduo esteja em repouso, a fim de que não realize movimentos que possam provocar artefatos elétricos. Nos casos em que não é possível realizar o exame adequadamente, este pode ser feito sob anestesia ou sedação. $O$ exame pode, também, ser realizado durante o sono natural, sendo este 
procedimento bastante utilizado em crianças pequenas. O BERA é considerado um teste de sincronia neural, o qual pode ser utilizado para inferir informações sobre a audição, pois ele depende e reflete, tanto a sensitividade auditiva periférica, como a integridade neurológica das vias auditivas (oitavo nervo e tronco encefálico) (Junqueira e Frizzo, 2002).

Para a realização do PEATE, podem ser empregados estímulos com polaridade rarefeita, condensada ou alternada. A polaridade rarefeita é a mais indicada para a realização deste potencial, pois propicia uma maior resolução e amplitude na formação da onda I. Para melhor definição desta onda, a melhor freqüência de apresentação do estímulo é 10/s ou menos, embora velocidades de até $20 / \mathrm{s}$ não comprometam sua morfologia (Schochat, 2004).

\subsection{2 - Potenciais Evocados Auditivos de Média Latência}

Um dos primeiros traçados do potencial evocado auditivo, captado por um computador, foi descrito por Geisler et al. (1958). Em seus achados, os autores obtiveram respostas precoces, com latência inicial de aproximadamente $20 \mathrm{~ms}$, caracterizada por uma deflexão positiva ( $\mathrm{Pa})$ em torno de $30 \mathrm{~ms}$. Este potencial foi, posteriormente, denominado de Potencial Evocado Auditivo de Média Latência (PEAML), ou ainda de Respostas de Média Latência (Middle Latency Response - MLR). 
Özdamar e Kraus (1983) realizaram um estudo utilizando uma técnica não convencional de avaliação da MLR. O filtro utilizado permitia a avaliação da $A B R$ simultaneamente à da $M L R$, o que facilitava a comparação entre as duas respostas evocadas. Os componentes $\mathrm{Na}$ e $\mathrm{Pa}$ da MLR e a onda $\mathrm{V}$ da ABR foram obtidos, confiavelmente, em todos os sujeitos, para os estímulos com intensidades médias e altas. Entretanto, para estímulos com intensidades baixas, houve melhor definição da onda $V$ do que dos componentes da MLR. Desta forma, os autores concluíram que a $A B R$ parece ser o melhor teste para avaliar a sensibilidade auditiva, enquanto que a MLR mostra-se útil, clinicamente, para avaliar pacientes com distúrbios de processamento auditivo ou neurológico.

Para Ruth e Lambert (1991), os Potenciais Evocados Auditivos de Média Latência (PEAML) são compostos por um conjunto de ondas positivas e negativas, presentes entre 10 e 80 ms após o início da estimulação acústica, os quais seguem o PEATE e antecedem os potenciais evocados auditivos tardios.

O PEAML não atinge os padrões adultos antes dos 08 ou 10 anos de idade, o que inviabiliza sua utilização para a identificação precoce de deficiências auditivas (Hall, 1992). 
Os múltiplos geradores que contribuem para a formação da MLR incluem a via auditiva tálamo-cortical, a formação reticular mesencefálica e o colículo inferior (Kraus et al, 1999), e o córtex auditivo (Musiek e Geurkink, 1981).

Kraus et al. (1999) referiram que a MLR é uma resposta de multicomponentes, a qual recebe contribuições, tanto da via auditiva principal, como da não principal (tais como a formação reticular e divisões multi-sensoriais do tálamo). Os geradores dessas duas vias parecem ter cursos de desenvolvimento diferentes no tempo, sendo que os geradores não principais dominam a resposta da MLR nas crianças. Os geradores não principais são dependentes do estágio do sono, o que é um fator limitante para a realização destes potenciais. A MLR é menos dependente da sincronia neural do que a $A B R$, desta forma, em casos clínicos, nos quais a sincronia neural está prejudicada, a MLR pode permanecer intacta, enquanto que a ABR está ausente. Os autores enfatizaram, ainda, que este potencial pode ser utilizado, clinicamente, na determinação do limiar eletrofisiológico de audição na faixa de freqüências baixas, na avaliação do funcionamento do implante coclear, na avaliação do funcionamento da via auditiva e possível localização de lesões neste trajeto, e no monitoramento intraoperatório, podendo, também, contribuir para o diagnóstico de síndromes que comprometem o sistema de geração das ondas. 
A primeira onda da MLR é a $\mathrm{Na}$, seguida pela $\mathrm{Pa}, \mathrm{Nb}, \mathrm{Pb}$ e, às vezes, Nc e Pc, sendo a onda Pa a mais robusta e consistente (Musiek e Lee, 2001), e sua amplitude o parâmetro de medida mais freqüentemente utilizado para fins diagnósticos.

O PEAML, devido à localização dos seus geradores, é considerado, atualmente, um dos melhores testes para avaliar o sistema nervoso auditivo central e os distúrbios do processamento auditivo. Entretanto, respostas eletrofisiológicas (com exceção do potencial evocado auditovo de longa latência), não dependem da habilidade linguística do sujeito, e não demandam um processamento cognitivo do estímulo acústico (Schochat, 2003).

Schochat et al. (2004) avaliaram 54 indivíduos entre 15 e 55 anos de idade, por meio do PEAML, a fim de estabelecer a efetividade-sensitividade e a especificidade deste potencial, para que, desta forma, pudesse ser utilizado com maior fidedignidade. Dos 54 indivíduos avaliados, 10 apresentavam lesão no sistema nervoso central, 17 deles transtorno de processamento auditivo, e os outros 27 eram normais. Foram medidas as latências e amplitudes da onda $\mathrm{Pa}$, visto que esta é a onda mais robusta. $\mathrm{O}$ valor utilizado para a análise foi o da amplitude da onda $\mathrm{Pa}$, sendo que foram considerados três cortes para a análise de normalidade (30\%, 40\% e $50 \%$ de diferença entre a amplitude da onda $\mathrm{Pa}$, em relação ao mesmo eletrodo, porém variando a orelha; e da amplitude da onda, em relação à 
mesma orelha, porém variando o eletrodo). Os resultados mostraram que o corte de $30 \%$ apresentou o melhor resultado para efeito de eletrodo e para efeito de orelha. As autoras verificaram que o efeito de orelha foi o mais fidedigno para evidenciar transtornos de processamento auditivo, enquanto que o efeito de eletrodo foi mais efetivo para evidenciar lesão.

\subsection{3 - Potenciais Evocados Auditivos de Longa Latência}

O potencial evocado auditivo de longa latência (PEALL) mais utilizado é o Potencial Cognitivo ou P300, o qual aparece, aproximadamente, em torno de 300 ms após a estimulação acústica. Sutton et al. (1965) publicaram o primeiro trabalho sobre a existência de um componente tardio positivo em humanos. Neste trabalho, os autores sugeriram que a resposta tardia captada (P300) refletia dois tipos de influência: uma exógena e relacionada à natureza do estímulo, e outra endógena e relacionada à reação do indivíduo frente ao estímulo.

Polich (1986) estudou o P300 em um grupo de cem indivíduos normais, com média de 20 anos de idade, utilizando um paradigma de dois tons. Foram examinadas algumas variáveis, a fim de determinar a extensão da variabilidade do P300, que eram: 1-confiabilidade da variação morfológica da onda intra-indivíduo; 2-diferença entre gênero; 3-efeito do histórico familiar referente ao alcoolismo; 4-relação entre latência e amplitude do P300. O 
autor encontrou os seguintes valores de latência para a onda P300: mínimo de 245 ms, máximo de 362 ms, e média de 305 ms. Foi observado que a amplitude e a latência mantinham uma correlação, pois, quando a amplitude diminuía, a latência apresentava-se aumentada, e vice-versa. Não foram encontradas diferenças significantes entre as medidas obtidas nas duas gravações (replicação do traçado do indivíduo), para cada posição de eletrodo, nem diferenças entre gêneros ou efeito do histórico familiar referente ao alcoolismo.

Polich (1991) revisou algumas pesquisas, as quais relatavam uma relação entre os achados no P300 e as desordens cognitivas, especialmente as encontradas nas demências. $\mathrm{O}$ autor discutiu vários fatores que podem contribuir para a variabilidade normal nas respostas do P300, e alertou para a necessidade de controlá-los, a fim de se obter uma maior precisão nas respostas e uma melhor interpretação dos resultados. Variáveis do indivíduo, como idade, gênero, ingestão de alimentos antes do exame, habilidade cognitiva, e temperatura corporal, podem afetar os valores de amplitude e/ou latência da onda. Além disso, os parâmetros utilizados para a avaliação, tais como o tipo de estímulo e a tarefa realizada, também influenciam nos componentes do P300. Concluiu que o P300 é um instrumento útil para o diagnóstico de disfunções cognitivas. Tal achado foi verificado em uma grande variedade de estudos que incluíam o espectro da demência, os quais relatavam que o P300 refletia o nível de disfunção cognitiva causado pelas desordens. Por fim, o autor afirmou que é importante controlar as variáveis 
ao empregar-se o P300 como objeto de estudo, a fim de se produzir maior sensibilidade e utilidade para este potencial.

Os Potenciais Evocados Auditivos de Longa Latência (PEALL), também conhecidos como Respostas de Longa Latência (Long Latency ResponseLLR), são registrados de 80 a 750 ms após a estimulação acústica, surgindo após a MLR (Ruth e Lambert, 1991).

De acordo com Picton (1992), quando a amplitude do P300 encontra-se menor, ou sua latência atrasada, é possível que exista algum déficit no processamento cognitivo, sendo a latência o indicador mais confiável, pois a amplitude é difícil de ser alterada em função da atenção.

Anormalidades no P300 foram observadas por Musiek e Bornstein (1992), em algumas populações, tais como crianças com alteração no processamento auditivo, com déficit de atenção, com desordens de fala e linguagem, demência, traumatismo craniano, e em pacientes portadores do vírus da imunodeficiência adquirida, ressaltando, assim, a necessidade de mais pesquisas com outras populações envolvendo estes potenciais evocados.

Para Kraus e McGee (1999), os PEALL refletem, principalmente, a atividade do tálamo e do córtex, estruturas que envolvem as funções de discriminação, integração, e atenção. As respostas de longa latência não 
dependem, necessariamente, dos potenciais anteriores. Uma das características destes potenciais é que são menos afetados pelas propriedades físicas do estímulo, e mais afetados pelo uso funcional que o organismo faz do estímulo. Ressaltaram que o P300 mostra-se útil no estudo das funções cognitivas e de atenção, estando os processos de atenção, discriminação auditiva, memória, e perspectiva semântica, envolvidos na geração desse potencial. Este potencial é provocado por um paradigma raro (paradigma "oddball", ou paradigma do alvo), no qual um estímulo inesperado ocorre dentro de uma série de estímulos esperados.

Colafêmina et al. (2000) estudaram o PEALL (P300) com o objetivo de estabelecer um padrão normativo para pesquisas futuras. Para isto, analisaram as latências e amplitudes dos componentes do P300, em 20 indivíduos entre 21 e 35 anos de idade (10 do gênero masculino e 10 do gênero feminino), otologicamente normais, e sem história de alterações neurológicas e de aprendizagem. Os valores médios de latência e amplitude foram condizentes com os valores estabelecidos pela literatura. Além disso, os valores de latência (componentes N1, P2 e N2) e de amplitude (componente N1) foram significantemente diferentes entre os indivíduos do gênero masculino e feminino.

Considerando as diferenças funcionais existentes entre os hemisférios cerebrais, Frizzo et al. (2001) realizaram um estudo com o objetivo de verificar a ocorrência de possíveis diferenciações entre os PEALL dos 
hemisférios direito e esquerdo. Para isto, realizaram as avaliações em 34 indivíduos, entre 08 e 18 anos de idade, com audição normal. Realizaram a comparação das latências e amplitudes dos componentes do PEALL, para os dois hemisférios, e verificaram a existência de diferenças, para o componente P2, apenas na população do gênero masculino. Os demais componentes do PEALL não apresentaram diferenças significantes entre hemisférios. Concluíram que futuros trabalhos ainda se fazem necessários, a fim de se identificar ou não evidências eletrofisiológicas que constatem a existência destas diferenças.

Cone-Wesson e Wunderlich (2003) destacaram as vantagens dos PEALL, quando comparados aos potenciais mais utilizados clinicamente, como a ABR. Uma das vantagens citadas por estes autores foi o fato dos potenciais corticais poderem ser evocados por sons complexos, como a fala, podendo ser utilizados na estimativa do limiar eletrofisiológico e na avaliação da discriminação e percepção de fala.

O P300 é um potencial endógeno, ou seja, seu resultado depende de uma tomada de decisão por parte do indivíduo avaliado. Assim, este potencial é gerado, satisfatoriamente, desde que o indivíduo seja capaz de focalizar sua atenção em alguns estímulos raros, os quais aparecem, aleatoriamente, dentro de uma série de estímulos freqüentes. O sistema auditivo habitua-se a ouvir o estímulo freqüente, gerando menos ativações neuronais. Entretanto, o estímulo raro, por ser ouvido poucas vezes, leva o 
sistema a gerar mais ativações neuronais, e desta forma, a curva gerada por este estímulo é maior, em amplitude, do que a gerada pelo estímulo freqüente. Ao subtrair o estímulo raro do freqüente, obtém-se o P300 (Schochat, 2004).

\section{2 - Achados comportamentais, eletroacústicos, e eletrofisiológicos da audição em autismo.}

Estudos que investigam a audição de indivíduos autistas, por meio de avaliações comportamentais e eletroacústicas, são raramente encontrados na literatura. De forma geral, estudos com esta finalidade utilizam potenciais evocados auditivos e avaliações de neuroimagem para identificar alterações auditivas nesta população.

A presença de anormalidades nos testes objetivos, os quais avaliam o Processamento Auditivo (PA), refletindo dificuldades de atenção, de discriminação, e de reconhecimento e compreensão da informação auditiva, podem também ser encontradas na população com autismo. Alguns estudos demonstram anormalidades eletrofisiológicas nos Potenciais Evocados Auditivos de Tronco Encefálico (PEATE), de Média Latência (PEAML) e de Longa Latência (Potencial Cognitivo - P300). 
Novick et al. (1980) realizaram avaliações eletrofisiológicas da audição em cinco crianças autistas e em cinco crianças normais. Os resultados destas avaliações mostraram que não houve diferença entre os grupos, para os componentes P60 e N100. Contudo, os componentes P200 e P300 encontraram-se menores em todos os sujeitos autistas, quando comparados com os sujeitos do grupo controle. Além disso, um sujeito autista apresentou alteração na resposta evocada auditiva de tronco encefálico. Os autores referiram que estes resultados foram consistentes com a idéia de que existiriam déficits auditivos no autismo, os quais podem, em alguns casos, envolver baixos níveis de transmissão neural. Essas alterações podem aparecer como anormalidades na resposta de tronco encefálico, porém, manifestam-se mais consistentemente em aspectos altos do processamento (que envolvem o registro e o armazenamento da informação). Por fim, os mesmos sugeriram que alterações severas de linguagem, encontradas em crianças autistas, podem ser secundárias em relação a déficits básicos no processamento auditivo alto.

Evidências de alterações nos resultados da Resposta Evocada de Tronco Encefálico (Brainstem evoked response - BSER) em crianças autistas foram mencionadas por Rosenblum et al. (1980). Neste estudo, seis crianças autistas e seis normais, da mesma faixa etária, foram avaliadas por meio do BSER, sendo que as autistas foram sedadas levemente (hidrato de cloral) para a realização deste exame. O grupo autista realizou audiometria tonal condicionada e audiometria com reforço visual, enquanto o grupo 
normal realizou audiometria tonal convencional. Além disso, ambos realizaram timpanometria, anteriormente à avaliação do BSER. O resultado dessas avaliações mostrou não haver comprometimento dos limiares de audibilidade e da via auditiva periférica, para ambos os grupos. Entretanto, os resultados da resposta evocada de tronco encefálico, em crianças autistas, mostraram grande variabilidade e aumento no tempo de latência das ondas. De acordo com os autores, estes achados indicariam evidência de disfunção em tronco encefálico nas crianças autistas, enquanto que a variabilidade eletrofisiológica sustenta a hipótese de inconstância perceptual.

Tanguay et al. (1982) realizaram a ABR em 16 crianças autistas e em 28 crianças normais, de mesma faixa etária (02 a 14 anos de idade). Os autores relataram dificuldades na realização da ABR em autistas, optando por avaliá-los em sono natural. Os achados do estudo mostraram que três crianças autistas apresentaram atraso na latência absoluta da onda I, sugerindo funcionamento alterado da via auditiva periférica. Além disso, os outros autistas também apresentaram atraso na latência absoluta da onda I, porém, nestes casos, apenas na orelha direita para o estímulo menos intenso. Oito crianças autistas mostraram valores de tempo de transmissão, na $A B R$, situados três desvios padrão além da média normal. Os autores levantaram algumas hipóteses, baseados nas anormalidades encontradas na ABR de autistas: (1) os achados podem não ter relação causal com as incapacidades das crianças autistas, (2) os achados podem representar uma distorção no "input" auditivo, a qual prejudicaria o aprendizado da linguagem, 
e (3) os achados podem refletir um estado inicial, em que o "input" anormal ocasiona um mau-desenvolvimento dos sistemas cerebrais necessários à linguagem e à função cognitiva.

Taylor et al. (1982) investigaram a ABR em 32 crianças autistas e em 22 normais, utilizando o estímulo clique. Os indivíduos autistas não colaboraram com a realização do exame, sendo, então, sedados uma hora antes da avaliação. Os pesquisadores analisaram as latências interpicos e os limiares eletrofisiológicos, para cada orelha. Os resultados mostraram uma série de alterações na via auditiva de crianças autistas. A perda auditiva de grau moderado foi verificada em 11 autistas (oito bilateralmente), e a perda auditiva de grau severo a profundo em três autistas (bilateralmente). Além disso, os interpicos I-III e I-V estavam significantemente aumentados nas crianças autistas. Foi observado, também, um aumento no tempo de condução, principalmente no início da via auditiva em tronco encefálico. Os resultados encontrados confirmam alguns estudos prévios sobre anormalidades em ABR de crianças autistas, e são concordantes com algumas teorias sobre a base etiológica do autismo. Os autores concluíram que a alta incidência de perda auditiva nesta população é significante e recomendaram a testagem auditiva, por meio da ABR, como rotina clínica.

Um estudo realizado por Gillberg et al. (1983) comparou a ABR em 24 crianças autistas (19 meninos e cinco meninas), em sete crianças com outras psicoses infantis, e em 31 crianças normais. Os resultados de 16 
crianças autistas apresentaram-se normais, sendo que as outras oito crianças mostraram resultados anormais na ABR. Os autores referiram que os resultados anormais encontrados na ABR de crianças autistas indicavam disfunção em tronco encefálico. Este achado foi considerado bastante comum nos casos de autismo infantil, ocorrendo de $23 \%$ a $33 \%$ dos casos. Os autores relataram um valor médio da latência da onda $\mathrm{V}(5.59 \mathrm{~ms})$, dos indivíduos autistas, maior do que o dos outros grupos avaliados. Os outros dois grupos de crianças não apresentaram alterações na ABR.

Os Potenciais Evocados Auditivos de Longa Latência também têm sido investigados na população com autismo. Niwa et al. (1983) estudaram a função cognitiva em sujeitos autistas empregando o Potencial Cognitivo (P300). Foram analisados os resultados de quatro indivíduos autistas, cinco indivíduos normais, e quatro indivíduos com síndrome de Down (os dois últimos grupos foram considerados controles). O P300 foi investigado por meio de três diferentes condições experimentais: "no-task" (o sujeito é instruído a simplesmente ouvir o estímulo, sem nenhuma informação a respeito dos componentes deste), "counting" (o sujeito é instruído a contar, silenciosamente, o número de vezes que estímulo alvo aparece entre o estímulo padrão - analisando-se, deste modo, se o sujeito tem capacidade de diferenciar dois tipos de estímulos), e "key-press" (o sujeito é instruído a apertar um botão de resposta quando ouvir o estímulo alvo). Os resultados mostraram que os autistas apresentaram menor amplitude do componente P300 sob a condição "no-task", quando comparados com os dois grupos 
controle. Desta forma, os autores sugeriram que os autistas tinham certas dificuldades cognitivas no "processo de avaliação de estímulo alvo", quando comparados com os dois grupos controle.

Gillberg et al. (1987) realizaram diversas avaliações neurobiológicas, incluindo a ABR, em 17 crianças autistas (14 meninos e três meninas), e em três com síndrome de Asperger, encontrando a presença de alterações na ABR em quatro das 17 crianças avaliadas. As alterações observadas consistiram em aumento no tempo de latência das ondas em uma criança com síndrome de Asperger e em duas com Autismo Infantil, bem como no aumento patológico da diferença interaural da onda $\mathrm{V}$ em outra criança autista.

Sersen et al. (1990) investigaram a Resposta Evocada Auditiva de Tronco Encefálico (Brainstem Auditory-Evoked Resposes - BAER) em 46 indivíduos controles, 16 com síndrome de Down e 48 autistas, todos do sexo masculino. Nestes indivíduos, foi necessário realizar a sedação naqueles em que as condições não permitiam uma boa avaliação. Sendo assim, seis indivíduos com síndrome de Down e 37 autistas foram sedados para a realização do exame. Os resultados mostraram que os indivíduos com síndrome de Down, sedados e não sedados, apresentaram latências absolutas e interpicos diminuídos, para os componentes mais precoces da BAER, enquanto que o grupo de autistas sedados apresentou prolongamento das latências, para os componentes médios e mais tardios 
deste potencial. Para os autores, o prolongamento das latências, encontrado nos autistas não sedados, não tinha relação com a idade ou o nível intelectual do sujeito. Os autores perceberam que os indivíduos que necessitaram de sedação podem ter maior probabilidade de apresentar alterações neurológicas, e que um efeito da sedação, na BAER, não pode ser excluído.

Considerando as alterações na prosódia da fala, freqüentemente apresentadas por crianças autistas, Erwin et al. (1991) propuseram-se a verificar se indivíduos autistas adultos seriam capazes de discriminar e/ou reconhecer contrastes prosódicos em estímulos auditivos. Para tanto, realizaram a avaliação eletrofisiológica (Potencial Cognitivo - P3) e comportamental, com estímulos prosódicos e fonêmicos, em 11 indivíduos autistas (meninos) e em 14 normais (controle) da mesma faixa etária. Contrariamente à hipótese dos autores, os autistas apresentaram respostas (P3) normais, para todos os estímulos, e realizaram os testes comportamentais em nível normal. No entanto, não foi demonstrada uma resposta significante no P3 dos autistas para a sílaba/pa/. Este resultado inesperado fez com que os autores reexaminassem os dados. Assim, perceberam que ocorria um aumento das respostas para a sílaba /pa/ quando esta era apresentada como estímulo freqüente na primeira parte da avaliação, e que esta hiper-reatividade inicial evitava a diferenciação do estímulo "freqüente/raro", quando o /pa/ era apresentado como estímulo raro na segunda parte da avaliação. Os autores concluíram que os dados 
indicavam P3 normais e processamento comportamental do estímulo prosódico normal, nos autistas de alto-funcionamento.

Steffenburg (1991) estudou 35 crianças com autismo (de dois a 12 anos de idade) e 17 com "autistic like conditions", ou seja, crianças com alterações que preencheram, em parte, os critérios para o autismo (três a 12 anos de idade). Estas foram submetidas a uma exaustiva avaliação neurobiológica, e os achados foram comparados com vários grupos controle. Aproximadamente $90 \%$ das crianças autistas e "autistic like conditions" tiveram indicação de disfunção cerebral. Algumas destas, as que não apresentaram esta anormalidade, mostraram uma semelhança com a síndrome de Asperger. Os autores concluíram que o autismo tem múltiplas etiologias biológicas, e que os sintomas do autismo em uma criança devem sempre obrigar uma imediata avaliação neurobiológica.

O uso do Potencial Evocado Auditivo de Média Latência (PEAML ou MLR - Middle Latency Response) em indivíduos autistas, diferentemente do PEATE, tem sido pouco descrito na literatura. Buchwald et al. (1992) utilizaram a MLR para avaliar um grupo de 11 sujeitos adultos com autismo de alto funcionamento, e um de 11 sujeitos normais. A partir da análise estatística dos valores de latência e amplitude dos componentes Pa, P1, e $\mathrm{Nb}$, verificou-se que, em relação ao componente $\mathrm{Pa}$, não houve diferenças significantes entre os grupos. Contudo, foram identificados dois tipos de anormalidades no componente P1 (positividade máxima entre 50-60 ms). O 
P1 foi significativamente menor em sujeitos autistas quando a velocidade de apresentação do estímulo era baixa, e o P1 "autístico" não mudou frente ao aumento da velocidade de apresentação do estímulo de 0,5 para 10/s. Este estudo foi o primeiro a relatar anormalidades na onda P1 em autismo. Considerando os resultados obtidos, os autores sugeriram que o sistema ascendente de ativação reticular, e/ou seu alvo talâmico pós-sináptico, podem apresentar disfunção em sujeitos com esta síndrome.

Klin (1993) realizou uma revisão de 11 pesquisas, cujos objetivos eram testar a integridade da via auditiva em tronco encefálico, por meio da ABR, em autistas. A autora descreveu os resultados das pesquisas e comparouos, quando possível, entre si. Constatou que os estudos, em sua maioria, verificavam as alterações audiológicas por meio da $A B R$ e não utilizavam a audiometria. Com relação às alterações auditivas periféricas, estas foram encontradas em um número significativo de sujeitos autistas dentre os trabalhos revisados (56 de 170 sujeitos autistas). Com relação às alterações na transmissão central, a autora relatou que a única generalização que se poderia fazer era a de que, se existe uma disfunção na via auditiva em nível de tronco encefálico no autismo, as indicações desta disfunção são bastante inconsistentes. Dentre 10 estudos que relataram resultados individuais dos valores dos interpicos, 35 de 159 sujeitos apresentaram indicações de anormalidades neste parâmetro. A autora concluiu que os estudos realizados com $A B R$, em autistas, não forneceram uma evidência clara de disfunção em tronco encefálico nesta população, embora não refutem esta 
possibilidade. Afirmou também que, a partir da análise realizada, ficou evidente a possibilidade de co-ocorrência de alterações auditivas periféricas e o autismo.

A investigação do processamento auditivo em nível cortical, por meio dos Potenciais Evocados Auditivos de Longa Latência em crianças autistas, também foi realizada por Bruneau et al. (1999). Foram avaliados três grupos com 16 crianças cada um, sendo um grupo de crianças com autismo e retardo mental, outro de crianças normais, e o terceiro composto por crianças apenas com retardo mental, na faixa etária de 04 a 08 anos de idade. Todos os indivíduos eram audiologicamente normais, resultado determinado pela ABR. Foram analisados dois picos negativos, que ocorrem entre 80 e 200 ms, de acordo com o nível de intensidade do estímulo acústico (50 a 80 dB NPS), o primeiro localizado na região fronto-central, e o segundo na região bitemporal. Posteriormente, comparados os resultados obtidos no grupo de crianças autistas com os obtidos nos outros dois grupos. Os resultados em crianças autistas mostraram anormalidades na onda N1, com amplitude diminuída no sítio gerador bitemporal, e considerável atraso na latência desta onda (por volta de $20 \mathrm{~ms}$ ). Além disso, nos dois grupos de referência (crianças normais e crianças com retardo mental), o efeito intensidade foi encontrado nos dois lados, enquanto que, nos autistas, este esteve ausente do lado esquerdo, mas presente do lado direito. Concluíram que os achados em crianças autistas, com distúrbio de comunicação verbal acentuado, apontam para uma disfunção nas áreas corticais envolvidas na 
geração do componente $\mathrm{N} 1$, isto é, o córtex auditivo associativo na parte lateral do giro temporal superior, com alterações mais específicas do lado esquerdo, quando o estímulo auditivo era processado.

A importância da avaliação audiológica, em crianças e adolescentes com autismo, foi enfatizada também por Rosenhall et al. (1999). Neste estudo, realizado ao longo de 12 anos, 199 crianças e adolescentes autistas (153 e 46 meninas) foram avaliados audiologicamente por meio do método apropriado para cada faixa etária (audiometria tonal, audiometria vocal, audiometria lúdica, audiometria com reforço visual, audiometria de observação comportamental, e reação à voz), além da timpanometria. A ABR foi realizada em 192 dos 199 casos e, em sua maioria, os indivíduos permaneceram acordados durante o exame. Dentre os resultados, foram observadas perdas auditivas de grau leve a moderado em $7,9 \%$ dos casos, e perda auditiva unilateral em $1,6 \%$ daqueles que puderam ser testados apropriadamente. Perdas auditivas bilaterais de grau severo a profundo, ou anacusia, foram obtidas em $3,5 \%$ de todos os casos. Além disso, a hiperacusia foi verificada em $18 \%$ dos indivíduos do grupo autista, dado não observado no grupo controle. Constatou-se a presença de otite média serosa em $23,5 \%$ da população, demonstrando, assim, que a perda auditiva condutiva parece ser um achado freqüente no autismo.

Um estudo realizado por Maziade et al. (2000) avaliou a BAER (Brainstem Auditory-Evoked Response) em 73 sujeitos autistas e em 251 
parentes não-afetados com autismo. Os resultados obtidos nestes grupos foram comparados aos resultados de 521 indivíduos do grupo controle (normais). Verificaram a presença de atraso na condução do estímulo no nervo auditivo em autistas, evidenciada pelo aumento do interpico I-III. Além disso, observaram o mesmo prolongamento no interpico I-III em parentes de 1ํ grau não afetados, quando comparados os resultados aos do grupo controle. O prolongamento do interpico I-III não foi encontrado em $53 \%$ dos familiares não afetados, e sendo assim, embora haja evidências de correlação entre o prolongamento I-III em autistas e familiares, esse não deve ser o único fator responsável pelo autismo. Os autores concluíram que o prolongamento do interpico I-III, nas respostas evocadas auditivas de curta latência, pode ser um marcador para um dos inúmeros déficits encontrados no autismo, e que merece uma análise mais detalhada para ser utilizado como um potencial fenótipo alternativo para o distúrbio.

Coutinho et al. (2002) estudaram a ABR em duas crianças com autismo, uma com 02 e outra com 04 anos de idade. Os dois casos desta pesquisa realizaram a imitanciometria, na qual os resultados apresentavamse normais, indicando, assim, ausência de patologias da orelha média. Não foi possível realizar os testes comportamentais (audiometria por reforço visual e audiometria lúdica) em um dos casos, sendo que o outro apresentou resultados inconclusivos. Os autores verificaram que os interpicos e as latências das ondas I, III, e V estavam dentro da média, em ambos os casos, entretanto, identificaram um padrão comum na resposta da ABR: a 
proeminência na amplitude da onda I em relação às amplitudes das ondas III e $\mathrm{V}$, em todas as orelhas a $90 \mathrm{~dB}$ NA. Esta proeminência da onda I ainda não havia sido relatada em outros trabalhos. Deste modo, os autores ressaltaram a necessidade de futuras pesquisas que possam estabelecer a importância deste achado e suas possíveis implicações no sistema auditivo central destas crianças. Os autores hipotetizaram uma possível associação destes achados com a hiperacusia e a reação anormal ao som, freqüentemente vistos em crianças autistas.

Reações exageradas a pequenas mudanças ambientais e comportamento anormal em resposta ao estímulo auditivo são freqüentemente observados em crianças com autismo. Gomot et al. (2002) estudaram o mecanismo cerebral envolvido na detecção automática de mudanças de freqüências sonoras por meio do "Mismatch Negativity" (MMN), em 15 crianças autistas e em 15 crianças normais (grupo controle). O BAER foi realizado em todos os indivíduos anteriormente à realização do MMN. Desta forma, garantiram a acuidade auditiva normal dos participantes da pesquisa. Comparadas com as respostas do grupo controle, o MMN registrado nas crianças autistas mostrou latência significantemente menor e foi seguido pela onda P3a. Embora o componente temporal tenha sido evidenciado bilateralmente em ambos os grupos, este ocorreu precocemente no hemisfério esquerdo em crianças autistas, precedido por um componente frontal esquerdo anormal. O padrão eletrofisiológico referido no estudo enfatizou disfunção no córtex frontal esquerdo, o qual também pode estar 
envolvido nos comprometimentos cognitivo e comportamental característicos deste transtorno neurodesenvolvimental complexo.

Bruneau et al. (2003) investigaram as relações entre os potenciais evocados auditivos tardios, obtidos em regiões temporais (ondas N1c ou $\mathrm{Tb}$ ), e as habilidades verbais e não-verbais, em 26 crianças autistas com retardo mental de 04 a 08 anos de idade. Todas as crianças apresentavam ABR dentro da normalidade, indicativo de acuidade auditiva normal. Os autores verificaram que a onda N1c apresentava a menor amplitude e latência aumentada, em crianças com autismo, dado sugestivo de hiporeatividade eletrofisiológica bitemporal. Foi verificado um padrão particular de assimetria no nível mais alto de intensidade do estímulo (80 dB NPS), nas crianças autistas, com maior ativação da região temporal direita. Os autores concluíram que os resultados sugerem uma reorganização no desenvolvimento das funções dos hemisférios direito-esquerdo no autismo, com ativação preferencial do hemisfério direito para funções normalmente localizadas no hemisfério esquerdo.

Relatos na literatura demonstram que crianças autistas apresentam anormalidades severas no comportamento social, que coexistem com atenção anormal às pessoas e aos estímulos sociais relevantes, e com déficit de linguagem. Devido à complexidade física dos estímulos sociais significantes, uma deficiência no processamento sensorial do estímulo complexo tem sido apontada como uma das causas para o déficit de 
atenção e de linguagem presentes em autistas. Levando em consideração estes aspectos, Ceponiene et al. (2003) realizaram um estudo utilizando o Potencial Evocado Auditivo relacionado a Eventos (Event-Related Brain Potentials - ERPs), para examinar o processamento sensorial e de atenção inicial a sons de diferentes complexidades, em crianças com autismo de alto funcionamento. Anteriormente à realização do ERP, verificaram a acuidade auditiva dos sujeitos por meio da audiometria, e todos os participantes da pesquisa apresentavam audição normal. Os resultados mostraram que o processamento sensorial do som estava intacto em crianças com autismo de alto funcionamento, e não foi afetado pela complexidade do som. Em contrapartida, sua orientação involuntária foi afetada pela natureza do estímulo, apresentando-se normal, tanto para mudanças de tons simples, quanto para tons complexos, mas sendo inteiramente abolida por mudanças de vogais. Estes resultados demonstraram que déficits de orientação auditiva no autismo não podem ser explicados por déficits sensoriais, e que estes podem ser específicos para sons da fala.

Ferri et al. (2003) estudaram dois componentes automáticos dos potenciais evocados auditivos relacionados a eventos (ERPs), o "Mismatch Negativity" (MMN) e o Potencial Cognitivo (P300), a fim de entender melhor as bases psicofisiológicas das anormalidades do processamento auditivo no autismo. Foram avaliados 10 sujeitos com autismo e retardo mental associado (média de 12,3 anos de idade) e 10 sujeitos normais da mesma faixa etária como grupo controle. Os resultados mostraram o componente N1 
com latências significantemente menores, e o MMN maior no grupo de indivíduos autistas, divergindo dos resultados obtidos no grupo controle. A amplitude do P300 mostrou-se maior em sujeitos autistas do que no grupo controle durante a infância; sendo que o oposto foi observado durante a adolescência. Frente a estes achados, os autores puderam concluir que mudanças significativas nos ERPs podem também ser notadas em indivíduos não cooperativos com autismo e retardo mental, podendo ser diferentes das mudanças já relatadas para sujeitos com autismo de alto funcionamento. Os resultados mostraram modificações no desenvolvimento, as quais deveriam ser levadas em consideração ao se analisar os dados obtidos em sujeitos autistas, enfatizando, desta forma, a necessidade de aprofundamento nas pesquisas envolvendo os potenciais relacionados a eventos na população com autismo.

Rosenhall et al. (2003) objetivaram investigar a presença de alterações na via auditiva em tronco encefálico, ou no nervo coclear, em crianças autistas, e também descrever quais eram as anormalidades encontradas. Para isto, 153 crianças e adolescentes autistas tiveram os resultados da ABR comparados com os resultados de crianças normais (grupo controle). Os resultados mostraram audição normal em 101 crianças autistas, prolongamento do interpico III-V, e aumento significante das latências das ondas I e V. Além disso, testes individuais mostraram que, no grupo de autistas com audição normal, 58\% apresentavam anormalidades em um ou mais dos oito parâmetros estudados na ABR. As anormalidades mais 
comumente encontradas foram o prolongamento da onda $\mathrm{V}(38 \%$ dos casos), e do interpico I-V (28\% dos casos). O aumento do interpico I-V também foi verificado em $27 \%$ das 49 crianças difíceis de serem avaliadas, ou com perda auditiva. Os autores concluíram que lesão em tronco encefálico, disfunção coclear, e envolvimento do sistema coclear eferente são possíveis fatores que podem explicar os achados da audiometria de tronco encefálico em crianças e adolescentes autistas.

Tecchio et al. (2003) utilizaram a "Magnetoencephalographic Measurements of Mismatch Field' (MMF), a qual reflete a detecção de uma mudança nas características físicas de um som repetitivo, para avaliar 14 sujeitos diagnosticados com distúrbio autístico (08 a 32 anos), e para comparar os resultados com os obtidos em 10 indivíduos do grupo controle. Todos os indivíduos realizaram a ABR, anteriormente ao MMF, sendo que os resultados mostraram acuidade auditiva normal e boa propagação do som ao longo da via auditiva até o tronco encefálico. Entretanto, os autores verificaram, no MMF, diferenças significantes nas respostas cerebrais entre os grupos, sugerindo que os sujeitos autistas de baixo funcionamento apresentam disfunção nos estágios pré-conscientes da discriminação auditiva cortical, levando a um processamento anormal das aferências sensoriais auditivas.

Indivíduos com autismo de alto funcionamento, ou com síndrome de Asperger, costumam referir dificuldades para compreender a fala em 
ambiente com ruído de fundo competitivo. Por esta razão, Alcántara et al. (2004) realizaram um estudo sobre habilidades de percepção de fala em ruído, utilizando Limar de Recepção de Fala (LRF ou "Speech Reception Thresholds"- SRT), definido como a razão fala-ruído ("Speech-to-Noise Ratio"- SNR) no qual $50 \%$ da fala é identificada corretamente. Foram avaliados 11 indivíduos com autismo de alto funcionamento / síndrome de Asperger e 09 indivíduos do grupo controle, por meio de procedimento adaptativo. Todos os indivíduos da pesquisa apresentavam limiar de audibilidade normal, para as freqüências de 250 a $8000 \mathrm{~Hz}$ na audiometria tonal, e normalidade das funções de orelha média. Os resultados demonstraram que o LRF dos indivíduos autistas de alto funcionamento / síndrome de Aspeger eram piores (2 a 3.5 dB maiores) do que os do grupo controle, para todos os cinco sons de fundo testados, demonstrando um decréscimo substancial no reconhecimento de fala. Tal fato indicou que esses indivíduos requerem um SRN maior para atingirem um nível de performance igual ao do grupo controle. Para os autores, a dificuldade de compreensão de fala, referida por indivíduos com essa patologia, pode ser causada por uma habilidade reduzida de integrar informações repentinas presentes em meio ao ruído.

Gomes et al. (2004) enfatizaram o uso das Emissões Otoacústicas (EOA) e dos reflexos acústicos, na avaliação do sistema auditivo periférico de crianças autistas, visto que estas apresentam alterações comportamentais e são difíceis de serem avaliadas. Citam, também, o teste 
do limiar de desconforto auditivo, utilizado para determinar o nível de tolerância a sons intensos. O objetivo do estudo foi verificar se a queixa de hipersensibilidade auditiva relatada pelos pais, cuidadores, e/ou terapeutas dos indivíduos, corresponderia aos achados audiológicos. A fim de excluir os indivíduos com perda auditiva, foram realizadas as emissões otoacústicas por produto de distorção (EOAPD). Foi realizada a pesquisa do reflexo acústico nas freqüências de 500, 1000, 2000, e 4000 Hz em 46 indivíduos autistas (39 meninos e sete meninas), entre 05 e 19 anos de idade. $O$ estudo da resposta a estímulos acústicos intensos (tom modulado pulsátil a $90 \mathrm{~dB}$, nas freqüências de 500 a $6000 \mathrm{~Hz}$ ), em campo, foi realizado nos 11 indivíduos que apresentaram queixa de hipersensibilidade a sons intensos (relatada pelos pais, responsáveis, ou terapeutas). Destes, apenas dois mostraram desconforto, quando expostos a estímulo acústico intenso em campo aberto. Os resultados demonstraram que manifestações comportamentais aos sons não estão associadas à hipersensibilidade da via auditiva, mas a dificuldades em níveis de processamento mais superiores do córtex cerebral, envolvendo sistemas que se encontram, normalmente, alterados em pacientes do espectro autístico, tais como o sistema límbico.

Khalfa et al. (2004) verificaram a hipótese de percepção anormal do "loudness" (sensação subjetiva da intensidade) em crianças e adolescentes autistas, por meio de testes psicoacústicos. Foram avaliados 11 indivíduos autistas (nove do gênero masculino) e um grupo de indivíduos normais, pareados por idade e sexo. Todos os sujeitos da pesquisa apresentavam 
audição normal e capacidade cognitiva adequada para a realização dos testes. Foi realizada a audiometria tonal convencional (freqüências de 250 a $8000 \mathrm{~Hz})$ e, posteriormente, foram obtidos os níveis de desconforto para as intensidades. A seguir, foi determinada a faixa dinâmica da audição (subtraindo o limiar de desconforto do limiar de audibilidade). Os resultados confirmaram a hipótese de percepção aumentada do "loudness" em crianças com autismo, além de demonstrarem uma faixa de percepção dinâmica restrita, apesar dos limiares de audibilidade normais. Desta forma, os autores confirmam a existência de hiperacusia em indivíduos autistas, e discutiram a origem dela (central ou periférica). Referiram que esta pode estar relacionada ao comportamento anormal e a alterações eletrofisiológicas auditivas, observadas no autismo.

Teder-Sälejärvi et al. (2005) realizaram uma pesquisa com o objetivo de comparar a habilidade de focalizar-se a atenção, seletivamente, a um som com origem em um ambiente ruidoso, em autistas adultos e em indivíduos do grupo controle. Os resultados mostraram que, tanto a medida comportamental de deteç̧ão do alvo, como a amplitude do ERP, indicavam que os sujeitos do grupo controle eram capazes de focalizar a atenção mais efetivamente no som de origem do que os sujeitos autistas. Para os autores, esses achados indicaram um déficit básico em focalização espacial da atenção auditiva, em autismo, o qual pode ser um fator que impede a interação social e o comportamento guiado pelo estímulo sensorial, particularmente em ambiente ruidoso. 
Métodos 


\section{4 - MÉTODOS}

Esse estudo foi realizado no Departamento de Fisioterapia, Fonoaudiologia e Terapia Ocupacional da Faculdade de Medicina da Universidade de São Paulo. A coleta de dados foi realizada no Laboratório de Investigação Fonoaudiológica em Potenciais Evocados Auditivos do referido departamento.

Esta pesquisa foi aprovada pela Comissão de Ética para Análise de Projetos de Pesquisa - CAPPesq da Diretoria Clínica do Hospital das Clínicas e da Faculdade de Medicina da Universidade de São Paulo, em sessão de 24/04/2003, com o protocolo de pesquisa no 237/03 (Anexo A).

As avaliações foram realizadas após assinatura do Termo de Consentimento Livre e Esclarecido pelos pais ou responsáveis (Anexo B).

\section{1 - CASUÍSTICA}

Participaram desta pesquisa 41 indivíduos com idades entre 08 e 20 anos, divididos em dois grupos:

Grupo Pesquisa (GP): Fizeram parte deste grupo 16 indivíduos com 
Autismo, um do gênero feminino e 15 do gênero masculino, com idades entre 08 e 19 anos (média de 11.94 anos de idade) .

Os indivíduos que compuseram o GP foram encaminhados pelo Serviço de Psiquiatria da Infância e da Adolescência do Instituto de Psiquiatria do Hospital das Clínicas da Faculdade de Medicina da Universidade de São Paulo, onde são atendidos, e pelo Laboratório de Investigação Fonoaudiológica em Linguagem e Cognição do Departamento de Fisioterapia, Fonoaudiologia e Terapia Ocupacional da FMUSP. Foram encaminhadas listas, para a pesquisadora responsável, com os dados do indivíduo (diagnóstico psiquiátrico, nome, idade, nome do responsável e telefone). Desta forma, a pesquisadora entrava em contato, por telefone, com os pais/responsáveis e agendava a data das avaliações. Muitos sujeitos encaminhados não puderam participar da pesquisa por motivos pessoais. Dentre os indivíduos que aceitaram participar, alguns não compareceram na data agendada, e outros foram excluídos da pesquisa por não permitirem a realização de nenhuma avaliação.

Grupo Controle (GC): Fizeram parte deste grupo 25 indivíduos com desenvolvimento normal, 16 do gênero feminino e nove do gênero masculino, com idades entre 08 e 20 anos (média de 12,16 anos de idade).

Os indivíduos que compuseram o GC foram encaminhados por escolas de ensino fundamental e médio, sendo selecionados pelas professoras por não apresentarem queixas psiquiátricas, neurológicas, de linguagem, e nem audiológicas. A pesquisadora entrava em contato com os pais/responsáveis 
dos indivíduos por meio de telefonema (dados encaminhados pelas professoras com o consentimento dos pais), e agendava as datas para as avaliações.

\subsection{1 - Critérios de Inclusão}

Os critérios de inclusão adotados nesta pesquisa foram:

Grupo Pesquisa: faixa etária de 08 a 20 anos, diagnóstico médico de Autismo de Alto-funcionamento, síndrome de Asperger, ou ainda Autismo Infantil com menor comprometimento cognitivo.

Grupo Controle: faixa etária de 08 a 20 anos, com histórico de desenvolvimento neuropsicomotor normal, sem queixas psiquiátricas, neurológicas, de linguagem, audiológicas, e nem de processamento auditivo.

\section{2 - MATERIAIS}

O material do presente estudo constou dos resultados das avaliações comportamentais, eletroacústicas, e eletrofisiológicas da audição, obtidos nos dois grupos estudados.

Os materiais e equipamentos utilizados para a realização das avaliações serão descritos a seguir: 
1 - Protocolo de coleta da história clínica do paciente. Protocolo elaborado e utilizado pelo Setor de Audiologia Clínica do Curso de Fonoaudiologia da Faculdade de Medicina da Universidade de São Paulo (Anexo C);

2 - Otoscópio da marca Heine, para a realização da inspeção visual do meato acústico externo;

3 - Analisador de orelha média marca Grason-Stadler, modelo GSI-33 (ANSI S3.39-1987) para a realização da avaliação eletroacústica da audição;

4 - Audiômetros modelos GSI-61 e GSI-68, marca Grason-Stadler e fones de ouvido supra aurais modelo TDH-50 atendendo aos padrões ANSI S3.6-1989 e IEC-1988. Cabina acústica atendendo à norma ANSI S3.1-1991 de quantidade de ruído ambiental, para a realização da avaliação comportamental da audição;

5 - Equipamento Sistema Portátil Traveler Express - Marca Bio-Logic (ANSI S3.7-1996), e o programa EP317 inserido no computador, para a realização da avaliação eletrofisiológica da audição. Este equipamento consiste de um computador portátil, um gerador de estímulos acústicos, um "mediador" (caixa na qual são conectados os eletrodos), cinco eletrodos de superfície (cobre), e fones de ouvido supra aurais modelo TDH-39. 


\section{3 - PROCEDIMENTOS}

Serão descritos, a seguir, os procedimentos realizados na ordem em que foram executados.

\subsection{1 - Informações sobre a pesquisa para os pais ou} responsáveis.

Os esclarecimentos sobre a pesquisa para os pais ou responsáveis dos indivíduos, de ambos os grupos, foram realizados no Laboratório de Investigação Fonoaudiológica em Potenciais Evocados Auditivos, anteriormente à realização das avaliações. Os esclarecimentos foram realizados, verbalmente, pela pesquisadora e por meio do termo de consentimento livre e esclarecido, aprovado previamente pela Comissão de Ética desta Instituição, o qual foi assinado pelo responsável após a explicação e a leitura. Foi informado aos pais ou responsáveis dos indivíduos dos grupos controle e pesquisa que as avaliações a serem realizadas não apresentavam riscos à saúde do indivíduo, e que os resultados destas avaliações seriam utilizados para pesquisa de Mestrado.

\subsection{2 - Coleta da história clínica dos indivíduos.}


Inicialmente, foi realizada a coleta da história clínica dos indivíduos com os pais ou responsáveis, utilizando-se do protocolo do Serviço de Audiologia Clínica do Curso de Fonoaudiologia da FMUSP para obtenção de dados pessoais do indivíduo, bem como de informações referentes à história pregressa do distúrbio em questão, desenvolvimento neuropsicomotor, alterações neurológicas, psiquiátricas, comportamentais, uso de medicamentos, presença de fatores pré, peri, e pós-natais considerados como de risco para deficiência auditiva, ocorrência de episódios de otite, supuração, e queixas dos pais sobre dificuldades auditivas.

\subsection{3 - Coleta dos dados das avaliações eletroacústicas,} comportamentais, e eletrofisiológicas da audição.

Após a coleta da história clínica do indivíduo, foi realizada a inspeção visual do meato acústico externo, com o objetivo de verificar possíveis obstruções por presença de cerume ou corpo estranho.

Para a realização das avaliações, foram dadas orientações aos indivíduos sobre sua realização. Tais orientações foram retomadas freqüentemente durante as avaliações do GP, a fim de que eles realizassem as tarefas da forma mais adequada.

As orientações e os exames específicos realizados em cada avaliação, serão descritos na ordem em que foram executados: 
I - Avaliação Eletroacústica da audição: realizada por meio das medidas de imitância acústica (timpanometria e pesquisa dos reflexos acústicos ipsilaterais, nas freqüências de 500, 1000, 2000, $4000 \mathrm{~Hz}$ e "Broad Band" - BB). Cada indivíduo foi orientado a permanecer quieto, principalmente, sem movimentar a cabeça e sem falar.

II - Avaliação Comportamental da audição: composta pelos seguintes exames:

II.A - Audiometria Tonal: realizada nas freqüências de 250, 500, 1000, 2000, 3000, 4000, 6000 e $8000 \mathrm{~Hz}$. Cada indivíduo foi orientado a levantar a mão, ou a apertar o "botão", sempre que escutasse o estímulo acústico, mesmo quando estivesse fraco. Para alguns indivíduos do GP, foi utilizado o condicionamento lúdico, a fim de se obter respostas mais fidedignas. O exame foi realizado com fones de ouvido supra-aurais em cabina acústica.

II.B - Logoaudiometria: foram pesquisados o Limiar de Reconhecimento de Fala (LRF) e o Índice de Reconhecimento de Fala (IRF) com as listas de vocábulos propostas por Santos e Russo (1991). Cada indivíduo foi orientado a repetir as palavras ditas pela pesquisadora da maneira que entendesse. Tais exames foram realizados com fones de ouvido supra-aurais em cabina acústica.

III - Avaliação Eletrofisiológica da audição: Os potenciais evocados auditivos foram realizados com o indivíduo sentado em uma poltrona 
reclinável, dentro de uma sala tratada acústica e eletricamente. A superfície da pele (fronte, mastóides, e couro cabeludo) foi limpa com pasta abrasiva, sendo em seguida fixados os eletrodos por meio de pasta eletrolítica, a fim de melhorar a condutividade elétrica, além de esparadrapo do tipo microporoso. Os estímulos acústicos foram apresentados por meio do fone de ouvido supra-aural. O primeiro potencial realizado foi o P300, seguido do PEAML, e, por último, o PEATE. Foi priorizada esta ordem, visto que o P300 e o PEAML sofrem influências do estado de alerta e de atenção ao estímulo acústico para a sua geração, enquanto que o PEATE pode ser gerado, tanto em estado de alerta, como durante o sono. Os valores de impedância dos eletrodos foram verificados, devendo situar-se abaixo de 5 kohms. A avaliação eletrofisiológica foi composta pelos seguintes exames:

III.A - Potencial Cognitivo (P300): para realização deste potencial, foi utilizado o estímulo "tone-burst", apresentado monoauralmente a $75 \mathrm{~dB}$ NA, em uma velocidade de apresentação de 1,1 cliques por segundo, sendo empregado um total de 300 estímulos. Os eletrodos foram posicionados no vértex $(\mathrm{Cz})$ e nas mastóides direita e esquerda (A2 e $A 1)$. O estímulo freqüente foi apresentado a $1000 \mathrm{~Hz}$ e o raro a $1500 \mathrm{~Hz}$. Dos 300 estímulos apresentados, $15 \%$ a $20 \%$ referiam-se ao estímulo raro, e o restante ao estímulo freqüente. Foi gravado apenas um registro para cada lado, não havendo, assim, registro de reprodução destas ondas. Cada indivíduo foi orientado a manter sua atenção no estímulo raro, o qual aparecia, aleatoriamente, dentro de uma série de estímulos freqüentes, e foi solicitado 
a contar, em voz alta, o número de vezes que escutasse o estímulo raro. Foi feita uma prévia demonstração da série de estímulos acústicos para garantir o entendimento da tarefa. Quando o indivíduo não compreendia esta orientação, eram dadas outras sugestões (levantar a mão, repetir oralmente o apito "pi", contar com os dedos, entre outras), a fim de garantir a atenção do indivíduo ao estímulo raro (Durrant e Ferraro, 2001; Musiek e Lee, 2001).

\section{III.B - Potencial Evocado Auditivo de Média Latência (PEAML): o} estímulo utilizado para a realização deste potencial foi o clique, apresentado monoauralmente a 70 dB NA, numa velocidade de apresentação de 9,9 cliques por segundo, sendo apresentado um total de 1000 estímulos. Os eletrodos foram posicionados no vértex $(\mathrm{Cz})$, nas mastóides direita e esquerda (A2 e A1), e nas junções têmporo-parietais direita e esquerda (C4 e C3). Foram gravados dois registros para cada modalidade (ipsi e contralateral - C3/A1, C4/A2, C3/A2, e C4/A1) a fim de se verificar a reprodutibilidade dos traçados, e de se realizar os cálculos necessários. Cada indivíduo foi orientado a permanecer quieto e imóvel, a prestar atenção ao som, a não dormir e nem falar.

\section{III.C - Potencial Evocado Auditivo de Tronco Encefálico} (PEATE): para a realização deste potencial, foi utilizado o estímulo clique com polaridade rarefeita, apresentado monoauralmente a $80 \mathrm{~dB}$ NA, em uma velocidade de apresentação de 19,0 cliques por segundo, com duração de 0,1 milissegundos, sendo empregado um total de 2000 estímulos. Os 
eletrodos foram posicionados no vértex $(\mathrm{Cz})$ e nas mastóides direita e esquerda (A2 e A1). Foram gravados dois registros para cada lado, verificando-se, assim, a reprodução dos traçados, e confirmando-se a existência de respostas. Cada indivíduo foi orientado a permanecer quieto e imóvel.

O tempo médio despendido para a realização da bateria completa de exames, com cada indivíduo do GC, foi de 02 horas, enquanto que, para os indivíduos do GP, foi de 04 a 05 horas. Os indivíduos do GP despendiam maior tempo para a realização dos exames devido às dificuldades que apresentavam para permanecerem quietos durante as avaliações objetivas da audição. Além disso, durante a realização da audiometria tonal, a maioria dos indivíduos respondia ao intervalo de tempo entre um estímulo e outro, e não ao estímulo acústico. Desta forma, a fim de se confirmar os limiares de audibilidade, a pesquisadora utilizou as técnicas ascendente e descendente, e variou bastante o intervalo entre os estímulos acústicos.

Todos os indivíduos do GC e a maioria dos indivíduos do GP realizaram todas as avaliações no mesmo dia. Isto foi possível devido à faixa etária e à boa cooperação destes durante os exames. Executar os procedimentos das avaliações em dias diferentes poderia interferir nos resultados, visto que, neste intervalo, o indivíduo poderia apresentar algumas intercorrências, como acúmulo de cerume, otites, disfunção tubária, 
e perfuração de membrana timpânica, os quais alterariam as características audiológicas medidas previamente.

Para alguns indivíduos do GP, foi necessário agendar outra data para dar continuidade às avaliações, isto porque, estes apresentavam dificuldades em manterem-se quietos, e em realizarem as tarefas solicitadas, necessitando, assim, de mais tempo para concluir a bateria de exames. Além disso, devido à ansiedade e ao comportamento obsessivo de preservar os rituais, foi necessário agendar outra data para que o indivíduo tivesse condições de concentrar-se na atividade proposta. Nestes casos, os primeiros exames realizados no segundo dia de avaliação foram as medidas de imitância acústica, o que permitiu verificar o aparecimento das intercorrências anteriormente citadas, e também, de mudanças nos resultados das medidas de imitância acústica obtidas na primeira avaliação. Como não foram observadas tais modificações, o fato de iniciar os procedimentos em uma data e terminar em outra não provocou eventuais mudanças nos resultados das avaliações.

\section{4 - CRITÉRIOS DE AVALIAÇÃO DOS RESULTADOS}

Os resultados das avaliações eletroacústicas, comportamentais, e eletrofisiológicas da audição, foram classificados como normal e alterado, para cada indivíduo. Posteriormente, foram descritos os tipos de alterações 
encontradas em cada exame.

Foram considerados como normal os resultados que apresentaram:

I - Medidas de Imitância Acústica: curva timpanométrica tipo A (Jerger, 1970), e reflexos acústicos ipsilaterais presentes nas freqüências de 500, 1000, e $2000 \mathrm{~Hz}$, entre 80 e 95 dB NA (Carvallo et al., 2000).

II - Audiometria Tonal: média dos limiares auditivos nas freqüências de 500, 1000, e $2000 \mathrm{~Hz}$, menores ou iguais a 25 dB NA (Lloyd e Kaplan, 1978).

\section{III - Logoaudiometria:}

- para o LRF, respostas iguais ou até $10 \mathrm{~dB}$ acima da média dos limiares auditivos das freqüências de 500,1000, e $2000 \mathrm{~Hz}$ na audiometria tonal (Santos e Russo, 1991).

- para o IRF, porcentagem de acerto entre $88 \%$ e $100 \%$ (Gates e Chakeres, 1988) na intensidade de 30dB NA acima do LRF.

IV - PEATE: Foram analisados os valores de latências absolutas das ondas I, III, e V, e interpicos I-III, III-V, e I-V. Utilizamos, como padrão de normalidade, os valores propostos pelo "Evoked Potential User Manual" do equipamento BIO-LOGIC, para crianças acima de 24 meses, que se encontram no quadro 1. 
Quadro 1: Padrão de normalidade dos valores de latência e interpicos do PEATE, para indivíduos acima de 24 meses, proposto pelo "Evoked Potential User Manual"

\begin{tabular}{|c|c|c|c|c|c|c|}
\hline & Onda I & Onda III & Onda V & $\begin{array}{c}\text { Interpico } \\
\text { I-III }\end{array}$ & $\begin{array}{c}\text { Interpico } \\
\text { III-V }\end{array}$ & $\begin{array}{c}\text { Interpico } \\
\text { I-V }\end{array}$ \\
\hline $\begin{array}{c}\text { Média } \\
\text { (ms) }\end{array}$ & 1,54 & 3,69 & 5,54 & 2,14 & 1,86 & 4,00 \\
\hline $\begin{array}{c}\text { Desvio } \\
\text { Padrão } \\
\text { (ms) }\end{array}$ & 0,11 & 0,10 & 0,19 & 0,23 & 0,14 & 0,20 \\
\hline
\end{tabular}

V - PEAML: Foram analisados os valores da amplitude (Na-Pa) da onda $\mathrm{Pa}$, nas diversas modalidades estudadas. Utilizamos a análise proposta por Musiek e Lee (2001), na qual a diferença menor ou igual a $50 \%$ entre as amplitudes obtidas, na comparação das modalidades ipsilateral e contralateral (C3/A1, $\mathrm{C} 4 / \mathrm{A} 2, \mathrm{C} 3 / \mathrm{A} 2, \mathrm{C} 4 / \mathrm{A} 1)$, duas a duas, indicam normalidade. Os valores das latências das ondas $\mathrm{Na}$ e $\mathrm{Pa}$ não foram considerados na análise dos resultados, devido ao fato da via auditiva, na sua porção subcortical, região geradora deste potencial, encontrar-se ainda em processo de maturação em alguns indivíduos avaliados, não existindo, na literatura, valores de normalidade estabelecidos para a faixa etária de algumas crianças que compuseram a amostra desta pesquisa (abaixo de 10 anos de idade). 
VI - P300: Para a análise deste potencial, foi considerado o valor de latência da onda P300. Utilizamos os valores de normalidade propostos por McPherson (1996), para cada faixa etária, conforme o quadro 2.

Quadro 2: Padrão de normalidade dos valores de latência da onda P300, para cada faixa etária, proposto por McPherson (1996)

\begin{tabular}{|c|c|}
\hline Faixa etária & Latência da onda P300 \\
\hline 5 a 17 anos & 241 a 396 milissegundos \\
\hline 17 a 30 anos & 225 a 365 milissegundos \\
\hline
\end{tabular}

Os resultados que não se enquadraram nos critérios anteriormente descritos foram considerados alterados. O indivíduo foi considerado alterado quando pelo menos uma das orelhas, ou um dos lados, apresentava alteração.

Os tipos de alterações encontradas foram classificados para cada exame:

I - Medidas de Imitância Acústica: curva timpanométrica tipo B, C, As ou $\mathrm{Ad}$, e/ou reflexos acústicos ausentes ou aumentados para uma ou mais freqüências (exceto $4000 \mathrm{~Hz}$ ).

II - Audiometria tonal: média dos limiares auditivos nas freqüências de 500,1000 e $2000 \mathrm{~Hz}$, maiores que 25dB NA. 


\section{III - Logoaudiometria:}

- diferença maior ou igual a $15 \mathrm{~dB}$ NA entre o LRF e a média dos limiares obtidos nas freqüências de 500,1000 , e $2000 \mathrm{~Hz}$ da audiometria tonal;

- para o IRF, porcentagem de acerto inferior a $88 \%$ na intensidade de 30dB NA acima do LRF.

IV - PEATE: Os resultados alterados foram divididos de acordo com a localização da alteração:

- Tronco Encefálico Baixo (TEB): quando os valores de latência das ondas III e V, e conseqüentemente, dos interpicos I-III e I-V encontravam-se aumentados, o resultado foi considerado como sugestivo de alteração na via auditiva em tronco encefálico baixo.

- Tronco Encefálico Alto (TEA): quando os valores da latência da onda $\mathrm{V}$ e dos interpicos I-V e III-V encontravam-se aumentados na presença de latências absolutas normais para as ondas I e III, o resultado foi considerado como sugestivo de alteração na via auditiva em tronco encefálico alto.

- Ambas: quando foram encontradas alterações do tipo TEB e TEA, concomitantemente, para o mesmo indivíduo.

V - PEAML: Utilizamos a análise proposta por Musiek e Lee (2001), na qual a diferença maior que $50 \%$ entre as amplitudes obtidas na comparação das modalidades ipsilateral e contralateral (C3/A1, C4/A2, C3/A2, C4/A1), 
duas a duas, é utilizada para indicar disfunções. As disfunções podem ser observadas por meio do Efeito Eletrodo (EE) e do Efeito Orelha (EO). Desta forma, os resultados considerados alterados foram classificados em:

- Efeito Eletrodo (EE): é a diferença maior que 50\%, quando comparadas as medidas de amplitude da onda $\mathrm{Pa}$ com os eletrodos posicionados sobre cada junção têmporo-parietal (comparação entre C3/A1 e C4/A1; e entre C3/A2 e C4/A2).

- Efeito Orelha (EO): ocorre quando uma orelha, independente do local do eletrodo (comparação entre C3/A1 e C3/A2; e entre C4/A1 e C4/A2), mostra amplitudes da onda Pa reduzidas de forma constante.

- Ambas: quando foram encontradas alterações do tipo EE e EO para o mesmo indivíduo.

VI - P300: Os resultados alterados foram divididos em:

- Atraso: quando a latência da onda P300 encontrava-se aumentada, se comparada aos valores de normalidade.

- Ausente: quando não foi encontrada presença da onda P300.

- Ambas: quando foram encontradas alterações do tipo atraso e ausente para o mesmo indivíduo. 


\section{5 - MÉTODO ESTATÍSTICO}

Para este trabalho, utilizamos a análise qualitativa, a qual foi realizada por meio da comparação dos resultados normais e dos alterados, em cada grupo e entre os grupos, em todas as avaliações da audição. Além disso, foram comparados os tipos de alterações encontrados em cada grupo e entre os grupos, porém, apenas nas avaliações eletrofisiológicas da audição. Para a análise das variáveis qualitativas, utilizamos os seguintes testes:

$\checkmark$ Teste de Igualdade de duas Proporções, que é um teste paramétrico, o qual compara se a proporção de respostas de duas determinadas variáveis, e/ou seus níveis, é estatisticamente significante;

$\checkmark$ intervalo de confiança para PROPOrção, que é uma técnica utilizada quando queremos verificar o quanto a proporção pode variar numa determinada probabilidade de confiança.

Realizamos também, a análise quantitativa por meio da média, mediana, desvio padrão, limite inferior, limite superior, máximo e mínimo dos resultados de cada potencial evocado auditivo, para cada grupo. Além disso, foram comparadas as médias entre os grupos e verificados os níveis de significância para cada comparação. Para a análise das variáveis quantitativas, utilizamos os testes: 
$\checkmark$ ANOVA - “ANALYSIS OF VARIANCE", é um teste paramétrico bastante usual que compara as médias, utilizando a variância;

$\checkmark \quad$ INTERVAlo de CONFIANÇA PARA A MÉdia, que é uma técnica utilizada quando queremos ver o quanto a média pode variar numa determinada probabilidade de confiança.

Os resultados das comparações realizadas possui uma estatística chamada de p-valor. Definimos para este trabalho um nível de significância de $0,05(5 \%)$ para este valor, sendo que os resultados que apresentaram diferença estatisticamente significante foram assinalados com asterisco $\left(^{*}\right)$. Lembramos também, que todos os intervalos de confiança construídos ao longo do trabalho foram construídos com 95\% de confiança estatística. 


\section{Resultados}




\section{5 - RESULTADOS}

Neste capítulo, apresentaremos os resultados obtidos nas avaliações comportamentais, eletroacústicas, e eletrofisiológicas da audição de 41 indivíduos, 16 do Grupo Pesquisa (GP) e 25 do Grupo Controle (GC).

Os resultados das avaliações comportamentais e eletroacústicas foram analisados de forma qualitativa, enquanto que os resultados das avaliações eletrofisiológicas foram analisados de forma qualitativa e quantitativa, para os dois grupos.

Ressaltamos que não foram encontradas alterações nas avaliações comportamentais da audição, para os dois grupos, e que, na avaliação eletroacústica, foi encontrada alteração em apenas um indivíduo do grupo pesquisa. Desta forma, não foi realizado o estudo dos tipos de alterações encontrados nas avaliações comportamentais e eletroacústicas, para os dois grupos.

Para facilitar a visualização dos resultados, este capítulo foi dividido em quatro partes, uma para a caracterização da amostra (quanto à faixa etária e ao gênero), e uma para cada tipo de avaliação da audição (comportamental, eletroacústica, e eletrofisiológica). 
PARTE I - Caracterização da faixa etária e gênero nos grupos controle e pesquisa.

PARTE II - Caracterização dos resultados das avaliações comportamentais nos grupos controle e pesquisa.

PARTE III - Caracterização dos resultados das avaliações eletroacústicas nos grupos controle e pesquisa.

PARTE IV - Caracterização dos resultados das avaliações eletrofisiológicas nos grupos controle e pesquisa.

PARTE I - Caracterização da faixa etária e gênero nos grupos controle e pesquisa.

Nesta primeira parte, analisamos as variáveis gênero e faixa etária dos grupos controle e pesquisa.

Inicialmente, comparamos os gêneros dos grupos controle e pesquisa, bem como entre os grupos. Para tanto, foi realizado o teste de Igualdade de Duas Proporções. 
TABELA 1 - Análise da distribuição dos gêneros nos grupos controle e pesquisa

\begin{tabular}{ccccc}
\hline \multirow{2}{*}{ Gênero } & & Controle & Pesquisa & p-valor \\
\hline \multirow{3}{*}{ Masculino } & Qtde & 9 & 15 & \\
\cline { 2 - 4 } & $\%$ & $36,0 \%$ & $93,8 \%$ & $<0,001^{*}$ \\
\cline { 2 - 4 } & var & $18,8 \%$ & $11,9 \%$ & \\
\cline { 2 - 4 } Feminino & Qtde & 16 & 1 & $<0,001^{*}$ \\
\cline { 2 - 4 } & var & $64,0 \%$ & $6,3 \%$ & \\
\cline { 2 - 4 } & & $18,8 \%$ & $11,9 \%$ & \\
\hline \multirow{2}{*}{ p-valor } & & $0,048 *$ & $<0,001 *$ & \\
\hline
\end{tabular}

* $\mathrm{p}$-valor considerado estatisticamente significante

Qtde = quantidade

Var = índice de variação em relação a média

A tabela 1 mostrou a comparação dos gêneros em cada grupo, e dos gêneros entre os grupos. Verificamos, então, que existiu diferença proporcional considerada estatisticamente significativa entre os gêneros feminino e masculino no grupo controle e no grupo pesquisa, e dos gêneros feminino e masculino entre os grupos.

$\mathrm{Na}$ tabela 2, comparamos os grupos com relação às faixas etárias. Para isto, utilizamos o teste de ANOVA. 
TABELA 2 - Análise da distribuição das faixas etárias nos grupos controle e pesquisa

\begin{tabular}{|c|c|c|}
\hline Idade & Controle & Pesquisa \\
\hline Média & 12,16 & 11,94 \\
\hline Mediana & 10 & 10 \\
\hline Desvio Padrão & 4,50 & 3,51 \\
\hline Mínimo & 8 & 8 \\
\hline Máximo & 20 & 19 \\
\hline Tamanho & 25 & 16 \\
\hline Limite Inferior & 10,40 & 10,22 \\
\hline Limite Superior & 13,92 & 13,66 \\
\hline p-valor & \multicolumn{2}{|c|}{0,868} \\
\hline
\end{tabular}

Verificamos, na tabela 2, que não houve diferença considerada estatisticamente significante para as médias das faixas etárias entre os grupos controle e pesquisa.

PARTE II - Caracterização dos resultados das avaliações comportamentais nos grupos controle e pesquisa.

Nesta segunda parte, serão apresentados os resultados qualitativos das avaliações comportamentais da audição, para os dois grupos. Os resultados foram classificados em normais e alterados, seguindo os critérios de avaliação apresentados no capítulo MÉTODOS. A distribuição da ocorrência de resultados normais e alterados encontra-se descrita nas tabelas 3 e 4. 
TABELA 3 - Distribuição da ocorrência de resultados normais e alterados na audiometria tonal, nos grupos controle e pesquisa

\begin{tabular}{|c|c|c|c|c|c|c|c|}
\hline \multirow{2}{*}{ Tabela 3} & \multicolumn{3}{|c|}{ Grupo Controle } & \multicolumn{3}{|c|}{ Grupo Pesquisa } & \multirow{2}{*}{ p-valor } \\
\hline & Qtde & $\%$ & var & Qtde & $\%$ & var & \\
\hline Normal & 25 & $100,0 \%$ & \multirow{2}{*}{$0,0 \%$} & 16 & $100,0 \%$ & \multirow{2}{*}{$0,0 \%$} & \multirow{2}{*}{--} \\
\hline Alterado & 0 & $0,0 \%$ & & 0 & $0,0 \%$ & & \\
\hline p-valor & & $<0,001 *$ & & & $<0,001 *$ & & \\
\hline
\end{tabular}

* $p$-valor considerado estatisticamente significante

Var = índice de variação em relação à média

$\mathrm{Na}$ tabela 3 , verificamos que existiu diferença proporcionalmente significante entre os resultados normal e alterado, em ambos os grupos. Não foi possível realizar a comparação entre os grupos, pois não houve variabilidade (todos os sujeitos, dos dois grupos, apresentaram resultados normais). 
TABELA 4 - Distribuição da ocorrência de resultados normais e alterados na logoaudiometria, nos grupos controle e pesquisa

\begin{tabular}{|c|c|c|c|c|c|c|c|}
\hline \multirow{2}{*}{ Tabela 4} & \multicolumn{3}{|c|}{ Grupo Controle } & \multicolumn{3}{|c|}{ Grupo Pesquisa } & \multirow{2}{*}{ p-valor } \\
\hline & Qtde & $\%$ & var & Qtde & $\%$ & var & \\
\hline Normal & 25 & $100,0 \%$ & \multirow{2}{*}{$0,0 \%$} & 16 & $100,0 \%$ & \multirow{2}{*}{$0,0 \%$} & \multirow{2}{*}{-} \\
\hline Alterado & 0 & $0,0 \%$ & & 0 & $0,0 \%$ & & \\
\hline $\mathrm{p}$-valor & & $<0,001^{*}$ & & & $<0,001 *$ & & \\
\hline
\end{tabular}

* p-valor considerado estatisticamente significante

Qtde = quantidade

Var = índice de variação em relação a média

$\mathrm{Na}$ tabela 4, encontramos diferença proporcionalmente significante entre os resultados normal e alterado, em ambos os grupos. Não foi possível realizar a comparação entre os grupos, pois não houve variabilidade.

PARTE III - Caracterização dos resultados das avaliações eletroacústicas nos grupos controle e pesquisa.

Nesta terceira parte, serão apresentados os resultados qualitativos das avaliações eletroacústicas, para os dois grupos. Os resultados foram classificados em normais e alterados, seguindo os critérios de avaliação apresentados no capítulo MÉTODOS. A distribuição da ocorrência de resultados normais e alterados encontra-se descrita na tabela 5. 
TABELA 5 - Distribuição da ocorrência de resultados normais e alterados na imitanciometria, nos grupos controle e pesquisa

\begin{tabular}{|c|c|c|c|c|c|c|c|}
\hline \multirow{2}{*}{ Tabela 5} & \multicolumn{3}{|c|}{ Grupo Controle } & \multicolumn{3}{|c|}{ Grupo Pesquisa } & \multirow{2}{*}{ p-valor } \\
\hline & Qtde & $\%$ & var & Qtde & $\%$ & var & \\
\hline Normal & 25 & $100,0 \%$ & \multirow{2}{*}{$0,0 \%$} & 15 & $93,8 \%$ & \multirow{2}{*}{$11,9 \%$} & \multirow{2}{*}{0,206} \\
\hline Alterado & 0 & $0,0 \%$ & & 1 & $6,3 \%$ & & \\
\hline p-valor & & $<0,001 *$ & & & $<0,001$ * & & \\
\hline
\end{tabular}

* $\mathrm{p}$-valor considerado estatisticamente significante

Qtde = quantidade

Var = índice de variação em relação à média

Verificamos, na tabela 5, que existiu diferença proporcionalmente significante entre os resultados normal e alterado, em ambos os grupos. Porém, não houve diferença estatisticamente significante quando comparados os resultados entre os grupos.

O grupo pesquisa apresentou apenas um sujeito com resultado alterado (ausência de reflexo acústico ipsilateral na orelha direita, em 2000 $\mathrm{Hz}$ ), enquanto que o grupo controle não apresentou alteração. Desta forma, não foi realizado o estudo dos tipos de alterações encontrados para ambos os grupos.

PARTE IV - Caracterização dos resultados das avaliações eletrofisiológicas nos grupos controle e pesquisa. 
Nesta quarta parte, serão apresentadas as análises qualitativas e quantitativas dos resultados obtidos nas avaliações eletrofisiológicas da audição, para os dois grupos. $\mathrm{Na}$ análise qualitativa, os resultados foram classificados em normais e alterados, e em tipos de alterações, seguindo os critérios de avaliação apresentados no capítulo MÉTODOS. Para a análise quantitativa, foram estabelecidos os valores de média, mediana, desvio padrão, limite inferior, limite superior, máximo e mínimo dos resultados de cada potencial evocado auditivo, para cada grupo. Além disso, foram comparados os valores de média obtidos entre os grupos e verificados os níveis de significância, para cada comparação.

Para melhor visualização dos resultados, esta parte foi subdividida em três, uma para cada potencial evocado auditivo realizado (PEATE, PEAML, e P300).

Parte IV.A - Caracterização dos resultados do Potencial Evocado Auditivo de Tronco Encefálico nos grupos controle e pesquisa.

Parte IV.B - Caracterização dos resultados do Potencial Evocado Auditivo de Média Latência nos grupos controle e pesquisa.

Parte IV.C - Caracterização dos resultados do Potencial Cognitivo nos grupos controle e pesquisa.

Parte IV.A - Caracterização dos resultados do Potencial Evocado Auditivo de Tronco Encefálico nos grupos controle e pesquisa. 
A primeira comparação realizada foi entre as orelhas direita e esquerda, para o PEATE, em cada grupo. Foram comparados os valores de latências absolutas das ondas I, III, e V e dos interpicos I-III, III-V, e I-V, entre as orelhas no mesmo grupo, lembrando que utilizamos o teste de ANOVA para esta comparação quantitativa.

TABELA 6 - Comparação das latências das ondas I, III, e V e dos interpicos I-III, III-V, e I-V entre as orelhas direita e esquerda no PEATE, para o grupo controle

\begin{tabular}{|c|c|c|c|c|c|c|c|c|c|c|}
\hline \multicolumn{2}{|c|}{$\begin{array}{c}\text { PEATE } \\
\text { (Controle) }\end{array}$} & Média & Médiana & $\begin{array}{l}\text { Desvio } \\
\text { Padrão }\end{array}$ & Mínimo & Máximo & Tamanho & $\begin{array}{c}\text { Limite } \\
\text { Inferior }\end{array}$ & $\begin{array}{c}\text { Limite } \\
\text { Superior }\end{array}$ & $\begin{array}{c}\mathrm{p}- \\
\text { valor }\end{array}$ \\
\hline \multirow{2}{*}{ Onda I } & OD & 1,52 & 1,52 & 0,08 & 1,36 & 1,68 & 25 & 1,48 & 1,57 & \multirow{2}{*}{0,669} \\
\hline & $\mathrm{OE}$ & 1,51 & 1,52 & 0,10 & 1,40 & 1,84 & 25 & 1,46 & 1,57 & \\
\hline \multirow{2}{*}{ Onda III } & OD & 3,60 & 3,60 & 0,10 & 3,44 & 3,80 & 25 & 3,55 & 3,66 & \multirow{2}{*}{0,454} \\
\hline & $\mathrm{OE}$ & 3,63 & 3,60 & 0,11 & 3,44 & 3,80 & 25 & 3,56 & 3,69 & \\
\hline \multirow{2}{*}{ Onda V } & OD & 5,59 & 5,60 & 0,11 & 5,40 & 5,80 & 25 & 5,53 & 5,66 & \multirow{2}{*}{0,833} \\
\hline & $\mathrm{OE}$ & 5,59 & 5,60 & 0,10 & 5,40 & 5,72 & 25 & 5,53 & 5,64 & \\
\hline \multirow{2}{*}{$\begin{array}{l}\text { Interpico } \\
\text { I - III }\end{array}$} & OD & 2,08 & 2,12 & 0,09 & 1,84 & 2,24 & 25 & 2,03 & 2,13 & \multirow{2}{*}{0,289} \\
\hline & $\mathrm{OE}$ & 2,11 & 2,08 & 0,12 & 1,92 & 2,28 & 25 & 2,05 & 2,17 & \\
\hline \multirow{2}{*}{$\begin{array}{l}\text { Interpico } \\
\text { III - V }\end{array}$} & OD & 1,99 & 2,00 & 0,08 & 1,88 & 2,16 & 25 & 1,95 & 2,03 & \multirow{2}{*}{0,119} \\
\hline & $\mathrm{OE}$ & 1,96 & 1,96 & 0,05 & 1,88 & 2,08 & 25 & 1,93 & 1,99 & \\
\hline \multirow{2}{*}{$\begin{array}{l}\text { Interpico } \\
\mathrm{I}-\mathrm{V}\end{array}$} & OD & 4,07 & 4,08 & 0,10 & 3,84 & 4,24 & 25 & 4,01 & 4,13 & \multirow{2}{*}{0,914} \\
\hline & $\mathrm{OE}$ & 4,07 & 4,08 & 0,10 & 3,88 & 4,20 & 25 & 4,01 & 4,13 & \\
\hline
\end{tabular}

OD = Orelha Direita.

$\mathrm{OE}=$ Orelha Esquerda

PEATE = Potencial Evocado Auditivo de Tronco Encefálico

Na tabela 6 verificamos que, para nenhum dos valores de latência absoluta das ondas I, III, e V, e interpicos I-III, III-V, e I-V, existiu diferença média que possa ser considerada estatisticamente significante entre as orelhas. 
TABELA 7 - Comparação das latências das ondas I, III, e V e dos interpicos I-III, III-V, e I-V entre as orelhas direita e esquerda no PEATE, para o grupo pesquisa

\begin{tabular}{|c|c|c|c|c|c|c|c|c|c|c|}
\hline \multicolumn{2}{|c|}{$\begin{array}{c}\text { PEATE } \\
\text { (Pesquisa) }\end{array}$} & Média & Médiana & $\begin{array}{l}\text { Desvio } \\
\text { Padrão }\end{array}$ & Mínimo & Máximo & Tamanho & $\begin{array}{l}\text { Limite } \\
\text { Inferior }\end{array}$ & $\begin{array}{l}\text { Limite } \\
\text { Superior }\end{array}$ & p-valor \\
\hline \multirow{2}{*}{ Onda I } & OD & 1,55 & 1,56 & 0,07 & 1,40 & 1,64 & 16 & 1,50 & 1,60 & \multirow{2}{*}{0,923} \\
\hline & $\mathrm{OE}$ & 1,55 & 1,54 & 0,07 & 1,40 & 1,68 & 16 & 1,50 & 1,60 & \\
\hline \multirow{2}{*}{ Onda III } & OD & 3,73 & 3,76 & 0,11 & 3,56 & 3,88 & 16 & 3,66 & 3,81 & \multirow{2}{*}{0,924} \\
\hline & $\mathrm{OE}$ & 3,74 & 3,72 & 0,11 & 3,60 & 3,92 & 16 & 3,66 & 3,81 & \\
\hline \multirow{2}{*}{ Onda V } & OD & 5,70 & 5,71 & 0,12 & 5,44 & 5,92 & 16 & 5,62 & 5,79 & \multirow{2}{*}{0,581} \\
\hline & $\mathrm{OE}$ & 5,68 & 5,68 & 0,12 & 5,48 & 5,88 & 16 & 5,59 & 5,76 & \\
\hline \multirow{2}{*}{$\begin{array}{l}\text { Interpico } \\
\text { I - III }\end{array}$} & OD & 2,18 & 2,17 & 0,10 & 2,00 & 2,36 & 16 & 2,11 & 2,25 & \multirow{2}{*}{0,883} \\
\hline & $\mathrm{OE}$ & 2,19 & 2,16 & 0,14 & 2,00 & 2,48 & 16 & 2,09 & 2,28 & \\
\hline \multirow{2}{*}{$\begin{array}{c}\text { Interpico } \\
\text { III - V }\end{array}$} & OD & 1,97 & 1,97 & 0,07 & 1,84 & 2,12 & 16 & 1,92 & 2,02 & \multirow{2}{*}{0,312} \\
\hline & $\mathrm{OE}$ & 1,94 & 1,95 & 0,08 & 1,80 & 2,08 & 16 & 1,89 & 2,00 & \\
\hline \multirow{2}{*}{$\begin{array}{c}\text { Interpico } \\
\mathrm{I}-\mathrm{V}\end{array}$} & OD & 4,15 & 4,13 & 0,12 & 4,00 & 4,40 & 16 & 4,07 & 4,23 & \multirow{2}{*}{0,637} \\
\hline & $\mathrm{OE}$ & 4,13 & 4,06 & 0,14 & 4,00 & 4,48 & 16 & 4,04 & 4,23 & \\
\hline
\end{tabular}

Encontramos, na tabela 7, que em qualquer valor de latência absoluta das ondas I, III, e V, e interpicos I-III, III-V, e I-V, as orelhas direita e esquerda se comportam estatisticamente iguais, ou seja, não há diferença estatisticamente significativa entre as orelhas no grupo pesquisa.

Visto que não foram encontradas diferenças médias estatisticamente significantes entre as orelhas, consideramos, para as próximas análises, os valores de latências e interpicos de ambas as orelhas, dobrando o número da amostra e aumentando, assim, a fidedignidade dos resultados. 
Para a análise quantitativa que se segue, foram comparados os valores de latências absolutas das ondas I, III, e V, e dos interpicos I-III, III-V, e I-V entre os grupos controle e pesquisa.

TABELA 8 - Comparação das latências das ondas I, III, e V e dos interpicos I-III, III-V, e I-V do PEATE, entre os grupos controle e pesquisa

\begin{tabular}{|c|c|c|c|c|c|c|c|c|c|c|}
\hline \multicolumn{2}{|c|}{ PEATE } & \multirow{2}{*}{$\begin{array}{c}\text { Média } \\
1,52\end{array}$} & \multirow{2}{*}{$\begin{array}{c}\text { Mediana } \\
1,52\end{array}$} & \multirow{2}{*}{$\begin{array}{c}\begin{array}{c}\text { Desvio } \\
\text { Padrão }\end{array} \\
0,09\end{array}$} & \multirow{2}{*}{$\begin{array}{c}\text { Mínimo } \\
1,36\end{array}$} & \multirow{2}{*}{$\begin{array}{c}\text { Máximo } \\
1,84\end{array}$} & \multirow{2}{*}{$\begin{array}{c}\text { Tamanho } \\
50\end{array}$} & \multirow{2}{*}{$\begin{array}{c}\begin{array}{c}\text { Limite } \\
\text { Inferior }\end{array} \\
1,49\end{array}$} & \multirow{2}{*}{$\begin{array}{c}\begin{array}{c}\text { Limite } \\
\text { Superior }\end{array} \\
1,54\end{array}$} & \multirow{3}{*}{$\begin{array}{c}\begin{array}{c}\mathrm{p}- \\
\text { valor }\end{array} \\
0,124\end{array}$} \\
\hline & Controle & & & & & & & & & \\
\hline & Pesquisa & 1,55 & 1,56 & 0,07 & 1,40 & 1,68 & 32 & 1,52 & 1,57 & \\
\hline \multirow{2}{*}{ Onda III } & Controle & 3,61 & 3,60 & 0,10 & 3,44 & 3,80 & 50 & 3,59 & 3,64 & \multirow{2}{*}{$<0,001^{*}$} \\
\hline & Pesquisa & 3,73 & 3,74 & 0,11 & 3,56 & 3,92 & 32 & 3,70 & 3,77 & \\
\hline \multirow{2}{*}{ Onda V } & Controle & 5,59 & 5,60 & 0,11 & 5,40 & 5,80 & 50 & 5,56 & 5,62 & \multirow{2}{*}{$<0,001 *$} \\
\hline & Pesquisa & 5,69 & 5,68 & 0,12 & 5,44 & 5,92 & 32 & 5,65 & 5,73 & \\
\hline \multirow{2}{*}{$\begin{array}{c}\text { Interpico } \\
\text { I - III }\end{array}$} & Controle & 2,09 & 2,10 & 0,11 & 1,84 & 2,28 & 50 & 2,07 & 2,12 & \multirow{2}{*}{$0,001 *$} \\
\hline & Pesquisa & 2,18 & 2,16 & 0,12 & 2,00 & 2,48 & 32 & 2,14 & 2,23 & \\
\hline \multirow{2}{*}{$\begin{array}{l}\text { Interpico } \\
\text { III - V }\end{array}$} & Controle & 1,98 & 1,96 & 0,07 & 1,88 & 2,16 & 50 & 1,96 & 1,99 & \multirow{2}{*}{0,227} \\
\hline & Pesquisa & 1,96 & 1,96 & 0,08 & 1,80 & 2,12 & 32 & 1,93 & 1,98 & \\
\hline \multirow{2}{*}{$\begin{array}{l}\text { Interpico } \\
\text { I - V }\end{array}$} & Controle & 4,07 & 4,08 & 0,10 & 3,84 & 4,24 & 50 & 4,04 & 4,10 & \multirow{2}{*}{$0,006^{*}$} \\
\hline & Pesquisa & 4,14 & 4,12 & 0,12 & 4,00 & 4,48 & 32 & 4,10 & 4,18 & \\
\hline
\end{tabular}

* $p$-valor considerado estatisticamente significante

$\mathrm{OD}=$ Orelha Direita

$\mathrm{OE}=$ Orelha Esquerda

PEATE $=$ Potencial Evocado Auditivo de Tronco Encefálico

$\mathrm{Na}$ tabela 8 , observamos diferenças médias, entre os grupos controle e pesquisa, consideradas estatisticamente significantes para as ondas III e V, e para os interpicos I-III e I-V. 
Para a análise qualitativa, foram comparados os resultados normais e alterados obtidos no PEATE, para cada grupo avaliado e entre os grupos (tabela 9).

TABELA 9 - Distribuição da ocorrência de resultados normais e alterados no PEATE, nos grupos controle e pesquisa

\begin{tabular}{|c|c|c|c|c|c|c|c|}
\hline \multirow{2}{*}{ Tabela 7} & \multicolumn{3}{|c|}{ Grupo Controle } & \multicolumn{3}{|c|}{ Grupo Pesquisa } & \multirow{2}{*}{ p-valor } \\
\hline & Qtde & $\%$ & var & Qtde & $\%$ & var & \\
\hline Normal & 25 & $100,0 \%$ & \multirow{2}{*}{$0,0 \%$} & 10 & $62,5 \%$ & \multirow{2}{*}{$23,7 \%$} & \multirow{2}{*}{$<0,001^{*}$} \\
\hline Alterado & 0 & $0,0 \%$ & & 6 & $37,5 \%$ & & \\
\hline $\mathrm{p}$-valor & & $<0,001^{*}$ & & & 0,157 & & \\
\hline
\end{tabular}

* p-valor considerado estatisticamente significante perante o nível de significância adotado. Qtde = quantidade

Var = índice de variação em relação à média

Averiguamos, na tabela 9, que entre os resultados normal e alterado, existiu diferença proporcionalmente significante somente para o grupo controle. Ao compararmos os grupos, verificamos que existiu diferença estatisticamente significante entre os resultados.

Na tabela 10, foram comparados os tipos de alterações encontrados no PEATE entre os grupos e no mesmo grupo. 
TABELA 10 - Distribuição dos tipos de alterações encontrados no PEATE, nos grupos controle e pesquisa

\begin{tabular}{ccccc}
\hline \multicolumn{2}{c}{ Tipos de alterações } & Controle & Pesquisa & p-valor \\
\hline \multirow{2}{*}{$\begin{array}{c}\text { Tronco encefálico } \\
\text { baixo }\end{array}$} & Qtde & 0 & 5 & \\
\cline { 2 - 4 } & $\%$ & $0,0 \%$ & $83,3 \%$ & - - \\
\hline \multirow{2}{*}{ Tronco encefálico alto } & Qtde & 0 & 0 & \multirow{2}{*}{ - - } \\
\cline { 2 - 4 } & $\%$ & $0,0 \%$ & $0,0 \%$ & \\
\hline \multirow{2}{*}{ Ambas } & Qtde & 0 & 1 & - \\
\cline { 2 - 4 } & $\%$ & $0,0 \%$ & $16,7 \%$ & \\
\hline
\end{tabular}

\begin{tabular}{cccc}
\hline \multirow{2}{*}{ Tipos de alterações } & $\begin{array}{c}\text { Tronco encefálico } \\
\text { baixo }\end{array}$ & $\begin{array}{c}\text { Tronco encefálico } \\
\text { alto }\end{array}$ \\
\hline \multirow{2}{*}{ Controle } & $\begin{array}{c}\text { Tronco encefálico } \\
\text { alto }\end{array}$ & -- & \\
\cline { 2 - 4 } & Ambas & -- & - - \\
\hline \multirow{2}{*}{ Pesquisa } & $\begin{array}{c}\text { Tronco encefálico } \\
\text { alto }\end{array}$ & $0,003 *$ & \\
\cline { 2 - 4 } & Ambas & $0,021 *$ & 0,296 \\
\hline
\end{tabular}

${ }^{*} \mathrm{p}$-valor considerado estatisticamente significante p-valores

Qtde = quantidade

Var = índice de variação em relação a média

É importante ressaltar que não foi possível realizar a comparação dos tipos de alterações entre os grupos, uma vez que o grupo controle não apresentou resultados alterados. Da mesma forma, não foi possível comparar os tipos de alterações para o grupo controle. Na análise realizada, verificou-se que, no grupo pesquisa, a alteração mais freqüente foi do tipo Tronco Encefálico Baixo (83,3\%), e que foi considerada, segundo o quadro de p-valores, estatisticamente significante em relação aos demais tipos de alterações (tronco encefálico alto, e ambas). 


\section{Parte IV.B - Caracterização dos resultados do Potencial Evocado} Auditivo de Média Latência nos grupos controle e pesquisa.

Inicialmente, comparamos as orelhas direita e esquerda para o PEAML, em cada grupo. Foram comparados os valores de amplitude $\mathrm{Na}-\mathrm{Pa}$, entre as modalidades $\mathrm{C} 3 / \mathrm{A} 1$ e $\mathrm{C} 3 / \mathrm{A} 2$, e as modalidades $\mathrm{C} 4 / \mathrm{A} 1$ e $\mathrm{C} 4 / \mathrm{A} 2$, em cada grupo. O teste utilizado foi a ANOVA para esta comparação quantitativa.

TABELA 11 - Comparação das amplitudes $\mathrm{Na}-\mathrm{Pa}$ entre as modalidades C3/A1 e C3/A2, e entre C4/A1 e C4/A2 do PEAML, para o grupo controle

\begin{tabular}{lcccc}
\hline \multirow{2}{*}{ PEAML (Controle) } & \multicolumn{2}{c}{ C3 } & \multicolumn{3}{c}{ C4 } \\
\cline { 2 - 5 } & $\mathbf{A 1}$ & $\mathbf{A 2}$ & $\mathbf{A 1}$ & $\mathbf{A 2}$ \\
\hline Média & 2,57 & 4,23 & 3,43 & 2,00 \\
\hline Mediana & 1,61 & 1,48 & 1,76 & 1,63 \\
\hline Desvio Padrão & 3,76 & 10,95 & 7,69 & 1,92 \\
\hline Mínimo & 0,25 & 0,53 & 0,64 & 0,34 \\
\hline Máximo & 19,93 & 55,95 & 39,91 & 10,20 \\
\hline Tamanho & 25 & 25 & 25 & 25 \\
\hline Limite Inferior & 1,09 & $-0,07$ & 0,42 & 1,24 \\
\hline Limite Superior & 4,05 & 8,52 & 6,45 & 2,75 \\
\hline p-valor & \multicolumn{3}{c}{0,478} & \multicolumn{2}{c}{0,369} \\
\hline
\end{tabular}

C3 = junção têmporo-parietal esquerda

C4 = junção têmporo-parietal direita

A1 = mastóide esquerda

A2 = mastóide direita

PEAML = Potencial Evocado Auditivo de Média Latência

A tabela 11 permite-nos averiguar que não existiu diferença estatisticamente significante nas amplitudes $\mathrm{Na}-\mathrm{Pa}$ entre as modalidades C3/A1 e C3/A2, e entre C4/A1 e C4/A2, no grupo controle. 
TABELA 12 - Comparação das amplitudes $\mathrm{Na}-\mathrm{Pa}$ entre as modalidades C3/A1 e C3/A2, e entre C4/A1 e C4/A2 do PEAML, para o grupo pesquisa

\begin{tabular}{lcccc}
\hline \multirow{2}{*}{ PEAML (Pesquisa) } & \multicolumn{2}{c}{ C3 } & \multicolumn{3}{c}{ C4 } \\
\cline { 2 - 6 } & $\mathbf{A 1}$ & $\mathbf{A 2}$ & $\mathbf{A 1}$ & $\mathbf{A 2}$ \\
\hline Média & 1,99 & 3,33 & 1,96 & 1,51 \\
\hline Mediana & 1,45 & 1,62 & 1,84 & 1,45 \\
\hline Desvio Padrão & 1,48 & 4,61 & 0,87 & 0,63 \\
\hline Mínimo & 0,64 & 0,43 & 0,70 & 0,56 \\
\hline Máximo & 5,72 & 15,66 & 3,71 & 2,39 \\
\hline Tamanho & 16 & 16 & 16 & 16 \\
\hline Limite Inferior & 1,27 & 1,07 & 1,53 & 1,19 \\
\hline Limite Superior & 2,71 & 5,59 & 2,38 & 1,82 \\
\hline p-valor & \multicolumn{3}{c}{0,277} & \multicolumn{3}{c}{0,105} \\
\hline
\end{tabular}

C3 = junção têmporo-parietal esquerda

C4 = junção têmporo-parietal direita

A1 = mastóide esquerda

A2 = mastóide direita

$\mathrm{PEAML}=$ Potencial Evocado Auditivo de Média Latência

Pudemos verificar, na tabela 12 , que não existiu diferença estatisticamente significante nas amplitudes $\mathrm{Na}-\mathrm{Pa}$ entre as modalidades C3/A1 e C3/A2 e entre C4/A1 e C4/A2, no grupo pesquisa.

A seguir, realizamos a comparação das amplitudes $\mathrm{Na}-\mathrm{Pa}$ entre as modalidades $\mathrm{C} 3 / \mathrm{A} 1$ e $\mathrm{C} 4 / \mathrm{A} 1$, e entre $\mathrm{C} 3 / \mathrm{A} 2$ e C4/A2, para cada grupo. 
TABELA 13 - Comparação das amplitudes $\mathrm{Na}-\mathrm{Pa}$ entre as modalidades C3/A1 e C4/A1, e entre C3/A2 e C4/A2 do PEAML, para o grupo controle

\begin{tabular}{lcccc}
\hline \multirow{2}{*}{ PEAML (Controle) } & \multicolumn{2}{c}{ A1 } & \multicolumn{2}{c}{ A2 } \\
\cline { 2 - 5 } & $\mathbf{C 3}$ & $\mathbf{C 4}$ & $\mathbf{C 3}$ & $\mathbf{C 4}$ \\
\hline Média & 2,57 & 3,43 & 4,23 & 2,00 \\
\hline Mediana & 1,61 & 1,76 & 1,48 & 1,63 \\
\hline Desvio Padrão & 3,76 & 7,69 & 10,95 & 1,92 \\
\hline Mínimo & 0,25 & 0,64 & 0,53 & 0,34 \\
\hline Máximo & 19,93 & 39,91 & 55,95 & 10,20 \\
\hline Tamanho & 25 & 25 & 25 & 25 \\
\hline Limite Inferior & 1,09 & 0,42 & $-0,07$ & 1,24 \\
\hline Limite Superior & 4,05 & 6,45 & 8,52 & 2,75 \\
\hline p-valor & \multicolumn{3}{c}{0,617} & \\
\hline
\end{tabular}

C3 = junção têmporo-parietal esquerda

$\mathrm{C} 4$ = junção têmporo-parietal direita

$\mathrm{A} 1=$ mastóide esquerda

A2 = mastóide direita

PEAML = Potencial Evocado Auditivo de Média Latência

$\mathrm{Na}$ tabela 13, pudemos verificar que não existiu diferença estatisticamente significante nas amplitudes $\mathrm{Na}-\mathrm{Pa}$ entre as modalidades C3/A1 e C4/A1, e entre C3/A2 e C4/A2, no grupo controle. 
TABELA 14 - Comparação das amplitudes $\mathrm{Na}-\mathrm{Pa}$ entre as modalidades C3/A1 e C4/A1, e entre C3/A2 e C4/A2 do PEAML, para o grupo pesquisa

\begin{tabular}{lcccc}
\hline \multirow{2}{*}{ PEAML (Pesquisa) } & \multicolumn{2}{c}{ A1 } & \multicolumn{3}{c}{ A2 } \\
\cline { 2 - 6 } & $\mathbf{C 3}$ & $\mathbf{C 4}$ & $\mathbf{C 3}$ & $\mathbf{C 4}$ \\
\hline Média & 1,99 & 1,96 & 3,33 & 1,51 \\
\hline Mediana & 1,45 & 1,84 & 1,62 & 1,45 \\
\hline Desvio Padrão & 1,48 & 0,87 & 4,61 & 0,63 \\
\hline Mínimo & 0,64 & 0,70 & 0,43 & 0,56 \\
\hline Máximo & 5,72 & 3,71 & 15,66 & 2,39 \\
\hline Tamanho & 16 & 16 & 16 & 16 \\
\hline Limite Inferior & 1,27 & 1,53 & 1,07 & 1,19 \\
\hline Limite Superior & 2,71 & 2,38 & 5,59 & 1,82 \\
\hline p-valor & \multicolumn{3}{c}{0,938} \\
\hline C3-jo
\end{tabular}

C3 = junção têmporo-parietal esquerda

$\mathrm{C} 4$ = junção têmporo-parietal direita

A1 = mastóide esquerda

A2 = mastóide direita

$\mathrm{Na}$ tabela 14, pudemos verificar que não existiu diferença estatisticamente significante nas amplitudes $\mathrm{Na}-\mathrm{Pa}$ entre as modalidades C3/A1 e C4/A1, e entre C3/A2 e C4/A2, no grupo pesquisa.

Lembramos que, somente para o PEAML, não unimos as orelhas e nem os hemisférios, uma vez que o objetivo foi comparar a amplitude $\mathrm{Na}-\mathrm{Pa}$ obtida em cada modalidade ( $\mathrm{C} 3 / \mathrm{A} 1, \mathrm{C} 3 / \mathrm{A} 2, \mathrm{C} 4 / \mathrm{A} 1$, e $\mathrm{C} 4 / \mathrm{A} 2)$ entre os grupos.

Comparamos, a seguir, os valores de amplitude $\mathrm{Na}-\mathrm{Pa}$, para cada modalidade (C3/A1, C3/A2, C4/A1, C4/A2), entre os grupos controle e pesquisa. 
TABELA 15 - Comparação das amplitudes Na-Pa nas modalidades C3/A1, C3/A2, C4/A1, C4/A2 do PEAML, entre os grupos controle e pesquisa

\begin{tabular}{|c|c|c|c|c|c|c|c|c|}
\hline \multirow{2}{*}{ PEAML } & \multicolumn{2}{|c|}{ C3/A1 } & \multicolumn{2}{|c|}{$\mathrm{C} 3 / \mathrm{A} 2$} & \multicolumn{2}{|c|}{ C4/A1 } & \multicolumn{2}{|c|}{$\mathrm{C} 4 / \mathrm{A} 2$} \\
\hline & Controle & Pesquisa & Controle & Pesquisa & Controle & Pesquisa & Controle & Pesquisa \\
\hline Média & 2,57 & 1,99 & 4,23 & 3,33 & 3,43 & 1,96 & 2,00 & 1,51 \\
\hline Mediana & 1,61 & 1,45 & 1,48 & 1,62 & 1,76 & 1,84 & 1,63 & 1,45 \\
\hline $\begin{array}{l}\text { Desvio } \\
\text { Padrão }\end{array}$ & 3,76 & 1,48 & 10,95 & 4,61 & 7,69 & 0,87 & 1,92 & 0,63 \\
\hline Mínimo & 0,25 & 0,64 & 0,53 & 0,43 & 0,64 & 0,70 & 0,34 & 0,56 \\
\hline Máximo & 19,93 & 5,72 & 55,95 & 15,66 & 39,91 & 3,71 & 10,20 & 2,39 \\
\hline Tamanho & 25 & 16 & 25 & 16 & 25 & 16 & 25 & 16 \\
\hline $\begin{array}{l}\text { Limite } \\
\text { Inferior }\end{array}$ & 1,09 & 1,27 & $-0,07$ & 1,07 & 0,42 & 1,53 & 1,24 & 1,19 \\
\hline $\begin{array}{l}\text { Limite } \\
\text { Superior }\end{array}$ & 4,05 & 2,71 & 8,52 & 5,59 & 6,45 & 2,38 & 2,75 & 1,82 \\
\hline p-valor & \multicolumn{2}{|c|}{0,561} & \multicolumn{2}{|c|}{0,759} & \multicolumn{2}{|c|}{0,451} & \multicolumn{2}{|c|}{0,331} \\
\hline
\end{tabular}

C3 = junção têmporo-parietal esquerda

$\mathrm{C} 4$ = junção têmporo-parietal direita

$\mathrm{A} 1$ = mastóide esquerda

A2 = mastóide direita

PEAML = Potencial Evocado Auditivo de Média Latência

Averiguamos, na tabela 15, que, embora tenha havido diferença média entre os grupos, em cada uma das modalidades, estas não foram consideradas estatisticamente significantes. Desta forma, os grupos são iguais em média com relação à amplitude $\mathrm{Na}-\mathrm{Pa}$ nas diversas modalidades estudadas.

A seguir, foram comparados os resultados qualitativos do PEAML, para os grupos controle e pesquisa. 
TABELA 16 - Distribuição da ocorrência de resultados normais e alterados no PEAML, nos grupos controle e pesquisa

\begin{tabular}{|c|c|c|c|c|c|c|c|}
\hline \multirow{2}{*}{ Tabela 16} & \multicolumn{3}{|c|}{ Grupo Controle } & \multicolumn{3}{|c|}{ Grupo Pesquisa } & \multirow{2}{*}{ p-valor } \\
\hline & Qtde & $\%$ & var & Qtde & $\%$ & var & \\
\hline Normal & 9 & $36,0 \%$ & \multirow{2}{*}{$18,8 \%$} & 11 & $68,8 \%$ & \multirow{2}{*}{$22,7 \%$} & \multirow{2}{*}{$0,041 *$} \\
\hline Alterado & 16 & $64,0 \%$ & & 5 & $31,3 \%$ & & \\
\hline p-valor & & $0,048 *$ & & & $0,034^{*}$ & & \\
\hline
\end{tabular}

* $\mathrm{p}$-valor considerado estatisticamente significante

Qtde = quantidade

Var = índice de variação em relação à média

$\mathrm{Na}$ tabela 16, observamos que existiu diferença proporcionalmente significante entre os resultados normal e alterado, em ambos os grupos. Quando comparamos os grupos controle e pesquisa, verificamos que a diferença existente entre eles também foi estatisticamente significante.

$\mathrm{Na}$ tabela 17, foram comparados os tipos de alterações encontrados no PEAML, entre os grupos controle e pesquisa, e no mesmo grupo. 
TABELA 17 - Distribuição dos tipos de alterações encontrados no PEAML, nos grupos controle e pesquisa

\begin{tabular}{ccccc}
\hline \multicolumn{2}{c}{ Tipos de alterações } & Controle & Pesquisa & p-valor \\
\hline \multirow{2}{*}{ Efeito orelha } & Qtde & 1 & 2 & \multirow{2}{*}{0,600} \\
\cline { 2 - 4 } & $\%$ & $6,3 \%$ & $40,0 \%$ & \\
\cline { 1 - 4 } Efeito eletrodo & Qtde & 3 & 0 & \multirow{2}{*}{0,296} \\
\cline { 2 - 4 } & $\%$ & $18,8 \%$ & $0,0 \%$ & 0,517 \\
\hline \multirow{2}{*}{ Ambas } & Qtde & 12 & 3 & \multirow{2}{*}{$\%$} \\
\cline { 2 - 4 } & $\%$ & $75,0 \%$ & $60,0 \%$ & \\
\hline
\end{tabular}

\begin{tabular}{cccc}
\hline \multirow{2}{*}{ Tipos de alterações } & Efeito orelha & Efeito eletrodo \\
\hline \multirow{2}{*}{ Controle } & Efeito eletrodo & 0,285 & \\
\cline { 2 - 4 } & Ambas & $<0,001^{*}$ & $0,001^{*}$ \\
\hline \multirow{2}{*}{ Pesquisa } & Efeito eletrodo & 0,114 & \\
\cline { 2 - 4 } & Ambas & 0,527 & $0,038^{*}$ \\
\hline
\end{tabular}

* p-valor considerado estatisticamente significante p-valores

Qtde = quantidade

Var = índice de variação em relação à média

Verificamos, na tabela 17, que não houve diferença proporcional entre os grupos, a qual pudesse ser considerada estatisticamente significante, em quaisquer dos tipos de alterações. No grupo controle, encontramos que a alteração mais freqüente foi do tipo Ambas (75,0\%), sendo considerada, segundo o quadro de p-valores, estatisticamente significante em relação aos demais tipos (efeito orelha e efeito eletrodo). Para o grupo pesquisa, embora o tipo Ambas $(60,0 \%)$ também tenha apresentado a maior ocorrência, esta 
foi estatisticamente diferente apenas em relação ao Efeito Eletrodo, não sendo estatisticamente diferente, do Efeito Orelha (40,0\%).

Parte IV.C - Caracterização dos resultados do Potencial Cognitivo nos grupos controle e pesquisa.

Primeiramente, comparamos os valores de latência da onda P300 entre as orelhas direita e esquerda, em cada grupo. Utilizamos o teste de ANOVA para esta comparação quantitativa.

TABELA 18 - Comparação das latências do P300 entre as orelhas direita e esquerda, para o grupo controle

\begin{tabular}{lcc}
\hline \multicolumn{1}{c}{ P300 (Controle) } & OD & OE \\
\hline Média & 318,64 & 328,96 \\
\hline Mediana & 316,00 & 326,00 \\
\hline Desvio Padrão & 27,78 & 28,82 \\
\hline Mínimo & 272,00 & 280,00 \\
\hline Máximo & 382,00 & 396,00 \\
\hline Tamanho & 25 & 25 \\
\hline Limite Inferior & 307,75 & 317,66 \\
\hline Limite Superior & 329,53 & 340,26 \\
\hline p-valor & \multicolumn{2}{c}{0,204} \\
\hline D & \multicolumn{2}{c}{}
\end{tabular}

$\mathrm{OD}=$ Orelha Direita.

$\mathrm{OE}=$ Orelha Esquerda

P300 = Potencial Cognitivo

$\mathrm{Na}$ tabela 18, não foram encontradas diferenças estatisticamente significantes nas latências do P300 entre as orelhas, para o grupo controle. 
TABELA 19 - Comparação das latências do P300 entre as orelhas direita e esquerda, para o grupo pesquisa

\begin{tabular}{lcc}
\hline \multicolumn{1}{c}{ P300 (Pesquisa) } & OD & OE \\
\hline Média & 303,69 & 335,08 \\
\hline Mediana & 306,00 & 328,00 \\
\hline Desvio Padrão & 35,71 & 50,67 \\
\hline Mínimo & 236,00 & 242,00 \\
\hline Máximo & 362,00 & 416,00 \\
\hline Tamanho & 13 & 13 \\
\hline Limite Inferior & 284,28 & 307,53 \\
\hline Limite Superior & 323,10 & 362,62 \\
\hline p-valor & & 0,101 \\
\hline
\end{tabular}

OD = Orelha Direita.

$\mathrm{OE}=$ Orelha Esquerda

P300 = Potencial Cognitivo

Verificamos, na tabela 19, que não foram encontradas diferenças estatisticamente significantes nas latências do P300 entre as orelhas, para o grupo pesquisa.

Não foram encontradas diferenças médias consideradas estatisticamente significantes entre as orelhas direita e esquerda, para os dois grupos. Desta forma, consideramos, para as próximas análises, ambos os valores de orelhas (unindo as orelhas direita e esquerda).

Comparamos, a seguir, os valores de latência da onda P300 entre os grupos controle e pesquisa. 
TABELA 20 - Comparação das latências do P300 entre os grupos controle e pesquisa

\begin{tabular}{|c|c|c|}
\hline P300 & Controle & Pesquisa \\
\hline Média & 323,80 & 319,38 \\
\hline Mediana & 324,00 & 316,00 \\
\hline Desvio Padrão & 28,49 & 45,83 \\
\hline Mínimo & 272,00 & 236,00 \\
\hline Máximo & 396,00 & 416,00 \\
\hline Tamanho & 50 & 26 \\
\hline Limite Inferior & 315,90 & 301,77 \\
\hline Limite Superior & 331,70 & 337,00 \\
\hline p-valor & & \\
\hline
\end{tabular}

$\mathrm{OD}=$ Orelha Direita.

$\mathrm{OE}=$ Orelha Esquerda

PEATE = Potencial Evocado Auditivo de Tronco Encefálico

$\mathrm{Na}$ tabela 20, não foram encontradas diferenças médias consideradas estatisticamente significantes entre os grupos controle e pesquisa para a latência do P300.

A seguir, comparamos os resultados qualitativos do P300, para os grupos controle e pesquisa. 
TABELA 21 - Distribuição da ocorrência de resultados normais e alterados no P300, nos grupos controle e pesquisa

\begin{tabular}{|c|c|c|c|c|c|c|c|}
\hline \multirow{2}{*}{ Tabela 21} & \multicolumn{3}{|c|}{ Grupo Controle } & \multicolumn{3}{|c|}{ Grupo Pesquisa } & \multirow{2}{*}{$\mathrm{p}$-valor } \\
\hline & Qtde & $\%$ & var & Qtde & $\%$ & var & \\
\hline Normal & 25 & $100,0 \%$ & \multirow{2}{*}{$0,0 \%$} & 11 & $68,8 \%$ & \multirow{2}{*}{$22,7 \%$} & \multirow{2}{*}{$0,003 *$} \\
\hline Alterado & 0 & $0,0 \%$ & & 5 & $31,3 \%$ & & \\
\hline p-valor & & $<0,001^{*}$ & & & $0,034 *$ & & \\
\hline
\end{tabular}

* $p$-valor considerado estatisticamente significante

Qtde = quantidade

Var = índice de variação em relação à média

Verificamos, na tabela 21, que existiu diferença proporcionalmente significante entre os resultados normal e alterado, em ambos os grupos. Quando comparamos os grupos controle e pesquisa, concluímos que a diferença existente entre eles também é considerada estatisticamente significante.

A próxima comparação realizada foi entre os tipos de alterações encontrados no P300 dos grupos controle e pesquisa e entre os grupos. 
TABELA 22 - Distribuição dos tipos de alterações encontrados no P300, nos grupos controle e pesquisa

\begin{tabular}{ccccc}
\hline \multicolumn{2}{c}{ Tipos de alterações } & Controle & Pesquisa & p-valor \\
\hline \multirow{2}{*}{ Atraso da latência } & Qtde & 0 & 2 & - - \\
\cline { 2 - 4 } & $\%$ & $0,0 \%$ & $40,0 \%$ & \\
\hline $\begin{array}{c}\text { Ausência de } \\
\text { resposta }\end{array}$ & Qtde & 0 & 3 & - - \\
\cline { 2 - 4 } Ambas & $\%$ & $0,0 \%$ & $60,0 \%$ & \\
\hline & Qtde & 0 & 0 & - \\
\hline
\end{tabular}

\begin{tabular}{cccc}
\hline \multicolumn{2}{c}{ Tipos de alterações } & $\begin{array}{c}\text { Atraso da } \\
\text { latência }\end{array}$ & $\begin{array}{c}\text { Ausência de } \\
\text { resposta }\end{array}$ \\
\hline \multirow{2}{*}{ Controle } & Ausência de resposta & -- & \\
\cline { 2 - 4 } & Ambas & -- & -- \\
\hline \multirow{2}{*}{ Pesquisa } & Ausência de resposta & 0,527 & \\
\cline { 2 - 4 } & Ambas & 0,114 & $0,038^{*}$ \\
\hline
\end{tabular}

* $\mathrm{p}$-valor considerado estatisticamente significante

p-valores

Qtde = quantidade

Var = índice de variação em relação a média

Com relação à comparação dos tipos de alterações encontrados no P300, vale salientar que não foi possível realizá-la, tanto para o grupo controle, como entre os grupos, visto que não foram encontradas alterações no grupo controle. A tabela 22 mostrou que, para o grupo pesquisa, embora a Ausência de Resposta $(60,0 \%)$ tenha a maior ocorrência, esta não pôde ser considerada estatisticamente diferente da proporção de Atraso de Latência $(40,0 \%)$, porém, apresentou diferença estatisticamente significante com relação ao tipo Ambas. 


\section{Discussão}




\section{6 - DISCUSSÃO}

Neste capítulo realizaremos a análise crítica dos resultados desta pesquisa, confrontando-os com a literatura específica consultada. Para tanto, seguiremos a mesma divisão do capítulo de resultados.

Parte I - Discussão sobre a caracterização da faixa etária e gênero nos grupos controle e pesquisa.

Parte II - Discussão sobre a caracterização dos resultados das avaliações comportamentais nos grupos controle e pesquisa.

Parte III - Discussão sobre a caracterização dos resultados das avaliações eletroacústicas nos grupos controle e pesquisa.

Parte IV - Discussão sobre a caracterização dos resultados das avaliações eletrofisiológicas nos grupos controle e pesquisa.

Parte I - Discussão sobre a caracterização da faixa etária e gênero nos grupos controle e pesquisa.

As tabelas 1 e 2 mostraram a distribuição dos participantes desta pesquisa quanto ao gênero e à faixa etária respectivamente, para ambos os grupos. 
Quanto ao gênero (tabela 1), verificamos que existiu diferença estatisticamente significante entre os grupos e no mesmo grupo, ou seja, ocorreu um número maior de indivíduos do gênero masculino (15) do que feminino (uma) no grupo pesquisa. Desta forma, este estudo indicou que o autismo é um distúrbio o qual acomete um número maior de indivíduos do gênero masculino, como relatado no DSM-IV (APA, 1995).

Além disso, encontramos na literatura, vários estudos sobre audição em autistas cujas casuísticas eram compostas por um número maior de indivíduos do gênero masculino no grupo com autismo, dentre eles Gillberg et al. (1983), Gillberg et al. (1987), Sersen et al. (1990), Erwin et al. (1991), Buchwald et al. (1992), Bruneau et al. (1999), Rosenhall et al. (1999), Ferri et al. (2003), Gomes et al. (2004) e Khalfa et al. (2004).

Quanto à faixa etária (tabela 2), pudemos verificar que não houve diferença estatisticamente significante entre os grupos, sendo assim, a média de idade entre eles apresentou-se bem próxima (12,16 anos para o GC e 11,94 anos para o GP), indicando homogeneidade dos grupos. Ferri et al. (2003), realizaram uma pesquisa na qual a média de idade do grupo autista era de 12,3 anos, ou seja, bem próxima da média encontrada no presente estudo.

Os estudos sobre avaliação da audição em indivíduos autistas, geralmente mostram uma faixa etária bastante abrangente, variando da 
infância à adolescência ou ainda da adolescência à idade adulta, como pudemos verificar nos seguintes trabalhos: Rosemblum et al. (1980), entre 05 e 15 anos de idade; Tanguay et al. (1982), entre 02 e 14 anos de idade; Taylor et al. (1982), entre 02 e 15 anos de idade; Gillberg et al. (1987), entre 03 e 21 anos de idade; Steffenburg (1991), entre 03 e 12 anos de idade; Buchwald et al. (1992), entre 17 e 39 anos de idade; Tecchio et al. (2003), entre 08 oito e 32 anos de idade; Gomes et al. (2004), entre 05 e 19 anos. Assim, os achados desta pesquisa estão de acordo com os da literatura citada, no que diz respeito à faixa etária abrangente, visto que encontramos um valor mínimo de 08 anos e máximo de 19 anos de idade para o GP. De acordo com o DSM-IV (APA, 1995), a prevalência do autismo é de dois a cinco casos por 10.000 indivíduos. Sendo assim, podemos inferir que esta grande abrangência de faixa etária deve-se ao fato de haver um número limitado de indivíduos autistas que encaixam-se nos critérios de inclusão das pesquisas. Desta forma, para que o número da amostra não seja muito pequeno, e inviabilize as análises, aumenta-se a faixa de idade para inclusão de mais indivíduos no grupo. A escolha da faixa etária, do presente estudo, levou em conta as avaliações a serem realizadas, e o número restrito de indivíduos possíveis de serem avaliados, sendo assim, optamos por uma faixa etária mais abrangente (08 a 20 anos), que por sua vez não limitaria a realização dos exames. 


\section{Parte II - Discussão sobre a caracterização dos resultados das avaliações comportamentais nos grupos controle e pesquisa.}

No presente estudo, não encontramos alterações nos resultados qualitativos das avaliações comportamentais do grupo controle e do grupo pesquisa (tabelas 3 e 4). Houve diferença estatisticamente significante na comparação entre os resultados normal e alterado para cada um dos grupos. Os resultados da audiometria tonal e da logoaudiometria, do grupo pesquisa, apresentaram-se dentro da normalidade (estabelecida no capítulo MÉTODOS), os quais concordaram com os achados de Rosemblum et al. (1980), Alcántara et al. (2004) e Khalfa et al. (2004).

Um estudo realizado por Rosenhall et al. (1999), mostrou que indivíduos com autismo podem apresentar limiares normais de audibilidade, além de perdas auditivas de grau leve a moderado (7,9\% do grupo autista) e de grau severo a profundo (3,5\% do grupo autista). Tais achados foram verificados por meio da $A B R$ e da avaliação comportamental da audição. Constataram também, a presença de otite média serosa em $23,5 \%$ do grupo autista, fato não observado no presente estudo.

Alguns estudos utilizaram como critério de inclusão, a ausência de alterações audiológicas (perda auditiva), na audiometria tonal (Ceponiene et al., 2003), e outros determinaram a ausência de alterações por meio dos resultados do PEATE. Desta forma, nestes últimos estudos, os autistas 
apresentaram audição normal e integridade da via auditiva periférica, entretanto, poderiam apresentar alterações eletrofisiológicas na via auditiva central (Bruneau et al. 1999, Gomot et al. 2002, Bruneau et al. 2003, Tecchio et al. 2003).

Klin (1993), em sua revisão, relatou que a maior parte dos estudos sobre audição em autistas utilizavam a $A B R$ e não a avaliação comportamental da audição. Visto que a literatura existente sobre avaliações comportamentais da audição em autismo é escassa, a comparação dos achados desta pesquisa com os da literatura tornou-se comprometida, prejudicando desta forma, a discussão dos resultados.

No presente estudo, pudemos observar as dificuldades na realização da avaliação comportamental da audição de indivíduos com autismo. Verificamos que, embora os sujeitos da pesquisa apresentassem menor comprometimento cognitivo, estes demonstravam dificuldades de atenção, de compreensão, de interação social, e de comunicação, as quais interferiam na realização dos testes. Um dos principais fatores que dificultavam a realização dos procedimentos, era a presença do repertório de atividades repetitivo, pois este prejudicava a atenção do indivíduo, e tornava difícil a continuidade dos testes. Dificuldades na realização da avaliação comportamental, também foram relatadas por Coutinho et al. (2002), pois em seu estudo, tentaram realizar as avaliações (audiometria por reforço visual e audiometria lúdica) em crianças autistas, porém seus resultados foram 
inconclusivos devido à idade e à falta de colaboração dos indivíduos. Ao confrontarmos o presente estudo com o de Coutinho et al. (2002), podemos inferir que as dificuldades na realização das avaliações tornam-se cada vez menores, com o avanço da idade dos indivíduos autistas.

\section{Parte III - Discussão sobre a caracterização dos resultados das avaliações eletroacústicas nos grupos controle e pesquisa.}

Nesta pesquisa, como demonstrou a tabela 5, encontramos diferença estatisticamente significante entre os resultados normal e alterado para os dois grupos, ou seja, os dois grupos apresentaram predominância de resultados normais. O grupo pesquisa apresentou um indivíduo com resultado alterado, porém, ao compararmos os resultados entre os grupos, não observamos diferença estatisticamente significante entre eles. Estes achados concordaram com os estudos de Rosemblum et al. (1980), Coutinho et al (2002), Alcántara et al. (2004) e Gomes et al. (2004), nos quais os resultados da imitanciometria encontravam-se normais, indicando assim, ausência de alterações auditivas periféricas em indivíduos autistas.

A única alteração encontrada em um indivíduo do grupo pesquisa foi a ausência do reflexo acústico ipsilateral na orelha direita em $2000 \mathrm{~Hz}$. Tal achado não foi considerado como alteração na via auditiva periférica pois os 
resultados das outras avaliações (audiometria tonal, logoaudiometria, timpanometria) indicavam normalidade.

Entretanto, podemos verificar que os achados do presente estudo discordaram dos encontrados na revisão de Klin (1993), que relatou um número significativo de sujeitos autistas com presença de alterações auditivas periféricas (56 de 160 indivíduos), porém estas eram determinadas por meio do PEATE e não pela imitanciometria ou audiometria tonal. Encontramos também, discordância com relação a pesquisa de Rosenhall et al. (1999), a qual constatou presença de otite média serosa no grupo autista (23,5\% dos casos), demonstrando que a perda auditiva condutiva pode ser um achado freqüente nesta população.

Da mesma forma como descrito na Parte II, a discussão dos resultados encontra-se prejudicada devido à escassez de literatura específica sobre imitanciometria em autistas.

Parte IV - Discussão sobre a caracterização dos resultados das avaliações eletrofisiológicas nos grupos controle e pesquisa.

Visto que os resultados de cada potencial evocado auditivo foram apresentados separadamente no capítulo anterior, esta parte também foi 
subdividida em três, uma para cada potencial evocado auditivo estudado e sua respectiva literatura especializada.

Parte IV.A - Discussão sobre a caracterização dos resultados do Potencial Evocado Auditivo de Tronco Encefálico nos grupos controle e pesquisa.

Parte IV.B - Discussão sobre a caracterização dos resultados do Potencial Evocado Auditivo de Média Latência nos grupos controle e pesquisa.

Parte IV.C - Discussão sobre a caracterização dos resultados do Potencial Cognitivo nos grupos controle e pesquisa.

\section{Parte IV.A - Discussão sobre a caracterização dos resultados do Potencial Evocado Auditivo de Tronco Encefálico nos grupos controle e pesquisa.}

As tabelas 6 e 7 mostraram a comparação das médias dos valores de latências absolutas das ondas I, III e V, e interpicos I-III, I-V e III-V entre as orelhas direita e esquerda para os dois grupos. Pudemos verificar que não houve diferença estatisticamente significante entre as orelhas, tanto para o grupo controle como para o grupo pesquisa. Este resultado sugeriu que não houve diferença na condução do impulso nervoso até o tronco encefálico entre as orelhas direita e esquerda, tanto para o grupo de indivíduos normais como para o grupo autista. Não encontramos na literatura especializada, 
trabalhos que comparassem os valores médios de latências absolutas e interpicos entre as orelhas direita e esquerda em indivíduos autistas.

Após a comparação entre as orelhas, foram realizadas as comparações das médias dos valores de latências absolutas das ondas I, III e V, e interpicos I-III, III-V e I-V entre os grupos controle e pesquisa, porém, unimos as orelhas direita e esquerda em cada grupo para assim, realizar tal comparação.

A tabela 8 mostrou que existiu diferença estatisticamente significante entre os grupos controle e pesquisa para as latências absolutas das ondas III e V e os interpicos I-III e I-V, ou seja, houve um aumento na latência dessas ondas no grupo pesquisa, quando comparados às latências do grupo controle. Sendo assim, estes resultados indicaram que os indivíduos autistas apresentaram altraso na condução do impulso nervoso nas regiões do tronco encefálico baixo (núcleo coclear e lemnisco lateral). Estes resultados concordaram com o trabalho de Rosenblum et al. (1980), que verificaram um aumento nas latências das ondas III e IV em indivíduos autistas, e com o de Taylor et al. (1982), que encontraram um aumento dos interpicos I-III e I-V em indivíduos autistas. Sersen et al. (1990), verificaram, também, atraso nos componentes médios e mais tardios (ondas III, V, VI e VII) do PEATE em indivíduos autistas sedados, porém, os autistas não sedados apresentaram latências normais neste potencial. Nos estudos de Maziade et al. (2000) e Gillberg et al. (1983) foi verificado respectivamente, aumento do interpico I- 
III, e do valor médio da latência da onda $V$ no grupo de indivíduos autistas, quando comparado com o grupo controle. Sendo assim, todos os estudos apontaram para uma disfunção em tronco encefálico de indivíduos com autismo.

Ao analisarmos qualitativamente os resultados do PEATE, encontramos, na tabela 9, diferença estatisticamente significante entre os grupos controle e pesquisa. Verificamos então, que o grupo pesquisa apresentou seis resultados alterados, enquanto que o grupo controle apresentou apenas resultados normais.

Gillberg et al. (1983) também verificaram resultados alterados na ABR de indivíduos autistas, os quais indicavam disfunção em tronco encefálico com ocorrência de 23 a 33\% dos casos estudados.

A tabela 10 mostrou a comparação entre os tipos de alterações encontradas em cada grupo, e entre os grupos. Visto que o grupo controle não apresentou resultados alterados, não foi possível realizar as comparações para este grupo. Verificamos para o grupo pesquisa, que existiu diferença estatisticamente significante entre a alteração do tipo Tronco Encefálico Baixo (TEB) e as demais (Tronco Encefálico Alto e Ambas), mostrando, assim, que este tipo de alteração é a mais freqüente neste grupo. Este resultado concordou com o obtido na tabela 8, pois 0 atraso nas latências das ondas III e V, e o aumento dos interpicos I-III e I-V, 
sugerem alteração do tipo TEB. Sendo assim, tanto a análise quantitativa como a qualitativa, indicaram disfunção em tronco encefálico em indivíduos autistas, com predomínio na região do núcleo coclear.

Os resultados descritos anteriormente concordaram com os encontrados por Rosenblum et al. (1980), que verificaram um aumento no tempo de transmissão do estímulo (do nervo ao tronco encefálico) quando comparado com os indivíduos do grupo controle. Os autores mediram do pico positivo da onda I até o pico negativo da onda IV para determinar o tempo de transmissão do estímulo ao longo da via auditiva até o tronco encefálico. Esse aumento no tempo de transmissão em tronco encefálico também foi constatado por outros estudos, dentre eles Tanguay et al. (1982), Taylor et al (1982) e Gillberg et al. (1987).

O presente trabalho corrobora os resultados encontrados por Taylor et al. (1982) e Maziade et al. (2000), pois o primeiro encontrou aumento dos interpicos I-III e I-V em indivíduos autistas, e o segundo encontrou aumento do interpico I-III em autistas. Desta forma, os autores verificaram uma lentidão na condução do estímulo no nervo auditivo e no início da via auditiva em tronco encefálico.

Rosenhall et al. (2003) encontraram resultados similares ao do presente estudo, pois constataram que mais da metade $(58,4 \%)$ dos indivíduos autistas com audição normal, apresentaram anormalidades na 
ABR. Dentre as anormalidades, $50 \%$ dos casos mostraram aumento de uma ou mais latências absolutas das ondas I, III e V, sendo que o atraso da onda $V$ foi encontrado em $37,6 \%$ destes. O prolongamento do interpico I-V foi o mais freqüente $(27,7 \%)$ dentre os outros prolongamentos (interpicos I-III e IIIV ocorrendo em proporções iguais). Desta forma, os autores concluíram que essas alterações podem ser decorrentes de disfunção em tronco encefálico, alteração coclear desconhecida ou envolvimento do sistema coclear efentente.

O presente estudo discordou dos achados de Tanguay et al. (1982), Taylor et al (1982), Klin (1993), Rosenhall et al. (1999), quanto à existência de perdas auditivas de diversos graus em indivíduos autitas. Tanguay et al. (1982) relataram atraso na latência absoluta da onda I, e alteração da via auditiva periférica em autistas. Por sua vez, Taylor et al. (1982) observaram perda auditiva de graus moderado, severo e profundo, obtidos por meio do limiar eletrofisiólogico, em autistas. Em sua revisão, Klin (1993) constatou a existência de perda auditiva periférica em indivíduos autistas, evidenciando a possibilidade de co-ocorrência entre autismo e alterações auditivas periféricas. Além disso, concluiu que os estudos realizados com ABR em autistas, não forneceram evidências claras de disfunção em tronco encefálico, embora não refutassem essa idéia. Rosenhall et al. (1999), em seu estudo, também encontraram a existência de perdas auditivas de grau leve a moderado $(7,9 \%$ do grupo) e de grau severo a profundo $(3,5 \%$ do grupo) em autistas, constatadas por meio da $A B R$ e da avaliação 
comportamental da audição. Desta forma, nossa pesquisa discordou dos estudos anteriores pois, ficou evidente a ausência de compromentimento auditivo periférico em indivíduos autistas como mostraram as tabelas 1, 2, 3 e 8. Além disso, ficou clara a presença do comprometimento de via auditiva em tronco encefálico, como mostraram as tabelas 8, 9 e 10.

Os achados deste estudo discordaram dos encontrados por Coutinho et al. (2002), no qual os valores de latências absolutas das ondas I, III e V e interpicos I-III, I-V, e III-V apresentaram-se normais em dois indivíduos autistas.

Ainda podemos citar alguns estudos que verificaram a acuidade auditiva de indivíduos autistas, os quais usavam como critério de inclusão a audição normal observada por meio do PEATE (Bruneau et al. 1999, Gomot et al. 2002, Bruneau et al. 2003, Tecchio et al. 2003). Os achados do presente estudo concordaram com os trabalhos citados anteriormente quanto a ausência de perda auditiva em indivíduos autistas, verificadas tanto por meio do PEATE, como por meio das avaliações comportamentais da audição, porém, discordaram da ausência de alterações no PEATE destes indivíduos.

Complementando a análise realizada, pudemos verificar inconsistência nos traçados das ondas do PEATE em indivíduos autistas. Observamos que as reproduções mostravam-se diferentes no grupo pesquisa, enquanto que 
no grupo controle, a variabilidade entre os traçados das ondas era muito menor. Esta característica concorda com os achados da pesquisa de Rosenblum et al. (1980), na qual relataram uma inconsistência de resposta verificada por meio da grande variabilidade encontrada nos traçados das ondas. Ao reproduzirem o traçado, encontraram diferenças importantes entre as ondas registradas.

\section{Parte IV.B - Discussão sobre a caracterização dos resultados do Potencial Evocado Auditivo de Média Latência nos grupos controle e pesquisa.}

Foram realizadas as comparações entre as médias das modalidades do PEAML, duas a duas, para cada grupo, ou seja, foram comparadas as orelhas (C3/A1 e $\mathrm{C} 3 / \mathrm{A} 2, \mathrm{C} 4 / \mathrm{A} 1$ e $\mathrm{C} 4 / \mathrm{A} 2)$ em cada grupo e, posteriormente os eletrodos (C3/A1 e C4/A1, C3/A2 e C4/A2) em cada grupo. De acordo com as tabelas 11, 12, 13 e 14, não encontramos diferença estatisticamente significante entre as médias das modalidades para os dois grupos. Sendo assim, constatamos que independentemente da orelha avaliada (comparação entre as modalidades $\mathrm{C} 3 / \mathrm{A} 1$ e $\mathrm{C} 3 / \mathrm{A} 2$, e entre $\mathrm{C} 4 / \mathrm{A} 1$ e C4/A2) as amplitudes $\mathrm{Na}-\mathrm{Pa}$ mostraram-se semelhantes, tanto no grupo pesquisa como no grupo controle. Por sua vez, verificamos que independentemente do posicionamento dos eletrodos sobre os hemisférios (comparação entre as 
modalidades $\mathrm{C} 3 / \mathrm{A} 1$ e $\mathrm{C} 4 / \mathrm{A} 1$, e entre $\mathrm{C} 3 / \mathrm{A} 2$ e $\mathrm{C} 4 / \mathrm{A} 2)$, houve semelhança entre as amplitudes $\mathrm{Na}-\mathrm{Pa}$, para ambos os grupos.

Após a comparação intra-grupo, foram comparadas as modalidades, C3/A1, C3/A2, C4/A1 e C4/A2, uma a uma, entre o grupo controle e o grupo pesquisa. Desta forma, a tabela 15 mostrou que os grupos não apresentaram diferenças estatisticamente significantes em nenhuma modalidade. Este resultado indicou que a amplitude $\mathrm{Na}-\mathrm{Pa}$ do grupo pesquisa, em todas as modalidades, foi semelhante à do grupo controle.

Não foram encontrados estudos em indivíduos autistas que realizassem as comparações descritas na presente pesquisa. Desta forma, não houve como confrontar os resultados com a literatura especializada .

As tabelas 16 e 17 apresentaram as análises qualitativas do PEAML para os grupos. Na tabela 16, verificamos que existiu diferença estatisticamente significante entre os resultados normal e alterado em ambos os grupos. Além disso, houve diferença estatisticamente significante quando comparados os resultados entre os grupos, ou seja, o grupo controle apresentou mais resultados alterados do que o grupo pesquisa.

Para Özdamar e Kraus (1983) e Schochat (2003), o PEAML é útil clinicamente na avaliação dos distúrbios do processamento auditivo. No presente estudo não foi realizada a avaliação comportamental do 
processamento auditivo (PA) dos sujeitos da pesquisa, sendo excluídos do grupo controle aqueles que apresentaram queixas de processamento auditivo, histórico de dificuldades escolares, e de otites recorrentes. Portanto, podemos levantar a hipótese de que os indivíduos do grupo controle poderiam apresentar alterações de PA, as quais justificariam as alterações encontradas no PEAML. No entanto, indivíduos autistas apresentam, como características comportamentais, distúrbios de percepção, do desenvolvimento, de relacionamento social, da fala e linguagem (Ritvo, 1976) as quais podem estar relacionadas com alterações do processamento auditivo. Sendo assim, as alterações encontradas no PEAML, provavelmente refletiram dificuldades no processamento auditivo da informação nas vias auditivas subcorticais e corticais.

A tabela 17 apresentou as comparações entre os tipos de alterações encontradas nos dois grupos avaliados e entre os grupos. Verificamos que não houve diferença estatisticamente significante entre os grupos para quaisquer dos tipos de alterações. Para o grupo controle, a alteração do tipo Ambas apresentou diferença estatisticamente significante com relação aos outros dois tipos (efeito orelha e efeito eletrodo), sendo a alteração que mais ocorreu neste grupo. Para o grupo pesquisa, a alteração do tipo Ambas também mostrou-se predominante com relação aos outros tipos, porém, pôde ser considerada estatisticamente significante apenas da alteração do tipo Efeito Eletrodo. 
No estudo realizado por Buchwald et al. (1992), não foram encontradas diferenças significantes entre os grupos, para o componente Pa (amplitude $\mathrm{Pa}-\mathrm{Nb}$ ). Entretanto, foram identificadas anormalidades no componente P1 (amplitude P1-Nb) em indivíduos autistas, sugerindo que o sistema ascendente de ativação reticular e/ou seu alvo talâmico pós-sináptico podem apresentar disfunção nesta população.

Respostas eletrofisiológicas (com exceção do potencial evocado auditivo de longa latência) não dependem da habilidade linguística do sujeito, e também, não demandam um processamento cognitivo do estímulo acústico (Schochat, 2003). Levando este aspecto em consideração, provavelmente as alterações cognitivas e de linguagem, presentes nos indivíduos autistas, não influenciaram os resultados obtidos no PEAML destes sujeitos.

Visto que o PEAML sofre pouca influência da sincronia neural (Kraus et al.,1999), pudemos verificar também, na presente pesquisa, que os resultados obtidos neste potencial não refletiram uma alteração na sincronia, dado que foi encontrado no PEATE dos indivíduos autistas.

Parte IV.C - Discussão sobre a caracterização dos resultados do Potencial Cognitivo nos grupos controle e pesquisa. 
As tabelas 18 e 19, mostraram as comparações dos valores de latências das ondas P300 entre as orelhas direita e esquerda, para ambos os grupos. Verificamos que não houve diferença estatisticamente significante entre as orelhas, tanto do grupo controle como do grupo pesquisa, sendo assim, as médias das latências das ondas P300 das orelhas direita e esquerda obtiveram valores próximos.

A presença de diferenciações entre os PEALL dos hemisférios direito e esquerdo em indivíduos com audição normal, entre 08 e 18 anos de idade, foi também investigada por Frizzo et al. (2001), que verificaram a existência de diferenças apenas para o componente P2 no gênero masculino, sendo que os demais componentes não apresentaram diferenças significantes entre os hemisférios.

Visto que os grupos não mostraram diferenças entre as orelhas, as outras análises foram realizadas a partir do agrupamento das orelhas direita e esquerda obtendo-se, assim, apenas uma média para cada grupo.

$\mathrm{Na}$ tabela 20, verificamos que não houve diferença estatisticamente significante quando comparados os valores de latência da onda P300 entre os grupos controle e pesquisa. Portanto, o grupo pesquisa apresentou média de latência com valor próximo ao do grupo controle. Este achado concordou com o estudo de Niwa et al. (1983), no qual não verificaram diferenças com relação à latência da onda P300 entre os grupos, sob quaisquer condições 
de teste. Entretanto, os autores encontraram menor amplitude da onda P300, na condição "no-task", em indivíduos autistas quando comparados aos outros dois grupos. Desta forma, sugeriram que indivíduos autistas apresentam dificuldades cognitivas no "processamento de avaliação do estímulo alvo".

Nossos resultados concordaram também com os estudos de Erwin et al. (1991), que não encontraram diferenças no P300 de indivíduos autistas de alto funcionamento quando comparado ao grupo controle, e de Ferri et al. (2003) que verificaram que a amplitude e a latência da onda P3a de indivíduos autistas não apresentaram diferenças estatisticamente significantes ao serem comparadas com o grupo controle.

As análises qualitativas foram apresentadas nas tabelas 21 e 22, nas quais foram comparados os resultados normal e alterado, e os tipos de alterações, nos grupos controle e pesquisa, e entre os grupos, respectivamente.

A tabela 21 mostrou que o grupo pesquisa apresentou resultados alterados no P300, sendo que o grupo controle apresentou apenas resultados normais. Assim, houve diferença estatisticamente significante entre os grupos. As tabelas 20 e $\mathbf{2 1}$ mostraram resultados discrepantes no P300, pois a primeira demonstrou que os grupos, controle e pesquisa, não apresentaram diferenças entre as médias das latências da onda P300, 
enquanto que a segunda, demonstrou que os grupos apresentaram diferenças estatisticamente significantes, quanto aos resultados alterados.

Esta discrepância provavelmente está relacionada ao método utilizado para a realização das duas análises, a quantitativa e a qualitativa. Isto porque a faixa de valores na qual a latência da onda P300 pode encontrar-se é bastante abrangente; desta forma, quando realizamos a média da latência da onda, para cada grupo, incluímos uma somatória de valores bastante diversificados. Sendo assim, a média entre os grupos não mostrou diferença significante, pois não houve número elevado de indivíduos que apresentassem valores de latência da onda próximos aos limites (inferior ou superior). Entretanto, para a análise qualitativa, as variáveis eram apenas duas (normal e alterado); desta forma, ao verificar-se a proporção de indivíduos alterados entre os grupos, foi detectada uma diferença estatisticamente significante entre eles, demostrando assim, que indivíduos autistas apresentam alterações no P300, as quais não foram encontradas nos indivíduos do grupo controle.

Com relação à comparação entre os tipos de alterações encontradas, a tabela 22 mostrou que não foi possível comparar os grupos pois o grupo controle não apresentou resultados alterados. Assim, na comparação entre os tipos de alterações encontrados no grupo pesquisa, observamos que a Ausência de Resposta (AR) foi a alteração mais freqüente, e esta pôde ser considerada estatisticamente significante da alteração tipo Ambas (A), mas 
não pôde ser considerada estatisticamente diferente da alteração do tipo Atraso de Latência (AL).

Estes achados indicaram que os indivíduos autistas apresentaram alterações no P300 que refletem suas dificuldades cognitivas e atencionais, pois, de acordo com Picton (1992), o atraso na latência da onda P300 indica a existência de um possível déficit no processamento cognitivo. Polich (1991), também relatou a aplicação clínica do P300 para diagnósticos de disfunções cognitivas. Ainda, Kraus e McGee (1999), ressaltaram a importância do P300 para o estudo das funções cognitivas e de atenção, visto que os processos de discriminação auditiva, memória, perspectiva semântica e atenção, estão diretamente envolvidos na geração desta onda.

Novick et al. (1980) encontraram alterações nos componentes P200 e P300 do potencial evocado auditivo de longa latência. Esses componentes encontraram-se menores em todos os sujeitos autistas quando comparados aos sujeitos do grupo controle. Para os autores, esses resultados indicaram anormalidades nos aspectos altos do processamento, e sugeriram que alterações severas de linguagem na infância podem ser secundárias a déficits no processamento auditivo alto.

O P300 é um potencial endógeno, portanto, sua geração, depende de uma tomada de decisão por parte do indivíduo avaliado. Este potencial é gerado satisfatoriamente desde que o indivíduo seja capaz de focalizar sua atenção nos estímulos raros que são apresentados dentre uma série de 
estímulos freqüentes (Schochat, 2004). Desta forma, os resultados do presente estudo indicaram que os indivíduos autistas apresentaram dificuldade em focalizar a atenção nos estímulos raros, confirmando, portanto, o déficit atencional encontrado nesta população.

Consultando a literatura especializada, encontramos alguns trabalhos que estudaram outros potenciais de longa latência em autistas, dentre eles Bruneau et al. (1999), que em seu estudo verificaram atraso na latência da onda N1 de indivíduos autistas; Gomot et al. (2002), que encontraram latências menores no $\mathrm{MMN}$ de crianças autistas e relataram um padrão eletrofisiológico sugestivo de disfunção em córtex frontal esquerdo que poderia estar relacionado com os comprometimentos cognitivo e comportamental dos autistas; Bruneau et al. (2003), que relataram um aumento na latência da onda N1c indicando uma hiporeatividade eletrofisiológica bitemporal em autistas; e Tecchio et al. (2003), que relataram alterações no MMF sugerindo disfunção nos estágios préconscientes da discriminação auditiva cortical.

Portanto, pudemos verificar que os estudos apontaram para alterações no sistema auditivo central, em níveis subcorticais e corticais, que podem estar relacionados com as dificuldades sociais e cognitivas apresentadas por indivíduos autistas. 


\section{CONSIDERAÇÕES FINAIS}

A função auditiva de indivíduos autistas foi verificada, por meio de diferentes testes, na presente pesquisa. Desta forma, pudemos investigar, de maneira ampla, o sistema auditivo desta população.

Verificamos, por meio das avaliações comportamentais e eletroacústicas da audição, que o limiar de audibilidade e as medidas de imitância acústica apresentaram-se normais, demonstrando assim, integridade do sistema auditivo periférico em indivíduos autistas. Entretanto, nas avaliações eletrofisiológicas da audição, encontramos alterações no PEATE e no P300.

Para Hood (1995) e Junqueira e Frizzo (2002), o PEATE verifica a habilidade do sistema nervoso central em responder à estimulação externa de maneira sincrônica. Constatamos, assim, que indivíduos autistas apresentaram disfunção em tronco encefálico, as quais poderiam ser decorrentes de um déficit na sincronia neural.

O P300 é considerado um potencial endógeno, o qual depende da focalização da atenção em um estímulo raro para ser gerado satisfatoriamente. Para Picton (1992), quando a latência da onda P300 encontra-se atrasada, é possível que exista um déficit no processamento 
cognitivo. Desta forma, o atraso e/ou ausência da onda P300, achados verificados nos indivíduos autistas, demonstraram um prejuízo no sistema de geração deste potencial, sugerindo a presença de déficit de atenção e alteração no processamento cognitivo da informação auditiva nessa população.

Verificamos, então, que indivíduos autistas apresentaram alterações nas avaliações eletrofisiológicas, as quais indicaram disfunção em diferentes níveis do sistema auditivo central.

Levando-se em consideração estes achados, pudemos verificar que a utilização e a associação de diferentes métodos, objetivos e subjetivos, de avaliação da audição, permite-nos reunir informações a respeito do sistema auditivo periférico e central imprescindíveis para a caracterização da função auditiva de indivíduos autistas. 


\section{Conclusões}




\section{7 - CONCLUSÕES}

Frente aos resultados obtidos podemos concluir que indivíduos com autismo:

$\checkmark \quad$ Não apresentam alterações nas avaliações comportamentais e eletroacústicas da audição, sugerindo integridade da via auditiva periférica e limiares de audibilidade normais;

$\checkmark$ Apresentam alterações no potencial evocado auditivo de tronco encefálico sugerindo:

1. comprometimento da via auditiva em tronco encefálico (nas regiões do núcleo coclear e lemnisco lateral) ;

1 alteração de sincronia na geração dos impulsos neuroelétricos na região do tronco encefálico;

1 alterações estruturais e/ou funcionais que interferem na transmissão do estímulo acústico ao longo da via auditiva;

Apresentam alterações no potencial cognitivo sugerindo:

ᄉ comprometimento da via auditiva em regiões corticais;

^ déficit no processamento cognitivo;

^ déficit de atenção;

1. déficit de discriminação auditiva;

^ déficit de memória. 
8-Anexos 


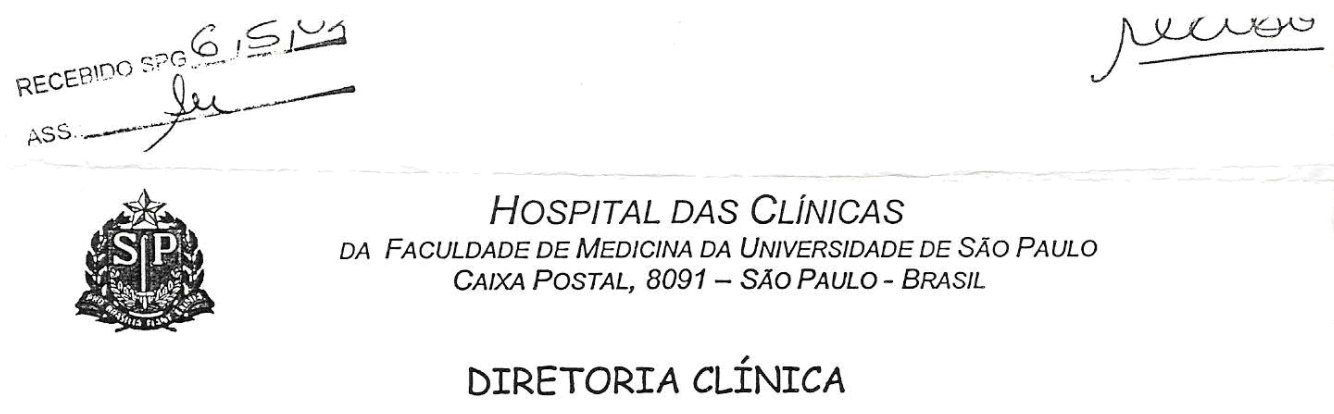

\section{Comissão de Ética para Análise de Projetos de Pesquisa}

\section{APROVACÃO}

A Comissão de Ética para Análise de Projetos de Pesquisa - CAPPesq da Diretoria Clínica do Hospital das Clínicas e da Faculdade de Medicina da Universidade de São Paulo, em sessão de 24.04.03, APROVOU o Protocolo de Pesquisa $n^{\circ}$ 237/03, intitulado: "Avaliação eletrofisiológica da audição em autismo" apresentado pela ÁREA DE FISIOPATOLOGIA EXPERIMENTAL, bem como o Termo de Consentimento Livre e Esclarecido.

Pesquisador(a) Responsável: PROFA. DRA. CARLA GENTILE MATAS Pesquisador(a) Executante: SRA. FERNANDA CRISTINA LEITE MAGLIARO

CAPPesq, 24 de Abril de 2003.

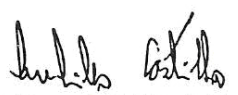

PROF. DR. EUCLIDES AYRES DE CASTILHO Presidente da Comissão Ética para Análise de Projetos de Pesquisa

OBSERVACÃO: Cabe ao pesquisador elaborar e apresentar à CAPPesq, os relatórios parciais Encaminhe-se àCPGFMUSP e final sobre a pesquisa (Resolução do Conselho Nacional de Saúde $n^{\circ} 196$. para as devidas providencias. de 10.10.1996, inciso IX.2, letra " $c$ ")

$$
\begin{aligned}
& \text { S.P., } 05105103 \text { C. autrikanton. } \\
& \text { Prof. }{ }^{2} \text { Dra. Mana Mitzı Brentanı } \\
& \text { Coordenadora do Curso de } \\
& \text { Pos-Graduaçăo do programa } \\
& \text { de Fisiopatologia Expermental }
\end{aligned}
$$


HOSPITAL DAS CLÍNICAS

I - DADOS DE IDENTIFICAÇÃo DO SUJEITO DA PESQUISA OU RESPONSÁVEL LEGAL

1. NOME DO PACIENTE

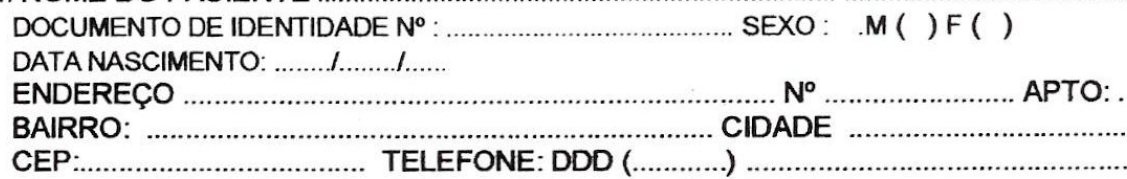

\section{II - DADOS SOBRE A PESQUISA CIENTÍFICA}

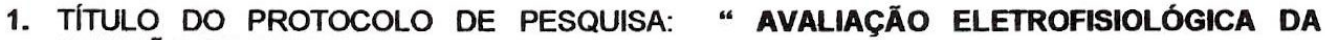
AUDIÇÃO EM AUTISMO".

2. PESQUISADOR: Fernanda Cristina Leite Magliaro CARGOFINÇÃO: mestranda

INSCRIÇÃO CONSELHO REGIONAL N 11.584 UNIDADE DO HCFMUSP: Fisiopatologia Experimental

3. AVALIAÇÃO DO RISCO DA PESQUISA:

$\begin{array}{lll}\text { SEM RISCO } & \text { X RISCO MINIMO } & \text { RISCO MÉDIO } \\ \text { RISCO BAIXO } & \text { RISCO MAIOR }\end{array}$

(probabilidade de que o indivíduo sofra algum dano como consequência imediata ou tardia do estudo)

4.DURAÇÃO DA PESQUISA : 3 anos 


\section{III - REGISTRO DAS EXPLICAÇÕES DO PESQUISADOR AO PACIENTE OU SEU REPRESENTANTE LEGAL SOBRE A PESQUISA, CONSIGNANDO:}

Gostaria de avaliar a audição de indivíduos com autismo para verificar se esta população apresenta alterações auditivas periféricas e/ ou centrais. Vou fazer as mesmas avaliaçöes em indivíduos normais, da mesma idade, para poder comparar os resultados entre as duas populações. Utilizarei testes que avaliam a audição. As avaliações serão realizadas primeiro em uma cabine, onde os indivíduos irão escutar alguns apitos através de fones de ouvido. Depois, serão colocados alguns fios na superfície da pele que serão fixados com esparadrapo, para captar as ondas cerebrais relacionadas à audição. Os testes utilizados não oferecem nenhum risco ou desconforto para os indivíduos. $O$ benefício dessa avaliação é verificar a audição dos indivíduos testados (normais e com autismo), observando se existe algum problema auditivo que possa estar interferindo no desenvolvimento global do sujeito avaliado.

\section{IV - ESCLARECIMENTOS DADOS PELO PESQUISADOR SOBRE GARANTIAS DO SUJEITO DA PESQUISA:}

1. acesso, a qualquer tempo, às informações sobre procedimentos, riscos e benefícios relacionados à pesquisa, inclusive para dirimir eventuais dúvidas.

2. liberdade de retirar seu consentimento a qualquer momento e de deixar de participar do estudo, sem que isto traga prejuizo à continuidade da assistência.

3. salvaguarda da confidencialidade, sigilo e privacidade.

4. disponibilidade de assistência no HCFMUSP, por eventuais danos à saúde, decorrentes da pesquisa.

5. viabilidade de indenização por eventuais danos à saúde decorrentes da pesquisa.

\section{INFORMAÇÓES DE NOMES, ENDEREÇOS E TELEFONES DOS RESPONSÁVEIS PELO ACOMPANHAMENTO DA PESQUISA, PARA CONTATO EM CASO DE INTERCORRÊNCIAS CLINICAS E REAÇÕES ADVERSAS.}

Em caso de dúvida favor entrar em contato com:

Dra Carla Gentile Matas (orientadora)

Fga Femanda C. L. Magliaro (pesquisadora responsável)

Endereço: rua Cipotânea 51 Cidade Universitária, Tel. 30917453

End. residencial: Av. Divino Salvador, 107 apto 32 - Planalto Paulista

Tel. Residencial: 50512217

e-mail: cgmatas@ usp.br

\section{OBSERVAÇÕES COMPLEMENTARES:}

\section{VII - CONSENTIMENTO PÓS-ESCLARECIDO}

Declaro que, após convenientemente esclarecido pelo pesquisador e ter entendido o que me foi explicado, consinto em participar do presente Protocolo de Pesquisa

São Paulo,

de

de 20 


\section{Univeridade de São Paulo - FaCuldade de MEdicina DEPARTAMENTO DE FISIOTERAPIA, FONOAUDIOLOGIAE TERAPIA OCUPACIONAL SETOR: AUDIOLOGIA CLINICA}

\begin{tabular}{|c|c|c|c|c|c|}
\hline \multicolumn{6}{|c|}{ ANAMNESE INFANTIL } \\
\hline Nome: & & & Sexo: & D. N.: & Idade: \\
\hline N. ${ }^{\circ}$ CDP: & Encaminhado por: ( & ) externo & & ( & \\
\hline $\begin{array}{l}\text { Responsável: } \\
\text { Endereço: }\end{array}$ & & & Paren & & \\
\hline Cidade: & & CEP: & & one: & \\
\hline
\end{tabular}

Existe consangüinidade entre os pais? Sim ( ) Não ( ) Qual? Alguém na família tem problema de audição? $\quad \operatorname{Sim}($ ) Não ( ) Congênita ( ) Adquirida ( ) Quem?

\section{GESTAÇ̃̃O}

Teve alguma doença/acidente durante a gestação? Não ( ) Sim ( ) Qual? Fez uso de medicamentos, drogas ou álcool? Não ( ) Sim ( ) Qual? Fumou durante a gestação?

Assinale as ocorrências durante a gestação:

Rubéola ( ) Hemorragia ( ) Fator Rh ( ) Hipertensão ( ) Quedas ( ) Outras ( ) Especificar:

\begin{tabular}{lll}
\hline PARTO & A termo( ) & Permaneceu em encubadora( ) \\
Normal ( ) & Prematuro ( ) & Cianose( ) \\
Cesariana ( ) & & Icterícia( ) \\
Fórceps ( ) & \\
Peso ao nascer (ver carteirinha de recém nascido): &
\end{tabular}

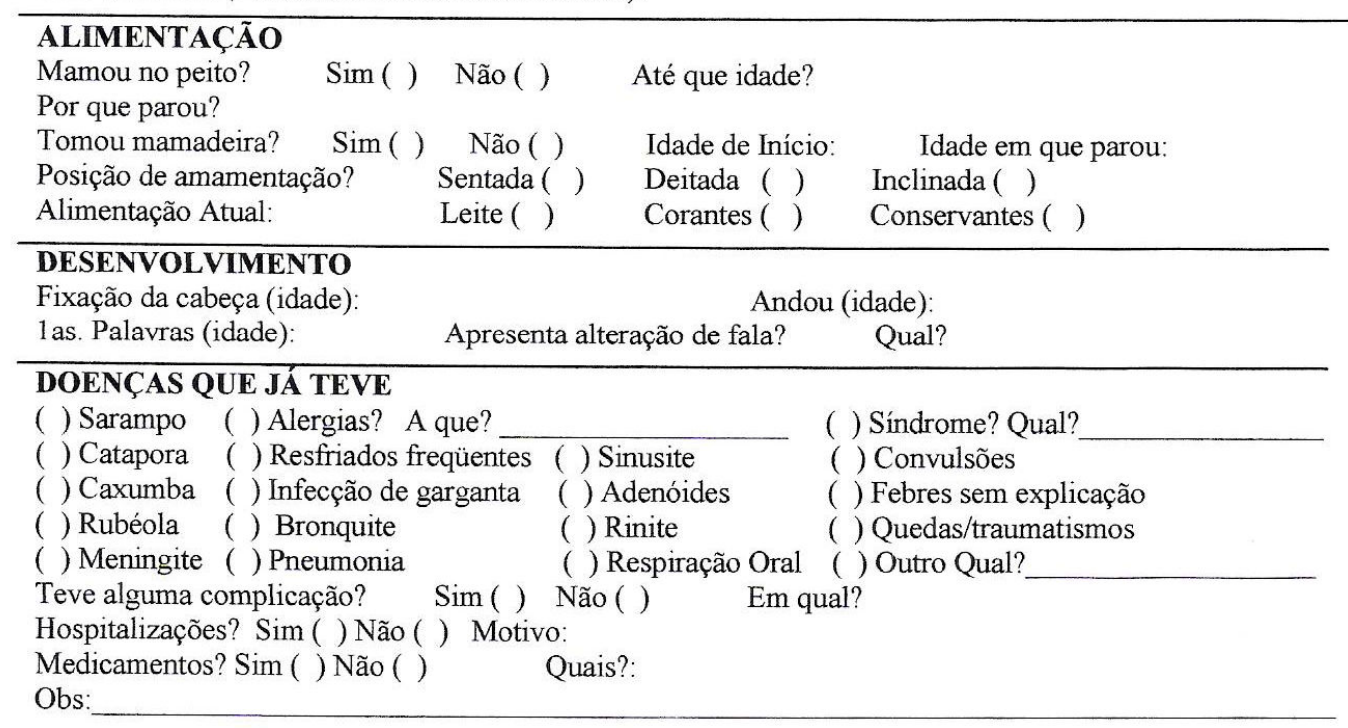

Está com alguma doença atualmente? ( ) Não ( ) Sim. Qual? 
AUDIÇÃO

\begin{tabular}{|l|}
\hline Reage a sons? $\operatorname{Sim}($ ) Não ( ) Tipo de reação: \\
\hline Quais sons? Voz da mãe ( ) música ( ) carro passando na rua ( ) batida de porta ( ) trovão ( ) \\
\hline buzina ( ) telefone ( ) descarga ( ) outros ( ) Especificar: \\
\hline Compreende ordens: Sim ( ) Não ( ) Especificar: \\
\hline Distraído na presença de ruído: Sim ( ) Não ( ) \\
\hline Esquece o que lhe é falado: Sim ( ) Não ( ) \\
\hline Pergunta ou solicita repetição - (O que? Hein?): Sim ( ) Não ( ) \\
\hline
\end{tabular}

Assinale as ocorrências:
( ) Dor de ouvido
( ) Supuração
( ) Exposição à ruído
( ) Flutuação da audição
( ) Infecção/otite
( ) Coceira
( )Progressão da perda auditiva
( ) Tontura
( ) Zumbido. Tipo
( ) Sensação de ouvido tapado (plenitude auricular)

Em que idade?

Tratamentos realizados:

Fez cirurgia de ouvido, nariz ou garganta?

Uso de AASI: ( ) não ( ) sim: Fabricante/Modelo:

Tipo de adaptação/Tempo de uso:

Assinale os comportamentos mais comuns:
( ) Ouve mal
( ) Alimenta-se mal
( ) Cai muito
( ) Isola-se
() Fala baixo
( ) Bebe muito líquido
( ) Agitado
( ) Baba
( ) Muito ativo
( ) Chora muito
( ) Fala alto
( ) Desorganizado
( ) Esquecido
( ) Reclama do barulho
( ) Desastrado
( ) Distraído
( ) Tímido
( ) Aumenta o volume da TV
( ) Desatento
( ) Irritado
( ) Fica com a boca aberta
( ) Outros. Especifique:
( ) Pede para repetir o que foi falado

a última?

\title{
ESCOLARIDADE
}

Freqüentou creche ou berçário desde que idade?

Freqüenta escola desde que idade?

Repetiu de ano?

Aprende com facilidade?

O professor tem alguma queixa da criança?

Qual?

Demora para realizar as tarefas

Faz as tarefas ( ) Sozinho ( ) Com ajuda

Qual a disciplina preferida?

Qual a disciplina menos apreciada?

\section{AMBIENTE}

Construção: ( ) tijolo ( ) madeira ( ) concreto ( ) outro. Especificar

$\mathrm{N}^{\circ}$ de cômodos: Quantas pessoas moram na casa?

Tem fumantes em casa? Sim ( ) Não ( ) Quem?

Usa produtos de limpeza? Sim ( ) Não ( ) Quais?

Ambiente: Úmido: Sim ( ) Não ( ) Ventilado: Sim ( ) Não ( ) Ruidoso: $\operatorname{Sim}($ ) Não ( )
( ) Animais
( ) Perfumes
( ) Mofo

\author{
Sim ( ) Não ( ) Especificar: \\ Sim ( ) Não( ) \\ Sim ( ) Não ( )
}

Série atual:

\section{RELACIONAMENTO}

Brinca sozinho ( ) com outras crianças ( ) Briga muito ( )

Prefere a companhia de crianças( ) de adultos( )

\section{OUTRAS OBSERVAÇÕES}




\section{9 - REFERÊNCIAS}

Alcántara JI, Weisblatt EJL, Moore BCJ, Bolton PF. Speech-in-noise perception in high-functioning individuals with autism or Asperger's Syndrome. J Child Psychol Psychiatry. 2004;45(6):1107-14.

American National Standards Institute. Specification for instruments to measure aural acoustic impedance and admittance. ANSI S3.39. 1987.

American National Standards Institute. Specification for audiometers. ANSI S3.6. 1989.

American National Standards Institute. Maximum permissible ambient noise for audiometric testing. ANSI S3.1. 1991.

American National Standards Institute. Specification for audiometers. ANSI S3.7. 1996.

APA. Manual diagnóstico e estatístico de transtornos mentais - DSM-IV. Porto Alegre: Artes Médicas;1995. p.65-76. 
Assumpção Jr FB. Distúrbios Globais do Desenvolvimento In: Assumpção Jr FB. Transtornos Invasivos do Desenvolvimento Infantil. São Paulo: Lemos; 1997. p.13-24.

Bosa C, Callias M. Autismo: Breve revisão das diferentes abordagens. Psicologia: Reflexão e Crítica. 2000;13(1):167-77.

Bruneau N, Bonnet-Brilhaut F, Gomot M, Adrien JL, Barthélémy C. Cortical auditory processing and communication in children with autism: electrophysiological/behavioral relations. Int J Psychophysiol. 2003;51:17-25.

Bruneau N, Roux S, Adrien JL, Barthélémy C. Auditory associative córtex dysfunction in children with autism: evidence from late auditory evoked potentials (N1 wave - T complex). Clin Neurophysiol. 1999;110:1927-34.

Buchwald JS, Erwin R, Van Lacker D, Guthrie D, Schawafel J, Tanguay P. Midlatency auditory evoked responses: P1 abnormalities in adult autistic subjects. Electroencephalogr Clin Neurophysiol. 1992;84(2):164-71.

Carvallo RMM, Carvalho M, Ishida IM. Auditory profile in individuals with and without CAPD. In: 12th Annual Convention \& Exposition of the American Academy of Audiology. Chicago. USA; 2000. p195.

Ceponiene R, Lepisto T, Shestakova A, Vanhala R, Alku P, Naatanen R, et 
al. Speech-sound-selective auditory impairment in children with autism: they can perceive but do not attend. Proc Natl Acad Sci U S A. 2003;100(9):556772.

Colafêmina JF, de Fellipe ACN, Junqueira CAO, Frizzo ACF. Potenciais Evocados Auditivos de longa latência (P300) em adultos jovens saudáveis: um estudo normativo. Rev Bras Otorinolaringol. 2000;66(2):144-8.

Cone-Wesson B, Wunderlich J. Auditory evoked potentials from the cortex: audiology applications. Otolaryngol Head Neck Surg. 2003;11(5):372-7.

Coutinho MB, Rocha V, Santos MC. Auditory brainstem response in two children with autism. Int J Pediatr Otorhinolaryngol. 2002;66:81-5.

Davis PA. The electrical response of the human brain to auditory stimuli. Am J Physiol. 1939;126:475-6.

Davis $\mathrm{H}$. United States-Japan seminars on auditory responses from the brain stem. Laryngoscope. 1979;89:1336-9.

Durrant JD, Ferraro JA. Potenciais auditivos evocados de curta latência: eletrococleografia e audiometria de tronco encefálico. In: Musiek FE, Rintelmann WF, org. Perspectivas atuais em avaliação auditiva. São Paulo: 
Manole; 2001. p.193-238.

Erwin R, Van Lacker D, Guthrie D, Schawafel J, Tanguay P, Buchwald JS. P3 responses to prosodic stimuli in adult autistic subjects. Electroencephalogr Clin Neurophysiol. 1991;80:561-71.

Ferraro JA, Durrant JD. Potenciais Auditivos Evocados: Visão geral e princípios básicos. In: Katz J, org. Tratado de Audiologia Clínica. $4^{a}$ ed. São Paulo: Manole; 1999. p.315-35.

Ferri R, Elia M, Agarwal N, Lanuzza B, Musumeci SA, Pennisi G. The mismatch negativity and the P3a components of the auditory event-related potentials in autistic low-functioning subjects. Clin Neurophysiol. 2003;114:1671-80.

Frith U. Emanuel Miller lecture: Confusions and controversies about Asperger Syndrome. J Child Psychol Psychiatry. 2004;45(4):672-86.

Frizzo ACF, Alves RPC, Colafêmina JF. Potenciais evocados auditivos de longa latência: um estudo comparativo entre hemisférios cerebrais. Rev Bras Otorinolaringol. 2001;67(5). 
Gates GA, Chakeres DW. Interpretation of dianostic tests for acoustic neuroma. American Academy of Otolaryngology-Head and Neck Surgery. Rochester, 1988.

Geisler C, Frishkopf L, Rosenblith W. Extracranial responses to acoustic clicks in man. Science. 1958;128:1210-11.

Gillberg C, Rosenhall U, Johansson E. Auditory brainstem responses in childhood psychosis. J Autism Dev Disord. 1983;13(2):181-95.

Gillberg C, Steffenburg S, Jakobsson G. Neurobiological findings in 20 relatively gifted children with Kanner-type autism or Asperger Syndrome. Dev Med Child Neurol. 1987;29:641-9.

Gomes E, Rotta NT, Pedroso FS, Sleifer P, Danesi MC. Auditory hypersensitivity in children and teenagers with autistic spectrum disorder. Arq Neuro-Psiquiatr. 2004;62 (3b):797-801.

Gomot M, Giard MH, Adrien JL, Barthelemy C, Bruneau N. Hypersensitivity to acoustic change in children with autism: electrophysiological evidence of left frontal cortex dysfunctioning. Psychophysiology. 2002;39(5):577-84.

Hall III JW. Handbook of auditory evoked responses. Boston: Allyn and Bacon; 1992. 
Hood LJ. Estimating auditory function with auditory evoked potentials. The hearing journal. 1995;48(10):32-42.

International Electrotechnical Commission. Standard for audiometers. IEC. 1988.

Jerger J, Clinical experience with impedance audiometry. Arch. Otolaryng.1970;92:311.

Junqueira CAO, Frizzo ACF. Potenciais evocados auditivos e curta, média e londa latência. In: Aquino AMCM, org. Processamento auditivo Eletrofisiologia e Psicoacústica. São Paulo: Lovise; 2002. p.63-85.

Khalfa S, Bruneau N, Rogé B, Georgieff N, Veuillet E, Adrien J-L, et al. Increased perception of loudness in autism. Hear Res. 2004;198:87-92.

Kanner L. La esquizofrenia. In : Kanner L. Psiquiatría Infantil. $3^{\mathrm{a}}$ ed. Buenos Aires: Paidós; 1962. p.720-3.

Klin A. Auditory brainstem responses in autism: brainstem dysfunction or peripheral hearing loss? J Autism Dev Disord. 1993;23(1):15-35. 
Kraus N, Kileny P, McGee T. Potenciais Auditivos Evocados de Média Latência (MLR). In: Katz J, org. Tratado de Audiologia Clínica. $4^{a}$ ed. São Paulo: Manole; 1999. p.384- 402.

Kraus N, McGee T. Potenciais Auditivos Evocados de Longa Latência. In: Katz J,org. Tratado de Audiologia Clínica. 4ª ed. São Paulo: Manole; 1999. p.403-20.

Lloyd LL, Kaplan H. Audiometric interpretation: a manual of basic audiometry. Baltimore: University Park Press; 1978.

Matas CG, Frazza MM, Munhoz MLL. Aplicação do Potencial Auditivo de Tronco Encefálico em Audiologia Pediátrica. In: Basseto, MCA, Brock R, Wajnsztejn R. Neonatologia: um convite à atuação fonoaudiológica. São Paulo: Lovise; 1998. p.301-10.

Maziade M, Mérette C, Cayer M, Roy MA, Szatmari P, Côté R, et al. Prolongation of Brainstem Auditory-Evoked Responses in Autistic Probands and Their Unaffected Relatives. Arch Gen Psychiatry. 2000;57(11):1077-83.

McPherson DL. Late potencials of the auditory system (evoked potencials). San Diego: Singular Publishing Group; 1996. 
Möller AR, Janneta P, Bennett M, Möller MB. Intracranially Recorded Responses from Human Auditory Nerve: new insights into the Origin of Brainstem Evoked Potentials. Electroencephalogr Clin Neurophysiol. $1981 ; 52: 18-27$.

Musiek FE, Bornstein S. Contemporary Aspects of diagnostic Audiology. Am J Otolaryngol. 1992;13(1):23-33.

Musiek FE, Borenstein SP, Hall III JW, Schwaber MK. Audiometria de tronco encefálico (ABR): neurodiagnóstico e aplicações intra-operatórias. In: Katz J, org. Tratado de Audiologia Clínica. $4^{a}$ ed. São Paulo: Manole; 1999. p.349 71.

Musiek FE, Geurkink N. Auditory Brainstem and Middle Latency Evoked Response Sensitivity near threshold. Ann Otol Rhinol Laringol. 1981;90:23640.

Musiek FE, Lee WW - Potenciais auditivos de média e longa latência - In: MusieK FE, Rintelmann WF, org. Perspectivas atuais em avaliação auditiva. São Paulo: Manole; 2001. p.239-56.

Niwa S, Ohta M, Yamazaki K. P300 and stimulus evaluation process in autistic subjects. J Autism Dev Disord. 1983;13(1):33-42. 
Novick B, Vaughan Jr HG, Kurtzberg D, Simson R. An electrophysiologic indication of auditory processing defects in autism. Psychiatry Res. 1980;3(1):107-14.

Özdamar Ö, Kraus N. Auditory middle-latency responses in humans. Audiology. 1983;22:34-49.

Picton TW. The P300 wave of the human event-related potential. J Clin Neurophysiol. 1992;9:456-79.

Polich J. Normal variation of P300 from auditory stimuli. Electroencephalogr Clin Neurophysiol. 1986;65:236-40.

Polich J. P300 in clinical applications: meaning, method, and measurement. Am J EEG Technol. 1991;31:201-31.

Ritvo ER - Autism diagnosis, current research and management. New York: Spectrum Publications Inc; 1976.

Rosenblum SM, Arick JR, Krug DA, Stubbs EG, Young NB, Pelson RO. Auditory brainstem evoked responses in autistic children. $J$ Autism Dev Disord.1980;10(2):215-25. 
Rosenhall U, Nordin V, Brantberg, Gillberg C. Autism and auditory brainstem responses. Ear Hear. 2003;24(3):206-214.

Rosenhall U, Nordin V, Sandstrom M, Ahlsen G, Gillberg C. Autism and hearing loss. J Autism Dev Disord. 1999;29(5):349-57.

Ruth RA, Lambert PR. Auditory evoked potentials. Otolaryngol Clin North Am. 1991;24(2):349-70.

Santos TMM, Russo ICP. Logoaudiometria. In: Santos TMM, Russo ICP. A prática da audiologia clínica. 3를. ed. São Paulo: Cortez; 1991. p.73-88.

Scheur Cl. Distúrbios Cognitivos. In: Fernandes FDM, Pastorello LM, Scheuer Cl. Fonoaudiologia em Distúrbios Psiquiátricos da Infância. São Paulo: Lovise; 1996. p.61-7.

Schochat E. Potenciais evocados auditivos. In: Carvallo RMM. Fonoaudilogia Informação para a formação: Procedimentos em Audiologia. Rio de Janeiro: Guanabara Koogan; 2003. p.57-70.

Schochat E. Avaliação eletrofisiológica da audição. In: Ferreira LP, BefiLopes D, Limongi SCO, org. Tratado de fonoaudiologia. São Paulo: Rocca; 2004. p.656-68. 
Schochat E, Rabelo CM, De A Loreti R C. Sensitividade e especificiadade do potencial de média latência. Rev Bras Otorinolaringol. 2004;70(3):353-8.

Sersen EA, Heaney G, Clausen J, Belser R, Rainbow S. Brainstem auditoryevoked responses with and without sedation in autism and Down's syndrome. Biol Psychiatry. 1990;27(8):834-40.

Steffenbburg S. Neuropsychiatric assessment of children with autism: a population-based study. Dev Med Child Neurol. 1991;33:495-511.

Sutton S, Braren M, Zubin J, John ER. Evoked potential correlates of stimulus uncertainty. Science. 1965;150:1187-8.

Tanguay PE, Edwards RM, Buchwald J, Schwafel J, Allen V. Auditory brainstem evoked responses in autistic children. Arch Gen Psychiatry. 1982;39(2):174-80.

Taylor MJ, Rosenblatt B, Linschoten L. Auditory brainstem responses abnormalities in autistic children. Can J Neurol Sci. 1982;9(4):429-33.

Tecchio F, Benassi F, Zappasodi F, Gialloreti LE, Palermo M, Seri S, et al. Auditory sensory processing in autism: a magnetoencephalographic study. Biol Psychiatry. 2003;54(6):647-54 . 
Teder-Sälejärvi WA, Pierce KL, Courchesne E, Hillyard SA. Auditory spatial localization and attention deficits in autistic adults. Brain Res Cogn Brain Res. 2005;23(2-3):221-34.

Wing L. The autistic continuum. In: Wing L, org. Aspects of autism: biological research. London: Royal College of Psychiatrists \& The National Austistic Society; 1988 . p.5-8. 


\section{Bibliografias Consultadas}




\section{0 - BIBLIOGRAFIAS CONSULTADAS}

Fonseca JS, Martins GA. Curso de Estatística, 6ª ed. São Paulo: Atlas; 1996.

Manual do equipamento BIO-LOGIC EvoKed Potential User Manual.

Spiegel MR. Estatística Coleção Schaum. 3를. ed. São Paulo: Afiliada; 1993. 